UNIVERSIDADE DE SÃO PAULO

INSTITUTO DE QUÍMICA

\title{
CARACTERIZAÇÃO DA 2,2':6',2'”-TERPIRIDINA ADSORVIDA SOBRE SUPERFÍCIE DE PRATA, ATRAVÉS DA TÉCNICA SERS (SURFACE ENHANCED RAMAN SPECTROSCOPY)
}

\author{
ANTONIO CARLOS SANT'ANA
}

DISSERTAÇÃO DE MESTRADO

ORIENTADORA:

PROFa DRA. MARCIA L. ARRUDA TEMPERINI

SÃO PAULO

2001 


\section{"Caracterização da 2,2':6',2" - Terpiridina Adsorvida Sobre Superfície de Ag, Através da Téenica SERS (Surface Enhanced Raman Spectroscopy)"}

\section{AWTOWIO CARLOS SAWT'AWA}

Dissertação de Mestrado submetida ao Instituto de Química da Universidade de São Paulo como parte dos requisitos necessários à obtenção do grau de Mestre em Ciências - Área: Fisico-Química.

Aprovado por:

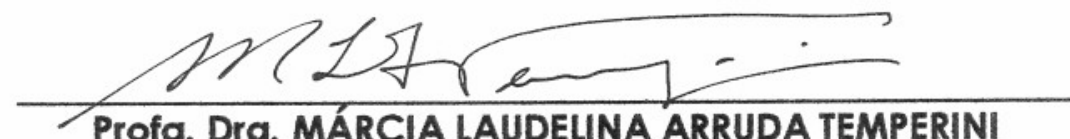

IQ - USP

(Orientadora e Presidente)

Profa. Dra. ElIZABETH PINHEIRO GOMES ARÊAS

$I Q$ - USP

Profa. Dra. TERESA BENITA IWASITA DE VIELSTICH

IQ SC - USP 


\section{AGRADECIMENTOS}

À Prof. Dra. Márcia Laudelina Arruda Temperini pela orientação, paciência e amizade.

Ao Prof. Dr. Oswaldo Sala pelo exemplo de dedicação.

Aos Profs. Drs. Dalva Lúcia A de Faria, Yoshio Kawano, Mauro C. C. Ribeiro, Susana I. Córdoba de Toressi e Luiz Fernando C. Oliveira pela colaboração e incentivo.

À Prof. Dra. Ana Maria C. Ferreira e ao Wendel A. Alves pela ajuda na obtenção dos complexos de cobre.

Ao Prof. Dr. Héctor D. Abruña pela colaboração.

A todos os colegas do laboratório Norberto, Lúcia, Paola, Lucydalva, Marcelo, Luiz Carlos (†), Mônica, Ricardo, Eduardo, Guilherme, Gustavo Morari, Gustavo Andrade, Ary, Ana Maria e Amira pela amizade e colaboração.

Aos funcionários Paulo, Nivaldo e Euzita pela presteza.

Às agências de fomento CNPq e FAPESP. 
Agradeço, especialmente, à minha esposa pelo zelo, carinho, dedicação, ... 


\section{ÍNDICE}

Resumo

Summary $\quad$ iii

Índice de tabelas $\quad$ v

Índice de figuras

1 - Introdução

1.1 - Motivações

1.2 - Efeito SERS 4

1.2.1 - Modelo eletromagnético 7

1.2.2 - Modelo químico 8

1.2.3 - Conclusões 11

1.2.4 - Aplicações 12

Referências 13

2 - Experimental 15

2.1 - Reagentes e sínteses $\quad 15$

2.2 - Equipamentos 16

2.3 - Procedimentos nos experimentos SERS 17

$\begin{array}{ll}\text { Referências } & 20\end{array}$

3 - Resultados e discussões $\quad 21$

3.1 - Padrões 21

3.2 - SERS ex situ da tpy adsorvida em Ag 38

3.3 - SERS in situ da tpy adsorvida em Ag 48

3.4 - SERS ex situ da tpy-SH adsorvida em Ag 66

3.5 - SERS ex situ da tpy e mpy coadsorvidas em Ag 72 
3.6 - Estudo do complexo $\left[\mathrm{Cu}(\mathrm{II}) \mathrm{tpyH}_{2} \mathrm{OClO}_{4}\right] \mathrm{ClO}_{4}$

3.6.1 - Estrutura do complexo $\left[\mathrm{Cu}(\mathrm{II}) \mathrm{tpyH}_{2} \mathrm{OClO}_{4}\right] \mathrm{ClO}_{4} \quad 78$

3.6.2 - Perfil de excitação do $\left[\mathrm{Cu}(\mathrm{II}) \mathrm{tpyH}_{2} \mathrm{OClO}_{4}\right] \mathrm{ClO}_{4}$

3.6.3 - SERS ex situ e in situ do $\left[\mathrm{Cu}(\mathrm{II}) \mathrm{tpyH}_{2} \mathrm{OClO}_{4}\right] \mathrm{ClO}_{4} \quad 85$

Referências

89

4 - Conclusões

91 


\section{RESUMO}

Monocamadas auto-organizadas de 2,2':6',2'-terpiridina (tpy) formadas sobre a superfície de eletrodos de $\mathrm{Ag}$ e $\mathrm{Cu}$ foram caracterizadas através da técnica SERS (Surface-Enhanced Raman Spectroscopy) em experimentos ex situ e in situ.

Foram estudadas alterações nas espécies adsorvidas em função da natureza das soluções-mãe e das soluções eletrolíticas utilizadas, tais como, solvente, $\mathrm{pH}$ da solução, ânion-suporte e a presença de outro adsorbato orgânico: a 2mercaptopirimidina (mpy).

Para estudar-se a adsorção da tpy foram obtidos padrões espectrais em que a molécula realiza diferentes interações com a vizinhança: no estado sólido, em solução, fundida e formando complexos com os íons $\mathrm{Cu}^{2+}$ e $\mathrm{Ag}^{+}$. Também foram obtidos padrões para o ânion $\mathrm{ClO}_{4}^{-}$coordenado ao $\mathrm{Cu}^{2+}$, possibilitando explicar a adsorção deste ânion à superfície.

Os resultados indicam que a tpy adsorve sobre a superfície metálica através de seus átomos de nitrogênio formando complexos de superfície do tipo I e do tipo II, nos quais assume uma conformação cis-cis. A tpy protonada, preferencialmente, perde o próton para adsorver sobre o eletrodo. Em experimentos in situ, quando potenciais mais negativos são aplicados, a tpy adsorve sobre a superfície metálica em uma posição próxima à horizontal através dos elétrons $\pi$ dos anéis piridínicos. $\mathrm{Na}$ presença da mpy a tpy adsorve horizontalmente sobre a superfície do eletrodo, não ocorrendo sua coordenação com o metal.

Estudos da adsorção do composto 4'-(5-mercaptopentil)-2,2':6',2"'terpiridina (tpy-SH) sobre eletrodo de Ag indicam que a molécula adsorve através do átomo de enxofre sem que ocorra interação entre os átomos de nitrogênio da parte tpy e a superfície metálica. Isto foi confirmado pela coordenação do cátion $\mathrm{Cu}^{2+}$ com a parte tpy das moléculas tpy-SH adsorvidas, bem como pela 
intensificação das bandas atribuídas à parte alcano-tiol da molécula devido sua proximidade com a superfície.

Os estudos do complexo $\left[\mathrm{Cu}(\mathrm{II}) \mathrm{tpyH}_{2} \mathrm{OClO}_{4}\right] \mathrm{ClO}_{4}$ mostram que a exposição à radiação excitante produz a perda da coordenação da água ao íon metálico com o ânion $\mathrm{ClO}_{4}{ }^{-}$passando a coordenar por dois átomos de oxigênio. $\mathrm{O}$ perfil de excitação deste complexo foi realizado e constatour se pré-ressonância do sinal Raman com a transição eletrônica da molécula na região entre 300 e 350 nm. Ao ser adsorvido sobre a superfície do eletrodo este complexo sofre redução e a tpy coordena aos átomos metálicos do eletrodo formando um complexo de superfície. 


\section{SUMMARY}

Self-assembly monolayers of 2,2':6',2"-terpyridine (tpy) were grown on Ag and $\mathrm{Cu}$ electrode surface and studied ex situ and in situ by SERS (Surface Enhanced Raman Spectroscopy).

The nature of the adsorbate species was studied as a function of the mothersolution, changing solvent, $\mathrm{pH}$ and supporting-anion. The effect of 2mercaptopyrimidine (mpy) as co-adsorbate was also investigated.

For comparis on purposes the Raman spectrum of tpy was obtained as solid, solution, molten and as $\mathrm{Ag}^{+}$and $\mathrm{Cu}^{2+}$ complexes. A supplementary Raman study of $\mathrm{Cu}^{2+}$ perchlorates was also performed to facilitate the understanding of the $\mathrm{ClO}_{4}{ }^{-}$ adsorption on the metal surface.

The results showed that tpy adsorb on the metallic surface through the nitrogen atoms forming two different surface complexes (type I and type II) that have cis-cis conformation. Protonated tpy, preferentially, loses the proton to adsorb on the electrode. In the in situ experiments, when more negative potentials were applied, the observed spectral changes were ascribed to a modification in the adsorption geometry leading to a nearly flat arrangement. In presence of mpy, tpy adsorbs flat on the electrode surface and coordination with the metal is not observed.

Studies on the adsorption of the 4'-(5-mercaptopentyl)-2,2':6',2'terpyridine (tpy- $\mathrm{SH}$ ) on $\mathrm{Ag}$ electrode showed that the molecule adsorbs through the sulfur atom and there is no interaction between the nitrogen atoms of tpy moiety and the metal. This was confirmed by coordination of $\mathrm{Cu}^{2+}$ with the tpy moiety of adsorbed tpy-SH molecules and by the enhancement of the alkyl-thiol bands, which are close to the surface. 
Studies of $\left[\mathrm{Cu}(\mathrm{II}) \mathrm{tpyH}_{2} \mathrm{OClO}_{4}\right] \mathrm{ClO}_{4}$ complex showed that depending on the energy density used the exciting radiation may cause the release of the coordinated water, leading to a bidentate coordination of the $\mathrm{ClO}_{4}{ }^{-}$anion.

The Raman excitation profile for this complex was obtained and preresonance enhancement associated with a transition between 300 e $350 \mathrm{~nm}$ was observed. When adsorbed on the electrode surface this complex undergoes reduction and the tpy coordinates to the metal atoms forming a surface complex. 


\section{ÍNDICE DE TABELAS}

TABELA 1: Resultados das análises elementares para $\mathrm{C}, \mathrm{N}$ e $\mathrm{H}$ (\% em massa) da tpy comercial e dos compostos sintetizados.

TABELA 2: Diferentes condições dos ciclos redox em eletrodo a partir de soluções aquosas com concentração $10^{-1} \mathrm{M}$ do eletrólito citado.

TABELA 3: Atribuição das freqüências fundamentais da tpy a partir da comparação com as atribuições vibracionais das moléculas de: benzeno, difenil, piridina e 2,2'- bipiridina.

TABELA 4: Atribuição das bandas dos espectros vibracionais da tpy em $\mathrm{cm}^{-1} 26$

TABELA 5: Resumo da variação da freqüência da respiração do anel.

TABELA 6: Correlação entre diferentes simetrias e atribuição das freqüências fundamentais do perclorato não coordenado e coordenado monodentado e bidentado ao $\mathrm{Cu}^{2+}$.

TABELA 7: Intensidades relativas das bandas dos espectros do complexo $\left[\mathrm{Cu}(\mathrm{II}) \mathrm{tpyH}_{2} \mathrm{OClO}_{4}\right] \mathrm{ClO}_{4}$ em diferentes radiações excitantes. 


\section{ÍNDICE DE FIGURAS}

FIGURA 1: Diferentes confôrmeros da terpiridina. 2

FIGURA 2: Tpy diprotonada isolada e ligada a uma molécula de água. 3

FIGURA 3: Variação da energia dos estados eletrônicos do metal em função da aplicação de potencial no eletrodo e em relação às energias do HOMO e do LUMO do adsorbato.

FIGURA 4: Célula eletrolítica utilizada em experimentos SERS.

FIGURA 5: Espectros vibracionais da tpy no estado sólido: infravermelho (em KBr) e Raman, $\lambda_{0}=632,8 \mathrm{~nm}$.

FIGURA 6: Espectros Raman da tpy em solução de acetonitrila com o campo elétrico do laser perpendicular e paralelo à direção de observação. $\lambda_{0}=514,5 \mathrm{~nm}$.

FIGURA 7: Espectros Raman da $\mathrm{tpyH}_{2}{ }^{2+}$ em solução aquosa $\mathrm{pH} \sim 0,0$; do tpyH ${ }^{+} \mathrm{CF}_{3} \mathrm{SO}_{3}{ }^{-}$sólido sobre silício; e da tpy no estado sólido.

FIGURA 8: Espectros Raman dos complexos $\left[\mathrm{Ag}(\mathrm{I}) \operatorname{tpyNO}_{3}\right]$, $\left[\mathrm{Cu}(\mathrm{II}) \mathrm{tpyH}_{2} \mathrm{OClO}_{4}\right] \mathrm{ClO}_{4},[\mathrm{Cu}(\mathrm{II}) \mathrm{tpyCl}] \mathrm{Cl}$ e da tpy.

FIGURA 9: Espectros Raman dos complexos [Ag(I)tpyNO $\left.\mathrm{N}_{3}\right]$, $\left[\mathrm{Cu}(\mathrm{II})\right.$ tpy $\left._{2} \mathrm{OClO}_{4}\right] \mathrm{ClO}_{4},[\mathrm{Cu}(\mathrm{II}) \operatorname{tpyCl}] \mathrm{Cl}$ e da tpy. Região de baixa freqüência.

FIGURA 10: Espectros Raman da tpy em diferentes solventes: $\mathrm{CCl}_{4}$, $\mathrm{H}_{3} \mathrm{CCN}$ e $\mathrm{H}_{3} \mathrm{CCH}_{2} \mathrm{OH}$.

FIGURA 11: Espectros Raman da tpy em solução de acetonitrila a $8^{\circ} \mathrm{C}$ e a $-19^{\circ} \mathrm{C}$ e no estado sólido a $25^{\circ} \mathrm{C}$ e fundida a $140^{\circ} \mathrm{C}$.

FIGURA 12: Espectros Raman do ânion $\mathrm{ClO}_{4}{ }^{-}$em diferentes simetrias: não coordenado ao metal, $\left[\mathrm{Cu}(\mathrm{II})\left(\mathrm{H}_{2} \mathrm{O}\right)_{4}\right]\left(\mathrm{ClO}_{4}\right)_{2}\left(\mathrm{H}_{2} \mathrm{O}\right)_{2}$, grupo de ponto $\mathrm{T}_{\mathrm{d}}$; coordenado monodentado ao metal, $\left[\mathrm{Cu}(\mathrm{II})\left(\mathrm{H}_{2} \mathrm{O}\right)_{2}\left(\mathrm{ClO}_{4}\right)_{2}\right]$, grupo de ponto $\mathrm{C}_{3 \mathrm{~V}}$; coordenado bidentado ao metal, $\left[\mathrm{Cu}(\mathrm{II})\left(\mathrm{ClO}_{4}\right)_{2}\right]$, grupo de ponto $\mathrm{C}_{2 \mathrm{~V}}$.

FIGURA 13: Espectros SERS ex situ do sistema tpy/Ag/Cl', com as seguintes soluções-mãe: etanólica e aquosas com $\mathrm{pH}=6, \mathrm{pH}=3, \mathrm{pH}=1,8$ e $\mathrm{pH}=0$.

FIGURA 14: Espectros SERS ex situ do sistema tpy/Ag/Cl', com as seguintes soluções-mãe: etanólica e aquosas com $\mathrm{pH}=6, \mathrm{pH}=3, \mathrm{pH}=1,8$ e $\mathrm{pH}=0$. Região de baixa freqüência. 
FIGURA 15: Espectros SERS ex situ do sistema tpy/Ag com soluções-mãe aquosas em pH 6, variando-se os ânions-suporte: $\mathrm{Cl}^{-}, \mathrm{ClO}_{4}{ }^{-}$e $\mathrm{I}$.

FIGURA 16: Espectros SERS ex situ do sistema tpy/Ag com soluções- mãe aquosas em pH 1,8, variando-se os ânions-suporte: $\mathrm{Cl}^{-}, \mathrm{ClO}_{4}{ }^{-}$e I.

FIGURA 17: Evolução dos espectros SERS ex situ do sistema $\mathrm{Ag} / \mathrm{tpy} / \mathrm{ClO}_{4}{ }^{-}$, em $\mathrm{pH}=1,8$, com o tempo de exposição ao laser.

FIGURA 18: Espectros SERS in situ do sistema $\mathrm{Ag} / \mathrm{tpy}(\mathrm{aq}) / \mathrm{Cl}$ em $\mathrm{pH}=6,0$, em vários potenciais.

FIGURA 19: Espectros SERS in situ do sistema $\mathrm{Ag} / \mathrm{tpy}(\mathrm{aq}) / \mathrm{Cl}^{-}$em $\mathrm{pH}=6,0$, em vários potenciais.

FIGURA 20: Espectros SERS in situ do sistema $\mathrm{Ag} / \mathrm{tpy}(\mathrm{aq}) / \mathrm{Cl}^{-}$em $\mathrm{pH}=6,0$, em vários potenciais. Região de baixa freqüência.

FIGURA 21: Espectros SERS in situ do sistema Ag/tpy(aq)/CI em pH=6,0, em vários potenciais. Região de alta frequiência.

FIGURA 22: Espectros SERS in situ do sistema $\mathrm{Ag} / \mathrm{tpy}(\mathrm{aq}) / \mathrm{Cl}$ em $\mathrm{pH}=3,0$, em vários potenciais.

FIGURA 23: Espectros SERS in situ do sistema $\mathrm{Ag} / \mathrm{tpy}(\mathrm{aq}) / \mathrm{Cl}^{-}$em $\mathrm{pH}=1,8$, em vários potenciais.

FIGURA 24: Espectros SERS in situ do sistema Ag/tpy(aq)/I em pH=6,0, em vários potenciais.

FIGURA 25: Espectros SERS in situ do sistema $\mathrm{Ag} / \mathrm{tpy}(\mathrm{aq}) / \mathrm{ClO}_{4}{ }^{-} \mathrm{em} \mathrm{pH}=6,0$, em vários potenciais.

FIGURA 26: Espectros SERS in situ do sistema $\mathrm{Ag} / \mathrm{tpy}(\mathrm{aq}) / \mathrm{ClO}_{4}{ }^{-} \mathrm{em} \mathrm{pH}=6,0$, em vários potenciais.

FIGURA 27: Espectros SERS in situ do sistema $\mathrm{Ag} / \mathrm{tpy}(\mathrm{aq}) / \mathrm{Cl}$ em $\mathrm{pH}=3,0$, em vários potenciais. Baixa ativação do eletrodo.

FIGURA 28: Espectros SERS in situ do sistema $\mathrm{Cu} / \mathrm{tpy}(\mathrm{aq}) / \mathrm{Cr}$, em pH=6,0, em vários potenciais.

FIGURA 29: Espectros SERS in situ dos sistemas $\mathrm{Cu} / \mathrm{tpy}(\mathrm{aq}) / \mathrm{Cl}^{-} / \mathrm{pH}=6,0$, $\mathrm{V}_{\mathrm{ap}}=-0,5 \mathrm{~V}, \mathrm{Ag} / \mathrm{tpy}(\mathrm{aq}) / \mathrm{Cl} / \mathrm{pH}=6,0, \mathrm{~V}_{\mathrm{ap}}=-0,2 \mathrm{~V}$ e espectro Raman do complexo $[\mathrm{Cu}(\mathrm{II}) \mathrm{tpyCl}] \mathrm{Cl}$.

FIGURA 30: Espectros SERS in situ dos sistemas $\mathrm{Cu} / \mathrm{tpy}(\mathrm{aq}) / \mathrm{CI} / \mathrm{pH}=6,0$, $\mathrm{V}_{\mathrm{ap}}=-0,5 \mathrm{~V}, \mathrm{Ag} / \mathrm{tpy}(\mathrm{aq}) / \mathrm{CI} / \mathrm{pH}=6,0, \mathrm{~V}_{\mathrm{ap}}=-0,2 \mathrm{~V}$ e espectro Raman do complexo $[\mathrm{Cu}(\mathrm{II}) \mathrm{tpyCl}] \mathrm{Cl}$. Região de baixa freqüência. 
FIGURA 31: Espectros Raman da tpy-SH sólida e da tpy sólida.

FIGURA 32: Espectros Raman da tpy-SH sólida e da tpy sólida.

FIGURA 33: Espectros SERS ex situ dos sistemas Ag/tpy-SH/Cl', solução-mãe etanólica, e Ag/tpy/CI, solução-mãe etanólica.

FIGURA 34: tpy- $\mathrm{SH}$ adsorvida sobre eletrodo de Ag

FIGURA 35: Espectros SERS ex situ dos sistemas Ag/tpy-SH/I, solução-mãe etanólica, $\mathrm{Ag} / \mathrm{tpy}-\mathrm{SH}, \mathrm{Cu}^{2+} / \mathrm{I}, \mathrm{Br}^{-}$, solução-mãe etanólica e Ag/tpy/I', solução-mãe aquosa, $\mathrm{pH}=6,0$.

FIGURA 36: Espectros Raman da mpy no estado sólido e SERS ex situ dos sistemas $\mathrm{Ag} / \mathrm{mpy} / \mathrm{Cl}$ em solução- mãe aquosa, $\mathrm{pH}=1,8$ e $\mathrm{Ag} / \mathrm{mpy} / \mathrm{CI}$ solução-mãe etanólica.

FIGURA 37: Espectros SERS ex situ dos sistemas Ag/mpy/CI, Ag/tpy/Cl e Ag/tpy, mpy/Cl, utilizando-se em todos solução-mãe aquosa em pH=1,8; espectro Raman da tpy no estado sólido.

FIGURA 38: Espectros SERS ex situ dos sistemas Ag/mpy/CI, Ag/tpy/Cl e Ag/tpy, mpy/Cl, utilizando-se em todos solução-mãe etanólica; espectro Raman da tpy no estado sólido.

FIGURA 39: Espectros infravermelho (em pastilha de $\mathrm{KBr}$ ) e Raman, do complexo $\left[\mathrm{Cu}(\mathrm{II}) \mathrm{tpyH}_{2} \mathrm{OClO}_{4}\right] \mathrm{ClO}_{4}$ no estado sólido.

FIGURA 40: Evolução dos espectros Raman do complexo $\left[\mathrm{Cu}(\mathrm{II}) \mathrm{tpyH}_{2} \mathrm{OClO}_{4}\right] \mathrm{ClO}_{4}$ com a potência do laser.

FIGURA 41: Evolução dos espectros Raman do complexo $\left[\mathrm{Cu}(\mathrm{II}) \mathrm{tpyH}_{2} \mathrm{OClO}_{4}\right] \mathrm{ClO}_{4}$ com a potência do laser. Região de baixa freqüência. 81

FIGURA 42: Espectro eletrônico do complexo $\left[\mathrm{Cu}(\mathrm{II}) \mathrm{tpyH}_{2} \mathrm{OClO}_{4}\right] \mathrm{ClO}_{4}$.

FIGURA 43: Espectros Raman do complexo $\left[\mathrm{Cu}(\mathrm{II}) \mathrm{tpyH}_{2} \mathrm{OClO}_{4}\right] \mathrm{ClO} 4$ no estado sólido com uso de cela rotatória e em diferentes radiações excitantes.

FIGURA 44: SERS ex situ do sistema $\mathrm{Cu} /\left[\mathrm{Cu}(\mathrm{II}) \operatorname{tpyH}_{2} \mathrm{OClO}_{4}\right] \mathrm{ClO}_{4} / \mathrm{Cl}$ em solução- mãe aquosa e pH=6,0.

FIGURA 45: Espectros SERS in situ do sistema

$\mathrm{Cu} /\left[\mathrm{Cu}(\mathrm{II}) \mathrm{tpyH}_{2} \mathrm{OClO}_{4}\right] \mathrm{ClO}_{4}(\mathrm{aq}) / \mathrm{CI}$ em $\mathrm{pH}=6$, em vários potenciais.

FIGURA 46: Espectros SERS in situ do sistema $\mathrm{Ag} /\left[\mathrm{Cu}(\mathrm{II}) \mathrm{tpyH}_{2} \mathrm{OClO}_{4}\right] \mathrm{ClO}_{4}(\mathrm{aq}) / \mathrm{ClO}_{4}{ }^{-}$, em $\mathrm{pH}=6$, em vários potenciais. 


\section{1 - INTRODUÇÃO}

\section{1 - MOTIVAÇÕES}

Nos últimos anos tem sido crescente o interesse em superfícies modificadas por espécies moleculares. A confecção e a caracterização de monocamadas autoorganizadas sobre superfícies levam ao surgimento dos mais diversos dispositivos moleculares, com amplo uso em eletrônica, catálise, bioeletroquímica, conversão de energia ${ }^{1}$, eletrocromismo ${ }^{2}$, etc.

Terpiridinas substituídas por grupos tiois ou carboxilatos, bem como seus complexos metálicos, são modificadores de superfície, apresentando propriedades adequadas para a confecção de dispositivos moleculares ${ }^{3,4}$. Complexos de rutênio com terpiridinas substituídas por grupos fosfato, adsorvidos sobre superfícies semicondutoras, foram utilizados como dispositivos fotossensibilizadores em células solares devido suas propriedades fotoeletroquímicas ${ }^{1}$. Estes complexos sofrem excitação eletrônica pela luz visível, ocorrendo uma rápida transferência de elétron do estado excitado do complexo para a banda de condução do semicondutor (eletrodo). A forma oxidada do complexo é rapidamente reduzida através de mediadores redox, como por exemplo íons iodeto, que separam a região fotossensível do contra-eletrodo. Esta seqüência de reações redox leva a uma rede de conversão de luz visível em eletricidade.

São poucos os trabalhos na literatura que investigam a molécula de 2,2',6',2"'-terpiridina (tpy) ${ }^{5,6,7}$ e não existem estudos sistemáticos de caracterização de monocamadas desta molécula sobre superfícies metálicas. Este trabalho tem por objetivo caracterizar monocamadas auto-organizadas puras ou mistas da tpy adsorvidas sobre eletrodo de prata, utilizando-se, para isto, o efeito SERS (Surface Enhanced Raman Scattering). 
Devido a intensificação do sinal Raman, observada nos experimentos SERS, ser função da proximidade do adsorbato com a superfície metálica, este efeito é adequado para investigar-se a competição de diferentes espécies pela superfície metálica. A competição pela superfície entre a tpy e outras espécies químicas, tais como cloreto, perclorato, iodeto, moléculas de solvente e moléculas de 2mercaptopirimidina (mpy) foram objeto deste estudo.

Este estudo é um primeiro passo para a caracterização de terpiridinas substituídas com grupos fosfatos ou tiois adsorvidas em monocamadas autoorganizadas sobre superfícies metálicas e sua utilização como dispositivos moleculares. Neste trabalho são apresentados alguns resultados da adsorção do composto 4'-(5-mercaptopentil)-2,2':6',2”-terpiridina (tpy-SH) adsorvido sobre superfície metálica de prata através do átomo de enxofre. Este composto foi gentilmente cedido pelo Prof. Dr. Héctor D. Abruña ${ }^{3}$.

A tpy possui diferentes confôrmeros devido à presença de ligações sigma entre os carbonos dos anéis piridínicos (figura 1), que lhes permitem relativa liberdade de rotação.

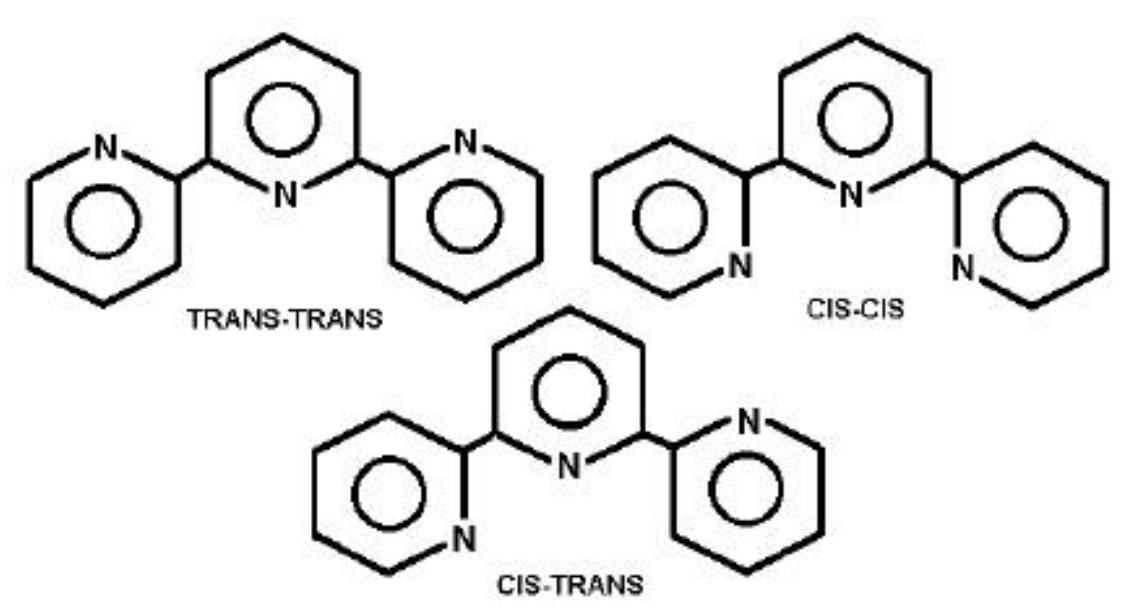

FIGURA 1: Diferentes confôrmeros da terpiridina.

Parte deste trabalho consiste na busca de padrões espectrais de compostos envolvendo tpy em diferentes conformações de forma a permitir a caracterização 
não só das espécies adsorvidas na superfície metálica mas também de sua conformação superficial.

A determinação da estrutura por difração de raios $\mathrm{X}$ de um monocristal de tpy mostrou que o composto cristaliza segundo o grupo de espaço não centrossimétrico ortorrômbico $\mathrm{P} 22_{1} 2_{1} 2_{1}$, na conformação trans-trans ${ }^{8}$.

Segundos dados da literatura, apenas os dois nitrogênios dos anéis laterais da tpy podem ser protonados, com o primeiro $\mathrm{pK}_{\mathrm{a}}$ próximo de 4,5 e o segundo $\mathrm{pK}_{\mathrm{a}}$ próximo de $3,0^{5,9,10}$. O cátion $\operatorname{tpyH}_{2}{ }^{2+}$ apresenta ligações de hidrogênio na cavidade tridentada que estabilizam a conformação cis-cis; estas ligações ocorrem entre os prótons dos anéis laterais e o nitrogênio do anel central (figura 2-a). Este arranjo foi determinado por medidas de difração de raios $\mathrm{X}$ para monocristais do cátion $\operatorname{tpyH}_{2}{ }^{2+}$ associado a diferentes ânions ${ }^{11,12}$. Em soluções aquosas é possível que o cátion tpyH $_{2}{ }^{2+}$ realize ligações de hidrogênio com a água mantendo a conformação cis-cis ${ }^{11}$ ( figura 2-b). A conformação da tpy monoprotonada do composto tpy $\mathrm{H}^{+} \mathrm{CF}_{3} \mathrm{SO}_{3}{ }^{-}$no estado sólido é cis-trans, com o nitrogênio protonado na posição cis ${ }^{13}$. Os espectros Raman deste composto, da tpy diprotonada em solução e da tpy sólida foram obtidos neste trabalho e utilizados como padrões nos estudos SERS de caracterização das espécies adsorvidas em superfícies.

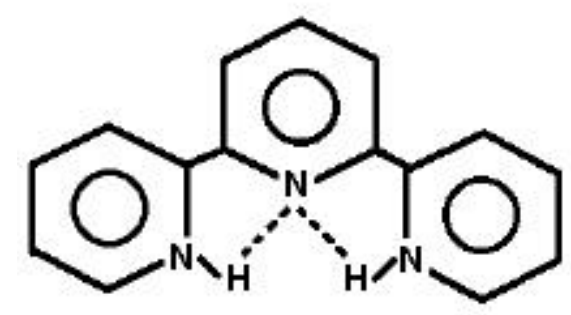

(a)

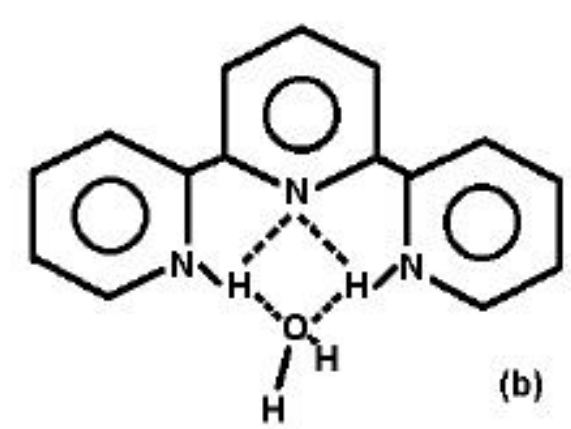

(b)

FIGURA 2: Tpy diprotonada isolada (a) e ligada a uma molécula de água (b).

É bastante conhecida a propriedade da tpy formar complexos com metais de transição, sendo um forte ligante tridentado (conformação cis-cis), portanto, é possível a adsorção da tpy em superfícies metálica através da coordenação dos 
nitrogênios dos anéis piridínicos com os átomos do metal em uma posição próxima à vertical ${ }^{7}$. Complexos de tpy com íons de $\mathrm{Cu}^{2+}$ e $\mathrm{Ag}^{+}$foram sintetizados e seus espectros Raman obtidos. Estes espectros são utilizados como padrões nos estudo da adsorção da tpy sobre eletrodos de $\mathrm{Cu}$ e $\mathrm{Ag}$.

Nas estruturas dos compostos envolvendo tpy mono ou diprotonada ou complexada, ou ainda da tpy pura no estado sólido, a molécula não é planar. Os ângulos diédricos entre os anéis laterais e o anel central são pequenos, normalmente menores que $10^{\circ}$, a menos da molécula diprotonada, que quando isolada possui ângulos diédricos $\mathrm{N}-\mathrm{C}-\mathrm{C}-\mathrm{N}$ de $-28^{\circ}$ e $28^{\circ}$ e quando ligada à água possui para os mesmos ângulos os valores de $-19^{\circ}$ e $19^{\circ}$, existindo em ambos os casos uma torção na molécula ${ }^{11}$ (esta torção não foi considerada na figura 2).

\section{2 - EFEITO SERS}

A espectroscopia de espalhamento Raman e a espectroscopia de absorção no infravermelho são técnicas complementares e largamente utilizadas na caracterização das propriedades vibracionais das moléculas nas mais variadas condições experimentais. O estudo de monocamadas adsorvidas pode ser realizado através da espectroscopia no infravermelho devido à grande eficiência desta técnica.

Para estudos de monocamadas adsorvidas através do efeito Raman em condições normais, a sensibilidade da técnica mostra-se insuficiente devido à baixa densidade de moléculas na superfície, $10^{14}$ a $10^{15}$ moléculas $/ \mathrm{cm}^{2}$ e à pequena secção de choque para o espalhamento Raman da molécula livre, $10^{-30} \mathrm{~cm}^{2}$ molécula ${ }^{-1} \mathrm{sr}^{-1}{ }^{14}$. Porém, devido à interação do campo elétrico incidente com superfícies rugosas de determinados metais, espécies químicas adsorvidas em monocamadas são observadas, ocorrendo a intensificação do sinal Raman por fatores da ordem de $10^{6}$ vezes. Este efeito convencionou-se chamar de efeito SERS ou "espalhamento Raman intensificado pela superfície" ${ }^{, 15,16}$. 
A intensificação do espectro infravermelho pela superfície foi também observada por A. Hartstein e col. em $1980{ }^{17}$. Batizada de SEIR ou SEIRA (Surface Enhanced Infra Red Absortion), esta técnica mostrou-se complementar ao efeito SERS na caracterização de adsorbatos.

O efeito SERS foi descoberto por M. Fleischmann e col. ${ }^{18}$ em 1974, quando estudaram a piridina adsorvida em eletrodo de prata cuja rugosidade superficial tinha sido aumentada eletroquimicamente através de vários ciclos de oxidação e redução do metal. A intensificação do sinal foi associada ao aumento da área superficial no eletrodo e, portanto, ao aumento do número de moléculas espalhadoras adsorvidas sobre a superfície metálica. Em 1977, dois trabalhos independentes de D. L. Jeanmarie e R. P. Van Duyne ${ }^{19}$ e M. G. Albrecht e J. A. Creyghton ${ }^{20}$, mostraram que o fator de intensificação Raman devido ao aumento da área superficial do eletrodo não justificava a elevação do sinal observada. Cálculos mostraram que a intensificação esperada devido ao aumento de área seria da ordem de $10^{2}$ vezes, enquanto que a intensificação observada era da ordem de $10^{6}$ vezes. Estava caracterizado um novo efeito e após sua constatação seguiram-se inúmeros trabalhos que inicialmente tentavam explicar teoricamente o fenômeno e, posteriormente, fizeram uso do efeito nas mais diversas aplicações.

A natureza do adsorbato é um importante fator na observação do efeito SERS: moléculas contendo átomos de nitrogênio e enxofre são, particularmente, fortes candidatas a apresentarem o efeito.

A intensificação do sinal é observada em apenas alguns metais como $\mathrm{Ag}$, $\mathrm{Au}$ e $\mathrm{Cu}$, porém, intensificações menores já foram observadas em superfícies de Pt, $\mathrm{Pd}, \mathrm{TiO}_{2}$ e de alguns metais alcalinos.

Há, ainda, forte dependência da observação do efeito com a freqüência da radiação excitante e com as características físicas da superfície. Os metais $\mathrm{Ag}, \mathrm{Au}$ e $\mathrm{Cu}$ mostramse bastante eficientes em experimentos SERS ${ }^{21}$; a prata fornece melhores espectros quando a radiação excitante possui frequiência próxima de 500 $\mathrm{nm}$ e os outros dois metais apresentam o efeito quando a frequiência da radiação 
excitante está próxima de $600 \mathrm{~nm}$. Quanto ao tipo de superfície na qual ocorre a interação adsorbato-metal são eficientes os colóides ou metal depositado sobre substrato em ultra-alto vácuo ou as superfícies metálicas com certo nível de rugosidade que podem ser obtidas por ciclos eletroquímicos de oxidação e redução do metal. Quando monocamadas do adsorbato são formadas sobre superfícies metálicas polidas destes metais o efeito SERS não é observado. Em função disto, há modelos que mostram a necessidade de uma estrutura fractal na superfície metálica para que ocorra a intensificação do espalhamento ${ }^{22}$.

Geralmente, os espectros Raman intensificados pela superfície diferem dos espectros Raman da espécie. A interação química com a superfície leva a mudanças nas freqüências. Alterações da simetria molecular, devidas à adsorção, podem gerar relaxamento das regras de seleção e modos proibidos no Raman são observados. Nos espectros Raman há uma dependência entre a intensidade do espalhamento e a quarta potência da radiação espalhada. Quando há intensificação do sinal Raman pela superfície esta dependência não ocorre e mudanças nas intensidades relativas das bandas são observadas.

$\mathrm{Na}$ década de 80 surgiram vários trabalhos teóricos que, a partir das constatações experimentais acima apresentadas, tentavam explicar o efeito. Estes podem ser agrupados, quanto à natureza do fenômeno, em dois grandes modelos: o modelo eletromagnético e o modelo molecular ou químico. No modelo eletromagnético, a intensificação dos campos elétricos das radiações incidente e espalhada próximo à superfície metálica seria o fator responsável pela intensificação do sinal Raman. No modelo molecular, esta intensificação deve-se à mudança da polarizabilidade da molécula devida às interações adsorbato-metal.

No entanto, nenhum destes modelos isolados pode justificar a intensificação do espalhamento Raman na ordem de grandeza em que é observada, o que indica que tanto processos eletromagnéticos como químicos devem estar envolvidos, simultaneamente, no efeito SERS. 


\subsection{1 - MODELO ELETROMAGNÉTICO}

A excitação coletiva de um gás de elétrons de um condutor é chamada de plasma. Quando a excitação ocorre confinada na região próxima à superfície metálica é dita plasma de superfície. Superfícies rugosas, com certa curvatura, são necessárias para que ocorra a interação entre o plasma de superfície e as radiações incidente e espalhada. Pelo modelo eletromagnético a intensificação do espalhamento Raman ocorre devido a esta interação ${ }^{23}$. A intensidade do espalhamento Raman $\left(I_{m}\right)$ em função da intensidade da radiação excitante $\left(I_{0}\right)$ é dada pela equação abaixo:

$$
\mathrm{I}_{\mathrm{m} \mathrm{n}}=\mathrm{kI}_{0} v^{4} \Sigma_{\mathrm{i} . \mathrm{j}}\left|\left(\alpha_{\mathrm{ij}}\right)_{\mathrm{m} \mathrm{n}}\right|^{2}
$$

onde $v$ é a freqüência da radiação espalhada e $\left(\alpha_{i j}\right)_{m ~ n}$ são as integrais de momento de transição da polarizabilidade ${ }^{24}$. A ressonância entre a frequiência da radiação incidente e a freqüência de excitação do plasma superficial do metal leva a intensificação do espalhamento Raman por fatores da ordem de $10^{4}$ vezes.

Este modelo explica a seletividade do efeito SERS em relação ao metal usado como substrato e a razão pela qual há uma dependência da atividade SERS do metal com a freqüência da radiação excitante.

O espectro de absorção da superfície de um filme de prata de $5 \mathrm{~nm}$ de espessura, depositado através da técnica de ultra-alto vácuo em uma placa de vidro, mostra uma banda larga entre $320 \mathrm{~nm}$ e $700 \mathrm{~nm}$ com máximo em $475 \mathrm{~nm}$. Esta banda é atribuída à excitação do plasma de superfície do metal, o que o torna SERS-ativo quando radiações excitantes com frequiências dentro desta banda são utilizadas ${ }^{25}$. No caso do Au, que apresenta atividade SERS na região do vermelho e não a apresenta na região do verde, o máximo da banda de absorção do plasma superficial ocorre em $700 \mathrm{~nm}$.

O efeito de intensificação eletromagnético é função da distância da molécula à superfície devido à dependência do fenômeno com o plasma superficial, portanto, 
a intensificação diminui com o aumento desta distância. Neste modelo não se faz necessário o contato físico entre o adsorbato e o substrato metálico, o que explicaria intensificações de longo alcance, em situações onde há mais de uma camada adsorvida sobre o metal.

Trabalhos recentes mostram que há uma associação entre estruturas fractais nas superfícies dos substratos e a intensificação do espalhamento Raman dos adsorbatos. Estruturas fractais são invariantes em função da escala e estão presentes nas superfícies de eletrodos metálicos após sofrerem ciclos de oxidação e redução, nas geometrias superficiais das partículas coloidais utilizadas em experimentos SERS, nos filmes metálicos depositados sobre vidro em ultra-alto vácuo e em outras superfícies que, sabidamente, apresentam o efeito SERS.

Em estudos de estruturas fractais foram observados pontos quentes de adsorção (hot spots), onde o fator de intensificação do espalhamento Raman pode chegar a $10^{14}$ vezes ${ }^{22,26}$. Nestes pontos as excitações óticas do plasma de superfície local podem levar ao espalhamento hiper-Raman, onde o termo de segunda ordem na equação do momento dipolo induzido deve ser considerado.

\subsection{2 - MODELO QUÍMICO}

Neste modelo as interações entre o adsorbato e a superfície metálica levam a uma variação do tensor de polarizabilidade Raman que passa a receber contribuições das integrais das transições eletrônicas e das integrais de Franck-Condon. O fator de intensificação devido este tipo de interação é da ordem de 10 a $10^{2}$ vezes.

Pelo modelo químico os espectros Raman intensificados pela superfície diferem dos obtidos em solução e deslocamentos de freqüências em algumas bandas são observados, o que caracteriza o contato entre as moléculas e a superfície e, portanto, alterações das espécies químicas. A intensificação do sinal Raman pelo efeito químico é de curto alcance e, com isto, as bandas dos modos vibracionais do 
grupamento molecular envolvido na interação metal-adsorbato são intensificadas, enquanto que os modos relacionados a sítios moleculares não envolvidos na adsorção não são intensificados.

As curvas de intensidades de bandas em função do potencial aplicado mostram máximos em diferentes potenciais para diferentes bandas. Estas curvas também apresentam máximos diferentes em função da freqüência da radiação excitante $^{27}$. Estas observações não podem ser explicadas pelo mecanismo eletromagnético, mas são associadas a um mecanismo de transferência de carga, envolvendo os estados eletrônicos do metal e do adsorbato, induzida pela radiação excitante.

Dentro deste modelo químico surge no início dos anos 80 uma teoria que tenta explicar os sítios ativos onde ocorre a adsorção, utilizando o conceito de adatoms $^{28,29}$. Por este modelo, adatoms são defeitos na superfície metálica em nível atômico, sendo que nestas nanorregiões os níveis de energia eletrônica devem estar um pouco abaixo do nível de Fermi do metal e, portanto, com carga elétrica ligeiramente positiva. A densidade destas nanopartículas na superfície metálica é baixa, mas compatível com o nível de recobrimento observado em experimentos SERS: menos de $10 \%$ de uma monocamada. Da interação dos adatoms com o adsorbato surgem as transições eletrônicas que, acopladas ao modo vibracional, resultam no efeito de intensificação SERS ${ }^{30}$, semelhante ao efeito de intensificação Raman ressonante.

Pode-se esquematizar o mecanismo de transferência de carga em um sistema eletroquímico, onde a superfície metálica é o eletrodo de trabalho, considerando os valores relativos de energia do nível de Fermi do metal e dos níveis eletrônicos ocupado de maior energia (highest occupied molecular orbital - HOMO) e desocupado de menor energia (lowest unoccupied molecular orbital - LUMO) do adsorbato. Após a interação entre os adatoms da superfície metálica e o adsorbato, chega-se ao equilíbrio em que o nível de Fermi se situa entre os níveis eletrônicos 
LUMO e HOMO. As energias relativas desses níveis vão depender da natureza do adsorbato e da superfície metálica (figura 3).

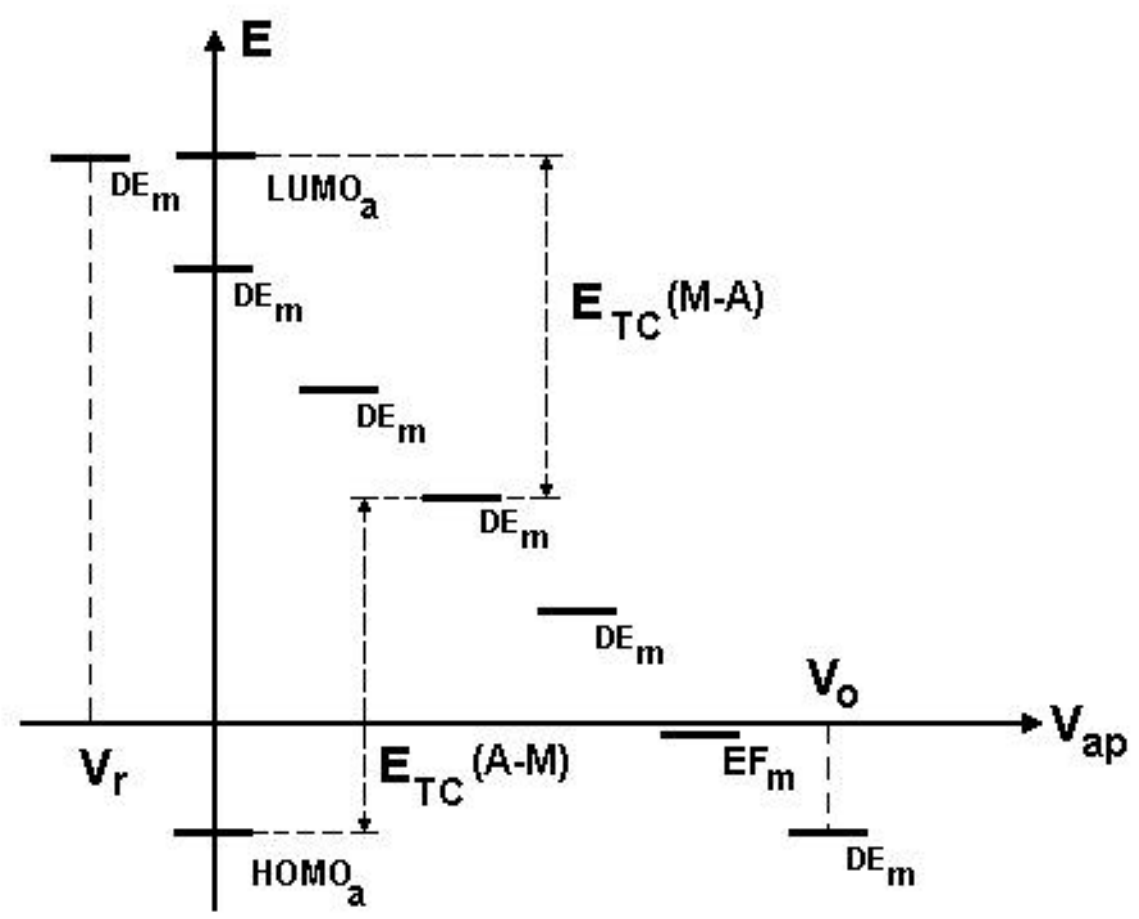

FIGURA 3: Variação da energia dos estados eletrônicos do metal em função da aplicação de potencial no eletrodo e em relação às energias do HOMO e do LUMO do adsorbato. $\mathrm{EF}_{\mathrm{m}}=$ energia do nível de Fermi do metal, $\mathrm{DE}_{\mathrm{m}}=$ densidade dos estados eletrônicos do metal, $\mathrm{V}_{\mathrm{ap}}=$ potencial aplicado no eletrodo metálico, $\mathrm{V}_{\mathrm{O}}=$ potencial de oxidação do adsorbato, $\mathrm{V}_{\mathrm{r}}=$ potencial de redução do adsorbato, $\mathrm{E}_{\mathrm{TC}}(\mathrm{M}-\mathrm{A})=$ energia de transferência de carga metal-adsorbato, $\mathrm{E}_{\mathrm{TC}}(\mathrm{A}-\mathrm{M})=$ energia de transferência de carga adsorbato-metal.

Considerando-se este diagrama, podem ocorrer transferências de carga do HOMO do adsorbato para o nível de Fermi do metal ou, o inverso, do nível de Fermi do metal para o LUMO do adsorbato induzidas pela radiação excitante, cujos fótons possuem energia igual à da transição eletrônica (ressonância) ${ }^{31}$. Além disso, pode-se variar o potencial da superfície metálica de forma a variar-se a energia dos estados eletrônicos do metal; com isto, a energia de transferência de carga também se altera, podendo ocorrer diferentes situações de ressonância. Portanto, moléculas que possuem bandas de absorção na região do ultravioleta passam a possuir transições por transferência de carga na região do visível e quando determinada 
radiação excitante estiver em ressonância com esta transição a intensidade do sinal SERS será máxima.

Quando o potencial é variado no sentido catódico a redução do adsorbato ocorre quando a energia de seu LUMO é semelhante à energia dos estados eletrônicos do metal $\left(\mathrm{V}_{\mathrm{r}}\right)$ e, vice-versa, o adsorbato é oxidado quando o potencial aplicado leva os estados eletrônicos do metal para uma energia semelhante à do HOMO do adsorbato $\left(\mathrm{V}_{\mathrm{o}}\right)$.

Em experimentos em que o potencial da superfície metálica é variado, podese obter máximos de intensidade do sinal SERS em diferentes potenciais em função da radiação excitante. Com isto, pode-se determinar se a transição eletrônica corresponde a uma transferência de carga metal-adsorbato ou adsorbato-metal. Por exemplo, se for aumentada a energia dos fótons da radiação excitante (variação para o azul) e, com isso, o potencial necessário para o máximo de intensidade SERS for mais negativo, a transferência de carga é no sentido adsorbato-metal e se a mesma variação na radiação incidente produzir máximo de sinal SERS em potencial mais positivo, a transferência se dá no sentido oposto, metal-adsorbato.

\subsection{3 - CONCLUSÃO}

A intensificação observada nos espectros Raman intensificados pela superfície não se deve apenas a um mecanismo. As interações químicas adsorbatometal, envolvendo transferência de carga, levam a intensificações no espalhamento Raman da ordem de $10^{2}$ vezes, enquanto que interações físicas, semelhantes às propostas pelo modelo eletromagnético, geram intensificações que chegam a $10^{4}$ vezes. A somatória destes fatores resulta na intensificação observada em experimentos SERS, da ordem de $10^{6}$ vezes.

Em regiões menores, com dimensões de dezenas de nanômetros, chamadas de hot spots, a intensificação do sinal chega a $10^{14}$ vezes. A intensificação máxima 
devida a efeitos eletromagnéticos e prevista teoricamente para estes pontos é de $10^{6}$ a $10^{7}$ vezes, enquanto que a devida a efeitos Raman ressonante é de $10^{4}$ a $10^{5}$ vezes. Portanto, para justificar-se o fator de intensificação observado, outros efeitos devem estar envolvidos. Uma hipótese possível é a intensificação do campo elétrico da radiação excitante associada à curvatura local dos aglomerados fractais de átomos

metálicos ${ }^{23}$. Outra possibilidade é o mecanismo eletrônico proposto por A. Otto ${ }^{32}$, no qual moléculas quimicamente adsorvidas interagem com elétrons balísticos das partículas do metal excitadas fortemente pela radiação laser.

São necessários novos estudos para que estas hipóteses sejam comprovadas, como por exemplo, a construção de estruturas em nível atômico sobre substratos metálicos, por técnicas de nanolitografia, com a finalidade de estudar-se o mecanismo de intensificação do espalhamento Raman e sua relação com estruturas fractais.

\subsection{4 - APLICAÇÕES}

Observa-se que o uso da técnica SERS para estudos de superfícies se diversifica e amplia. Com o melhoramento dos componentes ópticos dos espectrômetros, o desenvolvimento da microscopia Raman e o desenvolvimento de detectores mais sensíveis do tipo CCD (charge coupled device) ampliaram-se as possibilidades de uso da espectroscopia Raman e, em particular, da espectroscopia Raman intensificada pela superfície, como por exemplo na química forense e na identificação e caracterização de obras de arte. No futuro, com o aumento da capacidade de deteç̧ão do sinal Raman e com o estudo de nanorregiões dos sistemas adsorbato-metal, será possível compreender os mecanismos envolvidos nos fenômenos de aumento da secção de choque Raman do adsorbato pela superfície.

Atualmente, um dos empregos da espectroscopia Raman intensificada pela superfície é na química analítica, em experimentos envolvendo nanolitros de 
soluções, em que a concentração mínima detectável é da ordem de $10^{-14}$ mols/L. A detecção de moléculas adsorvidas em pequenos agregados coloidais de $\mathrm{Ag}$ ou $\mathrm{Au}$ com tamanho entre 100 e $1000 \mathrm{~nm}$ apresentam resultados bastante reprodutíveis ${ }^{33,34}$.

A produção e caracterização de eletrodos metálicos modificados pela adsorção de monocamadas de moléculas, utilizados em diversos campos, é um ramo de pesquisas na qual a técnica Raman intensificado pela superfície tem tido importante papel, pois possibilita a caracterização e o estudo do comportamento do adsorbato na superfície metálica em função do solvente, do substrato metálico, do potencial aplicado, etc ${ }^{35}$.

Há, também, aplicações desta técnica em estudos de nanotubos de carbono, onde os espectros Raman são, geralmente, obtidos de amostras em que espécies de diferentes diâmetros estão presentes. Através da adsorção destes em agrupamentos de partículas coloidais de prata com superfícies fractais de dimensões da ordem de $20 \mathrm{~nm}$, são obtidos espectros SERS que, devido à seletividade da técnica, podem ser atribuídos a um conjunto restrito de espécies de nanotubos ${ }^{36}$.

Outra área de pesquisa que vem utilizando-se, sistematicamente, do efeito Raman intensificado pela superfície é a de filmes poliméricos. Estes podem ser crescidos sobre superfícies metálicas gerando espectros SERS onde estudos de geometria molecular, dopagem, entre outros, podem ser realizados ${ }^{37,38}$.

\section{REFERÊNCIAS}

${ }^{1}$. S. M. Zakeeruddin, M. K. Nazeeruddin, P. Pechy, F. P. Rotzinger, R. Humphry-Baker, K. Kalyanasundaram e M. Grätzel, Inorg. Chem., 36, 5937 (1997).

2. S. C. Oliveira, R. M. Torresi e S. I. C. Torresi, Química Nova, 23 (1), 79, (2000).

${ }^{3}$. M. Maskus e H. D. Abrunã, Langmuir, 12, 4455 (1996).

4. G. S. Hanan, U. S. Schubert, D. Volkmer, E. Rivière, J. M. Lehn, N. Kyritsakas e J. Fischer, Can. J. Chem., 75, 169 (1997).

5 . K. Nakamoto, J. Phys. Chem., 64, 1420 (1960).

6. A. Sarkar e S. Chakravorti, Spectrosc. Lett., 27 (3), 305 (1994). 
7. L. S. Pinheiro e M. L. A. Temperini, Surface Science, 464, 176 (2000).

${ }^{8}$. C. A. Bessel. R. F. See. D. L. Jameson, M. R. Churchill e K. J. Takeuchi, J. Chem. Soc., Dalton Trans., 3223 (1992).

9 . P. O’D. Offenhartz, P. George e G. P. Haight Jr., J. Phys. Chem., 67, 116 (1962).

${ }^{10}$. G. Albano, V. Balzani, E. C. Constable, M. Maestri e D. R. Smith, Inorg. Chim. Acta, $\frac{277}{11}, 225$ (1998).

11. M. G. B. Drew, M. J. Hudson, P. B. Iveson, M. L. Russell, J. Liljenzin, M. Skalberg, L. Spjuth e C. Madic, J. Chem. Soc., Dalton Trans., 2973 (1998).

12. C. J. Kepert, B. W. Skelton e A. H. White, Aust. J. Chem., 47, 391 (1994).

13. A. Hergold-Brundic, Z. Popovix e D. Matkovic-Calogovic, Acta Cryst., C52, 3154 (1996).

14. J. R. Nestor e E. R. Lippincott, J. Raman Spectrosc., 1, 305 (1973).

15 . D. L. A. de Faria, M. L. A. Temperini e O. Sala, Química Nova, 22 (4), 541 (1999).

16 . J. C. Rubim, Tese de doutorado, IQUSP, 1985.

17. A. Hartstein, J. R. Kirtley e J. C. Tsang, Phys. Rev. Lett., 45, 201 (1980).

18 . M. Fleischmann, P. J. Hendra e A. J. McQuillan, Chem. Phys. Lett., 26, 163 (1974).

19 . D. L. Jeanmarie e R. P. Van Duyne, J. Electroanal. Chem., $\underline{84}, 1$ (1977).

20 . M. G. Albrecht e J. A. Creighton, J. Am. Chem. Soc., 99, 5215 (1977).

21 . B. Pettinger, U. Wenning e H. Wetzel, Surface Science, 101, 409 (1980).

22 . V. M. Shalaev, W. Kim, V. P. Drachev, V. Podolskiy, V. P. Safonov e R. L. Armstrong, Progr. Surf. Raman Spectrosc.- ICORS 2000, 21 (2000).

23. M. Moskovits, Rev. Mod. Phys., 57, 783 (1985).

24. O. Sala, Fund. da Espectroscopia Raman e Infravermelho, S. Paulo, Ed. UNESP, 36 (1996).

${ }^{25}$. P. Corio, Tese de doutorado, IQUSP (1998).

26 . S. Nie e S. R. Emory, Science, 275, 1102 (1997).

27 . J. Billmann e A. Otto, Solid State Commun., 44 (2), 105 (1982).

28 . E. Burstein, Y. J. Chen, C. Y. Chen, S. Lundquist e E. Tossatti, Solid State Commun., $\frac{29}{29}, 567$ (1979).

${ }^{29}$. A. Otto, J. Billmann, J. Eickmans, U. Ertürk e C. Pettenkofer, Surf. Science, 138, 319 (1984).

30. J. R. Lombardi, R. L. Birke, T. Lu e J. Xu, J. Chem. Phys, 84, 4174 (1986).

31 J. C. Rubim, P. Corio, M. C. C. Ribeiro e M. Matz, J. Phys. Chem., 99, 15765 (1995).

32. A. Otto, XVIth International Conference on Raman Spectroscopy, South Africa, 1998.

33. S. Nie e S. R. Emory, J. Phys. Chem. B, 102 (3), 493 (1998).

${ }^{34}$. K. Kneipp, H. Kneipp, I. Itzkan, R. R. Dasari e M. S. Feld, Chem. Rev., 99, 2957 (1999).

35 . L. S. Pinheiro e M. L. A. Temperini, J. Electroanal. Chem., 295, 169 (1990).

36 . P. Corio, S. D. M. Brown, A. Marucci, M. A. Pimenta, K. Kneipp, G. Dresselhaus e M. S. Dresselhaus, Phys. Rev. B, $\underline{61}, 13202$ (2000).

37 . P. Gao, D. Gosztola e M. J. Weaver, J. Phys. Chem., 93, 3753 (1989).

38. M. Baibarac, M. Lapkowski, A. Pron, S. Lefrant e I. Baltog, J. Raman Spectrosc., 29, 825 (1998). 


\section{2 - EXPERIMENTAL}

\section{1 - REAGENTES E SÍNTESES}

A tpy utilizada, de procedência Aldrich, foi purificada através do método de sublimação, utilizando-se temperatura do banho de aproximadamente $90^{\circ} \mathrm{C}$, vácuo de bomba mecânica e resfriamento do dedo frio, utilizando-se como mistura refrigerante acetona e gelo seco. A tpy também foi purificada por recristalizações com éter de petróleo e éter.

O composto 4'-(5-mercaptopentil)-2,2':6',2”-terpiridina (tpy-SH) foi utilizado sem purificação prévia devido à pequena quantidade disponível.

$\mathrm{O}$ composto $\mathrm{TpyH}^{+} \mathrm{CF}_{3} \mathrm{SO}_{3}{ }^{-}$foi sintetizado segundo procedimento descrito por D. Matkovic-Calogovic e cols. .

$\mathrm{O}$ complexo $\left[\mathrm{Ag}(\mathrm{I}) \operatorname{tpyNO}_{3}\right]$ foi preparado segundo procedimento descrito por W. J. Peard e R. T. Pflaum ${ }^{2}$.

TABELA 1: Resultados das análises elementares para C, $\mathrm{N}$ e H (\% em massa) da tpy comercial e dos compostos sintetizados.

\begin{tabular}{|c|c|c|c|c|}
\hline \multicolumn{2}{|c|}{ COMPOSTO } & \multicolumn{3}{|c|}{ ELEMENTOS (\%m) } \\
\hline & & $\mathrm{C}$ & $\mathrm{N}$ & $\mathrm{H}$ \\
\hline \multirow[t]{2}{*}{ tpy } & experimental & 77,0 & 18,1 & $\overline{4,6}$ \\
\hline & calculado & 77,2 & 18,0 & 4,8 \\
\hline \multirow[t]{2}{*}{ tpyH $^{+} \mathrm{CF}_{3} \mathrm{SO}_{3}^{-}$} & experimental & 49,6 & 10,7 & $\overline{3,4}$ \\
\hline & calculado & 50,1 & 11,0 & 3,2 \\
\hline \multirow{2}{*}[\mathrm{Ag}(\mathrm{I})\operatorname{tpyNO}_{3}]{} & experimental & 42,9 & 9,8 & 2,9 \\
\hline & calculado & 44,7 & 13,9 & 2,8 \\
\hline \multirow[t]{2}{*}[\mathrm{Cu}(\mathrm{II})\operatorname{tpyH}_{2}\mathrm{OClO}_{4}]{$\mathrm{ClO}_{4}$} & experimental & 35,3 & 8,2 & 2,5 \\
\hline & calculado & 35,1 & 8,2 & 2,5 \\
\hline \multirow[t]{2}{*}[\mathrm{Cu}(\mathrm{II})\mathrm{tpyCl}]{$\mathrm{Cl}$} & experimental & 48,9 & 11,2 & 3,1 \\
\hline & calculado & 49,0 & 11,4 & 3,0 \\
\hline
\end{tabular}


$\mathrm{O}$ complexo $\left[\mathrm{Cu}(\mathrm{II}) \mathrm{tpyH}_{2} \mathrm{OClO}_{4}\right] \mathrm{ClO}_{4}$ foi sintetizado preparando-se solução metanólica $1 \mathrm{mmol} / \mathrm{L}$ de tpy e acrescentando-se solução aquosa $1 \mathrm{mmol} / \mathrm{L}$ de $\mathrm{Cu}\left(\mathrm{ClO}_{4}\right)_{2}$. O precipitado foi filtrado e seco sob vácuo. O complexo $[\mathrm{Cu}(\mathrm{II}) \operatorname{tpyCl}] \mathrm{Cl}$ foi sintetizado preparando-se solução metanólica $1 \mathrm{mmol} / \mathrm{L}$ de tpy e acrescentandose solução metanólica $1 \mathrm{mmol} / \mathrm{L}$ de $\mathrm{CuCl}_{2}$. O precipitado foi filtrado e seco sob vácuo.

As análises elementares destes compostos são apresentadas na tabela 1.

\section{2 - EQUIPAMENTOS}

O espectrômetro utilizado nos experimentos de caracterização das espécies adsorvidas (SERS) e na obtenção da maioria dos demais espectros Raman foi um Renishaw, mod.: System 3000, com microscópio Olympus BTH-2, objetiva com aumento de 50 vezes, detector do tipo CCD (charge coupled device) e resolução de $2 \mathrm{~cm}^{-1}$. As radiações excitantes utilizadas foram a $632,8 \mathrm{~nm}$, de um laser $\mathrm{He}-\mathrm{Ne}$ da Spectra Physic, mod.: 127, as radiações 488,0 e 514,5 nm, de um laser de $\mathrm{Ar}^{+}$da Omnichrome, mod.: 543R-AP-A01 e a radiação 782,0 nm, de um laser de estado sólido semicondutor (GaAs dopado com Al) da Renishaw mod.: NIR-780/50. A potência de saída usada em todas as linhas laser foi de $30 \mathrm{~mW}$ e foram utilizados filtros que reduziam a intensidade da radiação incidente na amostra para evitar a sua decomposição.

Alguns espectros de solução foram obtidos em espectrômetro Jobin- Yvon U-1000, com duplo monocromador, detecção por fotomultiplicadora. A radiação excitante utilizada foi a 514,5 $\mathrm{nm}$ de um laser de $\mathrm{Ar}^{+}$da Innova 90 - Coeherent Radiation, cuja potência tipicamente usada estava entre 200 e 300 mW.

Os espectros eletrônicos foram obtidos em um Beckman DU-70, com lâmpadas de halogênio/tungstênio (radiação visível) e de deutério (radiação ultravioleta). Foram usadas cubetas de quartzo com caminho óptico de $10 \mathrm{~mm}$. 
Os espectros infravermelho foram obtidos em interferômetro da Bomem, BM-100, com divisor de feixe de $\mathrm{KBr}$ e detector DTGS e resolução de $4 \mathrm{~cm}^{-1}$. As amostras dos compostos no estado sólido foram preparadas em pastilhas com $\mathrm{KBr}$ ou em emulsões de nujol ou fluorolube.

As medidas eletroquímicas foram realizadas nos potenciostato-galvanostatos EG\&G Mods.: PAR-263 ou PAR-273 (Princeton Applied Research). As medidas de pH das soluções foram realizadas em um Digimed, mod.: DM-20.

As análises elementares foram realizadas na central analítica do IQUSP em um aparelho Perkin-Elmer, Elementar Analyser CHN, mod.: 2400, para determinação de porcentagem de $\mathrm{C}, \mathrm{N}$ e $\mathrm{H}$, com precisão de aproximadamente $0,01 \%$.

As análises termogravimétricas do perclorato de cobre (II) foram realizadas em um aparelho Shimadzu, TGA 50.

\section{3 - PROCEDIMENTOS NOS EXPERIMENTOS SERS}

Os espectros Raman intensificados pela superfície das espécies adsorvidas no eletrodo foram obtidos ex situ, com o eletrodo fora da célula eletrolítica, e in situ, com o eletrodo na célula eletrolítica com variação de potencial. Para a obtenção destes espectros sempre foi utilizada a radiação excitante 632,8 nm. Nos experimentos SERS ex situ o eletrodo era ativado na célula eletrolítica através de ciclos de oxidação e redução da prata, sem a presença da espécie a ser adsorvida. Os ciclos de ativação do eletrodo através de oxidação e redução eram feitos sem a incidência do laser e a solução eletrolítica utilizada continha o mesmo solvente e o mesmo ânion que estavam presentes nas soluções-mãe. A concentração do sal utilizado como eletrólito foi de $10^{-1} \mathrm{~mol} / \mathrm{L}$. Após a ativação o eletrodo era lavado copiosamente com água deionizada e imerso em uma solução-mãe contendo a 
espécie a ser adsorvida sobre a superfície metálica para que uma monocamada autoorganizada se formasse. A concentração utilizada de adsorbato foi de $10^{-3} \mathrm{~mol} / \mathrm{L}$.

Os experimentos mostraram que 1 hora era o tempo necessário para se obter um espectro com a melhor relação sinal/ruído. Porém, quando o ânion utilizado era $\mathrm{ClO}_{4}{ }^{-}$, por sua maior dificuldade de adsorção, o tempo necessário para a formação de uma monocamada auto-organizada do adsorbato, que permitisse a obtenção de espectros, estendeu-se para 3 horas. Após este tempo o eletrodo era, novamente, lavado com água deionizada e seco com fluxo de $\mathrm{N}_{2}$ para a obtenção dos espectros. Estes eram obtidos com a mínima potência de laser (transmissão entre 1\% e 10\% da potência inicial pelo uso de filtros) para evitar-se aquecimento local e decomposição ou mudanças na conformação das espécies adsorvidas.

As ativações nos experimentos SERS in situ foram realizadas de forma semelhante àquelas dos experimentos ex situ, utilizando-se solução eletrolítica com concentração de $10^{-1} \mathrm{~mol} / \mathrm{L}$ do eletrólito, sem a presença da espécie a ser adsorvida durante os ciclos eletroquímicos. As ativações eram feitas sem a incidência da radiação excitante. Depois de ativado o eletrodo, a solução eletrolítica utilizada era retirada da célula, esta era lavada copiosamente com água deionizada e nova solução eletrolítica, contendo o composto a ser adsorvido, era adicionada à célula. As concentrações utilizadas nesta solução eram de $10^{-1} \mathrm{~mol} / \mathrm{L}$ de eletrólito e de $10^{-3}$ mol/L de adsorbato. Após aproximadamente dez minutos eram obtidos os espectros, variando-se o potencial da superfície metálica do eletrodo no sentido catódico em intervalos de $0,1 \mathrm{~V}$.

Nos ciclos de oxidação e redução realizados para ativação das superfícies metálicas dos eletrodos, os valores de potencial foram selecionados de forma a obter-se correntes anódicas de pico entre 0,8 e 1,5 mA e velocidades da ordem de $35 \mathrm{mV} / \mathrm{s}$. As ativações foram realizadas em diferentes condições para os diferentes ânions e metais utilizados (tabela 2). 
Estes valores foram escolhidos experimentalmente de forma a obter-se a melhor ativação da superfície metálica e com isso maximizar-se o sinal nos espectros.

Nos experimentos SERS in situ e ex situ em que foi necessário o uso de ácidos no preparo de soluções, foi evitado que estes tivessem ânions diferentes daqueles presentes nos sais utilizados como eletrólito. Para isto, os ácidos utilizados foram $\mathrm{HCl}, \mathrm{HClO}_{4}$ e $\mathrm{HI}$, para soluções que continham como eletrólitos $\mathrm{CI}, \mathrm{ClO}_{4}{ }^{-}$e I, respectivamente.

TABELA 2: Diferentes condições dos ciclos redox em eletrodo a partir de soluções aquosas com concentração $10^{-1} \mathrm{M}$ do eletrólito citado. Ei, Em e Ef são os potenciais iniciais, intermediários e finais, respectivamente.

\begin{tabular}{|c|c|c|c|c|}
\hline $\begin{array}{c}\text { ELETROD } \\
\mathbf{O}\end{array}$ & $\begin{array}{c}\text { ELETRÓLI } \\
\text { TO }\end{array}$ & Ei / V & Em / V & Ef / V \\
\hline $\mathrm{Ag}$ & $\mathrm{KCl}$ & $-0,2$ & $+0,2$ & $-0,2$ \\
\hline $\mathrm{Ag}$ & $\mathrm{NaClO}_{4}$ & $-0,3$ & $+0,65$ & $-0,3$ \\
\hline $\mathrm{Ag}$ & $\mathrm{KI}$ & $-0,6$ & $-0,2$ & $-0,6$ \\
\hline $\mathrm{Cu}$ & $\mathrm{KCl}$ & $-0,4$ & $+0,1$ & $-0,4$ \\
\hline
\end{tabular}

Nos estudos SERS de adsorção da tpy protonada foram escolhidos valores de $\mathrm{pH}$, a partir dos $\mathrm{pK}_{\mathrm{a}}(\mathrm{s})$ conhecidos, de forma a obter-se nas soluções aquosas utilizadas as seguintes espécies: tpy não protonada $(\mathrm{pH}=6)$, aproximadamente $50 \%$ de tpy monoprotonada e 50\% de tpy diprotonada $(\mathrm{pH}=3)$, aproximadamente $90 \%$ de tpy diprotonada $(\mathrm{pH}=1,8)$ e praticamente a totalidade das moléculas de tpy diprotonada $(\mathrm{pH}=0)$.

A célula eletrolítica utilizada foi confeccionada em teflon e está representada esque maticamente na figura 4 . 
O eletrodo de referência utilizado foi $\mathrm{Ag} / \mathrm{AgCl}$ e os eletrodos de trabalho foram confeccionados em $\mathrm{Ag}$ e $\mathrm{Cu}$, embutidos em teflon e possuindo área aproximada de $7 \mathrm{~mm}^{2}$.

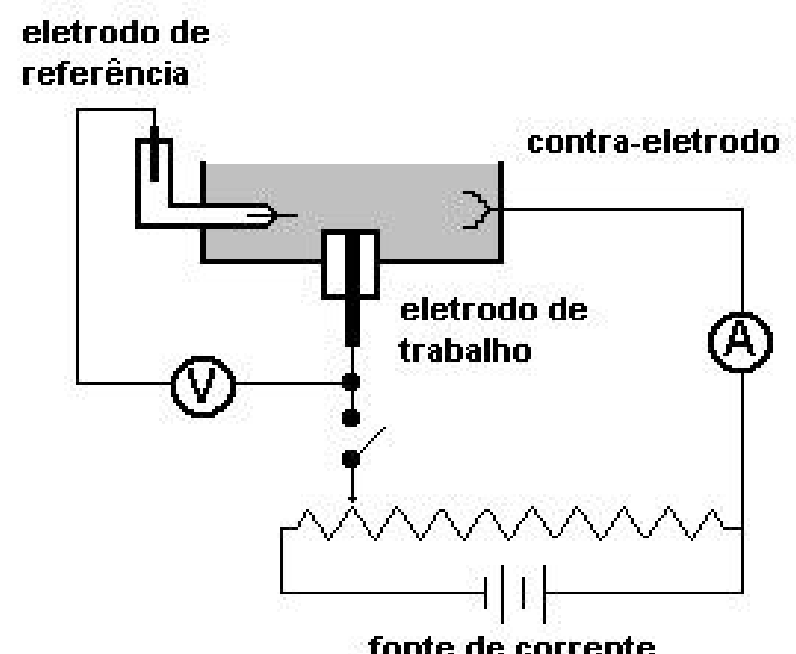

FIGURA 4: Célula eletrolítica utilizada em experimentos SERS.

\section{REFERÊNCIAS:}

1. A. Hergold-Brundic, Z. Popovic e D. Matkovic-Calogovic, Acta Cryst., C52, 3154 (1996).

2. W. J. Peard e R. T. Pflaum, J. Am. Chem. Soc., $\underline{80}, 1593$ (1958). 


\section{3 - RESULTADOS E DISCUSSÕES}

\section{1 - PADRÕES}

Para analisar-se os espectros Raman intensificados pela superfície (SERS) da tpy adsorvida sobre a superfície metálica foram obtidos espectros deste composto, envolvido em diferentes interações com as vizinhanças, que foram utilizados como padrões. Estes são os espectros Raman da tpy no estado sólido, em soluções aquosas com diferentes $\mathrm{pH}(\mathrm{s})$ e em outros solventes orgânicos. Também foram sintetizados alguns compostos nos quais a tpy possui conformações conhecidas e sofre interações químicas diversas.

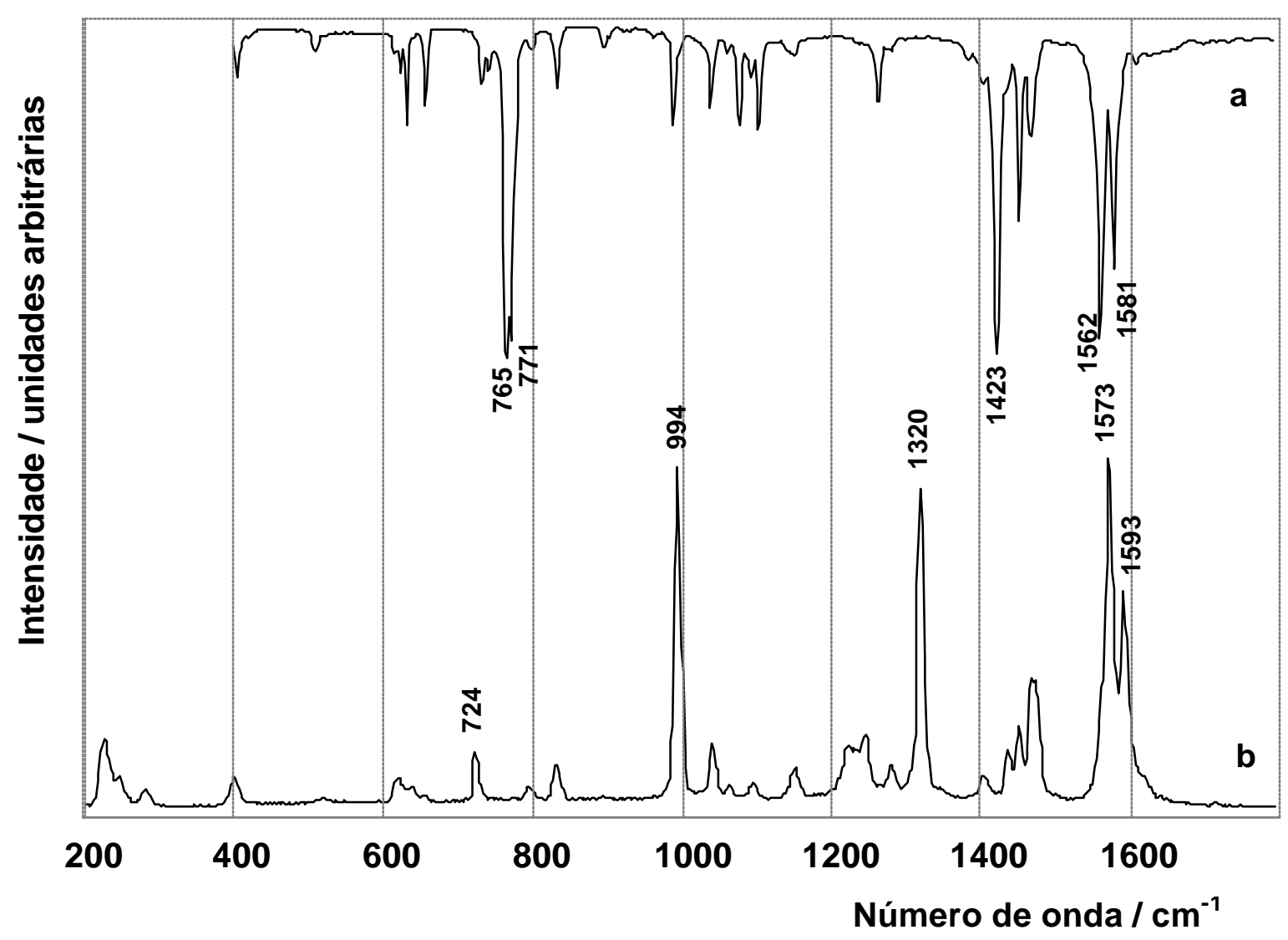

FIGURA 5: Espectros vibracionais da tpy no estado sólido: infravermelho (em $\mathrm{KBr}$ ) (a) e Raman, $\lambda_{0}=632,8 \mathrm{~nm}$ (b). 
Os espectros Raman e infravermelho da tpy no estado sólido estão apresentados na figura 5 .

Foram realizadas medidas de polarização das bandas Raman da tpy em solução de acetonitrila para auxiliar na atribuição dos modos vibracionais. Estes espectros estão apresentados na figura 6.

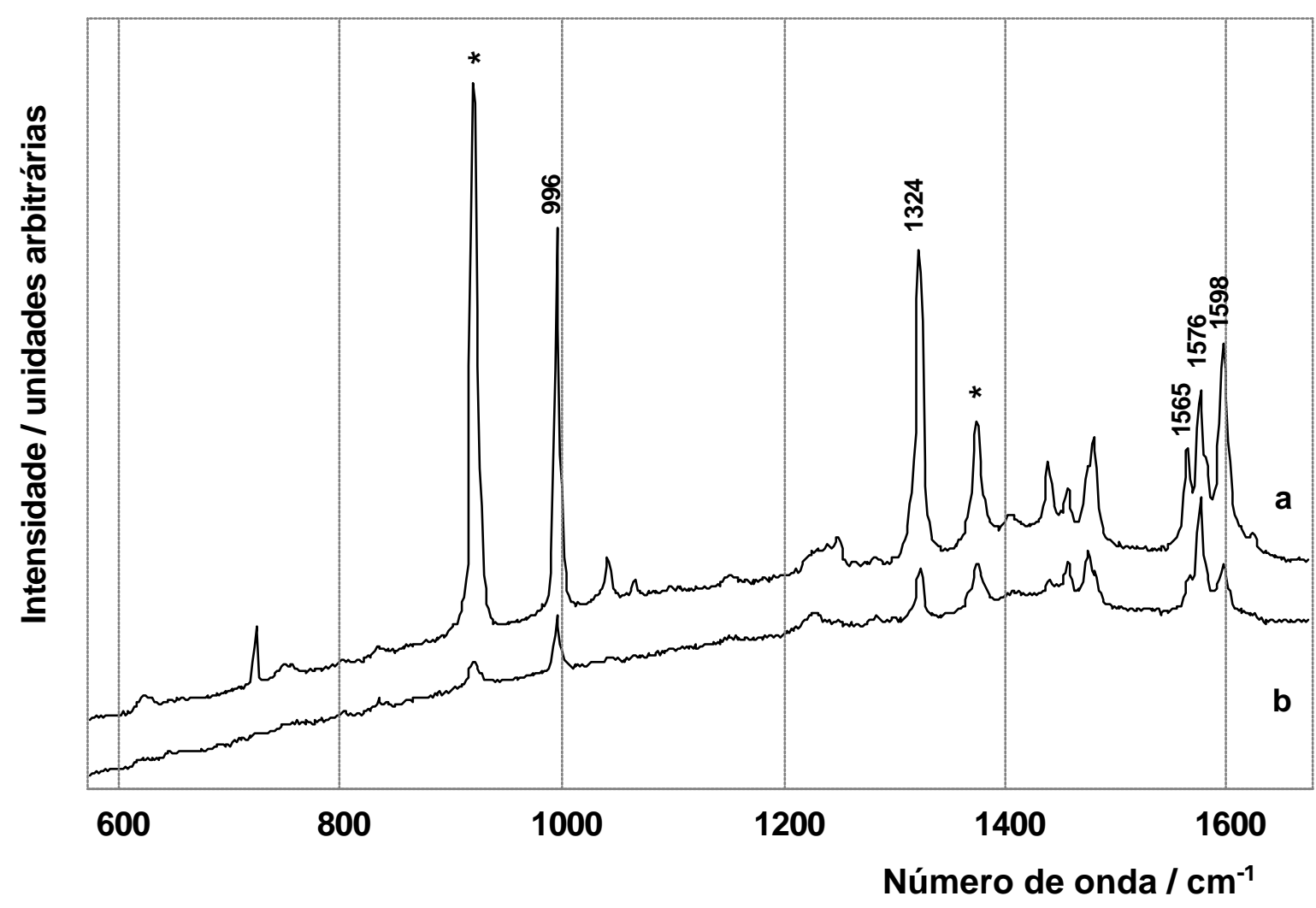

FIGURA 6: Espectros Raman da tpy em solução de acetonitrila com o campo elétrico do laser perpendicular (a) e paralelo (b) à direção de observação. $\lambda_{0}=514,5 \mathrm{~nm}$. (*) Bandas do solvente.

Na tabela 3 é apresentada uma atribuição tentativa das bandas da tpy baseada na medida de polarização e nas atribuições de freqüências da tpy ${ }^{1}$ e de compostos semelhantes, benzeno ${ }^{2,3}$, difenil $^{4}$, piridina ${ }^{3}, 2,2^{\text {'-bipiridina }}{ }^{5,6}$, obtidas da literatura.

Através deste estudo comparativo a atribuição de freqüências da tpy, obtida da referência 1 , foi complementada. 
TABELA 3: Atribuição das frequiências fundamentais da tpy a partir da comparação com as atribuições vibracionais das moléculas de: benzeno, difenil, piridina e 2,2' - bipiridina.

$\vee \mathrm{CC} \Rightarrow$ estiramento $\mathrm{C}-\mathrm{C} ; \vee \mathrm{CH} \Rightarrow$ estiramento $\mathrm{C}-\mathrm{H} ; \vee \mathrm{CN} \Rightarrow$ estiramento $\mathrm{C}-\mathrm{N} ; \beta \mathrm{CH} \Rightarrow$ deformação de ângulo $\mathrm{C}-\mathrm{H}$ no plano ; $\alpha \mathrm{CCC} \Rightarrow$ deformação de ângulo $\mathrm{C}-\mathrm{C}-\mathrm{C}$ no plano; $\phi \mathrm{CC} \Rightarrow$ deformação de ângulo C-C-C fora do plano; $\gamma \mathrm{CH} \Rightarrow$ deformação de ângulo $\mathrm{C}-\mathrm{H}$ fora do plano.

\begin{tabular}{|c|c|c|c|c|c|c|c|c|c|c|c|}
\hline \multirow[t]{2}{*}{\begin{tabular}{|c|}
$N^{P}$ \\
de \\
Wilson
\end{tabular}} & \multicolumn{2}{|c|}{$\begin{array}{c}\text { Benzeno } \\
D_{6 h}\end{array}$} & \multicolumn{2}{|c|}{$\begin{array}{c}\text { Difenil } \\
\mathrm{C}_{2 \mathrm{~V}}\end{array}$} & \multicolumn{2}{|c|}{$\begin{array}{c}\text { Piridina } \\
\mathrm{C}_{2 \mathrm{~V}}\end{array}$} & \multicolumn{2}{|c|}{$\begin{array}{c}\text { 2,2'Bipiridina } \\
\mathrm{C}_{2 \mathrm{~h}}\end{array}$} & \multicolumn{2}{|c|}{$\begin{array}{c}\text { 2,2',6',2"'-terpiridina } \\
\mathrm{C}_{2 \mathrm{~V}} / \mathrm{C}_{\mathrm{S}}\end{array}$} & \multirow[t]{2}{*}{$\begin{array}{l}\text { Atribuiçãa } \\
\text { tentativa }\end{array}$} \\
\hline & $\mathbf{c m}^{-1}$ & Repr & $\mathbf{c m}^{-1}$ & Repr & $\mathbf{c m}^{-1}$ & $\overline{\text { Repr }}$ & $\mathbf{c m}^{-1}$ & Repr & $\mathbf{c m}^{-1}$ & Repr & \\
\hline & & & 246 & $\mathrm{~B}_{1}$ & & & $\begin{array}{l}224 \\
332\end{array}$ & $\begin{array}{l}\mathrm{B}_{\mathrm{g}} \\
\mathrm{Ag}_{\mathrm{g}}\end{array}$ & $\begin{array}{c}245 / 227 \\
283\end{array}$ & $\begin{array}{c}\mathrm{B}_{1} / \mathrm{A}^{\prime \prime} \\
\mathrm{A}_{1}\end{array}$ & $\begin{array}{c}\phi \text { CC }(\chi \text { sens. }) \\
\alpha \operatorname{CCC}(\chi \text { sens. })\end{array}$ \\
\hline & & & 302 & $\mathrm{~B}_{2}$ & & & & & 419 & $\overline{\mathrm{B}_{2}}$ & $\chi$ sens. \\
\hline & & & & & & & 440 & $\mathrm{~A}_{\mathrm{g}}$ & & & $\alpha \mathrm{CCC}$ \\
\hline \multirow[t]{2}{*}{16} & 404 & $\mathrm{E}_{2 \mathrm{u}}$ & 397 & $\mathrm{~A}_{2}$ & 380 & $\mathrm{~A}_{2}$ & 400 & $\mathrm{~A}_{\mathrm{u}}$ & 509 & $\overline{\mathrm{A}_{2}}$ & $\phi \mathrm{CC}$ \\
\hline & & & 470 & $\mathrm{~B}_{1}$ & 406 & $\overline{\mathrm{B}_{1}}$ & 409 & $\mathrm{~B}_{\mathrm{g}}$ & 401 & $\overline{\mathrm{B}_{1}}$ & $\phi \mathrm{CC}$ \\
\hline \multirow[t]{3}{*}{6} & 607 & $E_{2 g}$ & $\overline{531}$ & $\mathrm{~A}_{1}$ & 603 & $\mathrm{~A}_{1}$ & 614 & $\overline{A_{g}}$ & 622 & $\mathrm{~A}^{\prime}$ & $\alpha$ CCC ( $\chi$ sens. $)$ \\
\hline & & & & & & & & & 639 & $\mathrm{~A}^{\prime}$ & $\alpha \operatorname{CCC}(\chi$ sens. $)$ \\
\hline & & & 606 & $\mathrm{~B}_{2}$ & 654 & $\mathrm{~B}_{2}$ & 620 & $\mathrm{~B}_{\mathrm{u}}$ & $522 / 655$ & $\mathrm{~B}_{2} / \mathrm{A}^{\prime}$ & $\alpha \mathrm{CCC}$ \\
\hline \multirow[t]{2}{*}{11} & 675 & $\mathrm{~A}_{2 \mathrm{u}}$ & 696 & $\mathrm{~B}_{1}$ & 703 & $\mathrm{~B}_{1}$ & & & 765 & $\mathrm{~B}_{1}$ & $\gamma \mathrm{CH} / \phi \mathrm{CC}$ \\
\hline & & & & & & & 815 & $\mathrm{~B}_{\mathrm{g}}$ & $832 / 796$ & $\mathrm{~B}_{2} / \mathrm{A}^{\prime}$ & $\phi \mathrm{CC}(\chi$ sens. $)$ \\
\hline 4 & 707 & $\mathrm{~B}_{2 \mathrm{~g}}$ & 738 & $\mathrm{~B}_{1}$ & 747 & $\mathrm{~B}_{1}$ & 742 & $\mathrm{~B}_{\mathrm{g}}$ & 771 & $\mathrm{~B}_{1} / \mathrm{A} "$ & $\gamma \mathrm{CH}$ \\
\hline \multirow[t]{2}{*}{10} & 849 & $\mathrm{E}_{1 \mathrm{~g}}$ & 834 & $\mathrm{~A}_{2}$ & 884 & $\mathrm{~A}_{2}$ & 755 & $\mathrm{~A}_{\mathrm{u}}$ & & & $\gamma \mathrm{CH}$ \\
\hline & & & 904 & $\mathrm{~B}_{1}$ & 884 & $\mathrm{~B}_{1}$ & 909 & $\mathrm{~B}_{\mathrm{g}}$ & 897 & $\overline{\mathrm{B}_{1}}$ & $\gamma \mathrm{CH}$ \\
\hline 17 & 969 & $\mathrm{E}_{2 \mathrm{u}}$ & 985 & $\mathrm{~A}_{2}$ & 980 & $\mathrm{~A}_{2}$ & 975 & $\mathrm{~A}_{\mathrm{u}}$ & & & $\gamma \mathrm{CH}$ \\
\hline 5 & 989 & $\mathrm{~B}_{2 \mathrm{~g}}$ & 970 & $\mathrm{~B}_{1}$ & 941 & $\mathrm{~B}_{1}$ & & & 962 & A" & $\gamma \mathrm{CH}$ \\
\hline 1 & 992 & $\mathrm{~A}_{1 \mathrm{~g}}$ & 996 & $\mathrm{~A}_{1}$ & 991 & $\mathrm{~A}_{1}$ & 994 & $\mathrm{~A}_{\mathrm{g}}$ & 994 & $\mathrm{~A}_{1} / \mathrm{A}^{\prime}$ & v CC, CN (Respir. anel) \\
\hline 12 & 1010 & $\frac{\mathrm{B}_{1 \mathrm{u}}}{1 \mathrm{u}}$ & 733 & $\mathrm{~A}_{1}$ & 1030 & $\mathrm{~A}_{1}$ & 764 & $\mathrm{Ag}_{\mathrm{g}}$ & 724 & $\mathrm{~A}_{1} / \mathrm{A}^{\prime}$ & $\alpha$ CCC (Resp.Trigonal) \\
\hline \multirow[t]{2}{*}{18} & 1035 & $\mathrm{E}_{1 \mathrm{u}}$ & 1025 & $\mathrm{~A}_{1}$ & 1069 & $\mathrm{~A}_{1}$ & 1044 & $\mathrm{~A}_{\mathrm{g}}$ & $1096 / 1041$ & $\mathrm{~A}_{1} / \mathrm{A}^{\prime}$ & $\beta \mathrm{CH} / v \mathrm{CC}, \mathrm{CN}$ \\
\hline & & & 1077 & $\mathrm{~B}_{2}$ & 1069 & $\mathrm{~B}_{2}$ & 1065 & $\mathrm{~B}_{\mathrm{u}}$ & & & $\beta \mathrm{CH} / v \mathrm{CC}, \mathrm{CN}$ \\
\hline 15 & 1146 & $\mathrm{~B}_{2 \mathrm{u}}$ & 1151 & $\mathrm{~B}_{2}$ & 1146 & $\mathrm{~B}_{2}$ & 1085 & $\mathrm{~B}_{\mathrm{u}}$ & $1152 / 1064$ & $\mathrm{~B}_{2} / \mathrm{A}^{\prime}$ & $\beta \mathrm{CH} / v \mathrm{CC}, \mathrm{CN}$ \\
\hline \multirow[t]{3}{*}{9} & 1177 & $\mathrm{E}_{2 \mathrm{~g}}$ & 1185 & $\mathrm{~A}_{1}$ & 1217 & $\mathrm{~A}_{1}$ & 1146 & $\mathrm{~A}_{\mathrm{g}}$ & & & $\beta \mathrm{CH}$ \\
\hline & & & & $\mathrm{B}_{2}$ & & & 1140 & $\mathrm{~B}_{\mathrm{u}}$ & 1152 & $\mathrm{~B}_{2}$ & $\beta \mathrm{CH}$ \\
\hline & & & 1275 & $\mathrm{~A}_{1}$ & & & 1301 & $\mathrm{~A}_{\mathrm{g}}$ & 1320 & $\mathrm{~A}^{\prime}$ & $v$ CC interanéis ( $\chi$ sens. $)$ \\
\hline 14 & 1309 & $\mathrm{~B}_{2 \mathrm{u}}$ & 1235 & $\mathrm{~B}_{2}$ & 1293 & & 1236 & $\mathrm{~A}_{\mathrm{g}}$ & 1224 & $\mathrm{~B}_{2}$ & v CC, CN (Kekulé) \\
\hline 3 & 1346 & $\mathrm{~A}_{2 \mathrm{~g}}$ & 1316 & $\mathrm{~B}_{2}$ & 1227 & $\mathrm{~B}_{2}$ & 1250 & $\mathrm{~B}_{\mathrm{u}}$ & 1246 & $\mathrm{~A}_{1} / \mathrm{A}^{\prime}$ & $v \mathrm{CC}, \mathrm{CN} / \beta \mathrm{CH}(\chi$ sens. $)$ \\
\hline \multirow[t]{3}{*}{19} & 1479 & $\mathrm{E}_{1 \mathrm{u}}$ & 1448 & $\mathrm{~B}_{2}$ & 1437 & $\mathrm{~B}_{2}$ & 1450 & $\mathrm{~B}_{\mathrm{u}}$ & $1406 / 1438$ & $\mathrm{~B}_{2} / \mathrm{A}^{\prime}$ & $v \mathrm{CC}, \mathrm{CN} / \beta \mathrm{CH}$ \\
\hline & & & 1497 & $\mathrm{~A}_{1}$ & 1483 & $\mathrm{~A}_{1}$ & 1482 & $\mathrm{~A}_{\mathrm{g}}$ & $1470 / 1453$ & $\mathrm{~A}_{1} / \mathrm{A}^{\prime}$ & $v \mathrm{CC}, \mathrm{CN} / \beta \mathrm{CH}$ \\
\hline & & & & & & & & & 1475 & $\mathrm{~A}_{1}$ & Ressonância de Fermi \\
\hline \multirow[t]{2}{*}{8} & 1595 & $E_{2 g}$ & 1583 & $\mathrm{~B}_{2}$ & 1574 & $\mathrm{~B}_{2}$ & 1575 & $\mathrm{~B}_{\mathrm{u}}$ & $1573 / 1563$ & $\mathrm{~B}_{2} / \mathrm{A}^{\prime}$ & $v \mathrm{CC}$ \\
\hline & & & 1603 & $\mathrm{~A}_{1}$ & 1581 & $\mathrm{~A}_{1}$ & 1589 & $\mathrm{Ag}_{\mathrm{g}}$ & $1593 / 1573$ & $\mathrm{~A}_{1} / \mathrm{A}^{\prime}$ & $v \mathrm{CC}$ \\
\hline 7 & 3047 & $E_{2 g}$ & 3031 & $\mathrm{~B}_{2}$ & 3034 & $\mathrm{~B}_{2}$ & & & 3016 & $\mathrm{~B}_{2}$ & $\mathrm{VCH}$ \\
\hline 13 & 3048 & $\mathrm{~B}_{1 \mathrm{u}}$ & 3031 & $\mathrm{~A}_{1}$ & 3034 & $\mathrm{~A}_{1}$ & & & & & $\mathrm{VCH}$ \\
\hline \multirow[t]{2}{*}{20} & 3057 & $\mathrm{E}_{1 \mathrm{u}}$ & 3067 & $\mathrm{~A}_{1}$ & 3057 & $\mathrm{~A}_{1}$ & 3060 & $\mathrm{~A}_{\mathrm{g}}$ & 3050 & $\mathrm{~A}_{1} / \mathrm{A}^{\prime}$ & $\mathrm{VCH}$ \\
\hline & & & 3083 & $\mathrm{~B}_{2}$ & 3079 & $\mathrm{~B}_{2}$ & 3086 & $\mathrm{~B}_{\mathrm{u}}$ & & & $\checkmark \mathrm{CH}$ \\
\hline 2 & 3062 & $\mathrm{~A}_{1 \mathrm{~g}}$ & 3083 & $\mathrm{~A}_{1}$ & 3079 & $\mathrm{~A}_{1}$ & 3074 & $\mathrm{~A}_{\mathrm{g}}$ & 3065 & $\mathrm{~A}_{1} / \mathrm{A}^{\prime}$ & $\mathrm{v} \mathrm{CH}$ \\
\hline
\end{tabular}


Geralmente, na análise vibracional das espécies que possuem mais de um anel aromático, são consideradas as simetrias de cada anel separadamente como, por exemplo, na molécula de difenil ${ }^{4}$, cujos anéis monossubstituídos pertencem ao grupo de ponto $\mathrm{C}_{2} \mathrm{~V}$.

No caso da molécula de 2,2' - bipiridina é possível que ela possua conformação cis-cis coplanar, pertencendo ao grupo de ponto $\mathrm{C}_{2} \mathrm{~V}$, ou trans-trans coplanar, pertencendo ao grupo de ponto $\mathrm{C}_{2 \mathrm{~h}}$, ou ainda conformações intermediárias nas quais nenhuma simetria é observada. Na tabela 3 a atribuição foi realizada para o espectro do sólido cuja estrutura é coplanar, com conformação trans-trans ${ }^{5}$.

A tpy no estado sólido possui conformação trans-trans, com as moléculas desviando-se ligeiramente da coplanaridade ${ }^{7}$. Os ângulos diédricos entre o anel central e os anéis periféricos são 5.1 e $7,2^{\circ}$. Na referência 1 , a atribuição da tpy foi realizada considerando-se os grupos de ponto separadamente para cada anel piridínico. O anel central, dissubstituído nas posições 2 e 6, pertence ao grupo de ponto $\mathrm{C}_{2 \mathrm{~V}}$ e os anéis periféricos, monossubstituídos na posição 2 , pertencem ao grupo de ponto $\mathrm{C}_{\mathrm{S}}$.

$\mathrm{Na}$ tabela 3 observa-se a progressiva diminuição de simetria entre as moléculas estudadas, passando-se do grupo de ponto $\mathrm{D}_{\mathrm{bh}}$ do benzeno, com a molécula bastante simétrica possuindo vários modos degenerados, até o grupo de ponto $\mathrm{C}_{\mathrm{s}}$ dos anéis laterais da tpy, que possuem baixa simetria. A quebra da degenerescência já é observada na molécula de difenil, grupo de ponto $\mathrm{C}_{2 \mathrm{~V}}$, com aumento no número de bandas no espectro, quando comparado ao benzeno. O número de bandas é maior ainda na tpy, pois além do número maior de átomos, possui diferentes simetrias e atribuições independentes para os anéis laterais e o anel central da molécula.

Da comparação entre os espectros vibracionais do benzeno e do difenil destaca-se a presença de uma banda intensa nos espectros Raman deste último, atribuída ao modo de estiramento C-C da ligação entre os anéis, em $1275 \mathrm{~cm}^{-1}$. Esta banda é também observada quando são comparados os espectros Raman da piridina e da 2,2' - bipiridina, tendo esta última uma banda em seus espectros, atribuída a este 
estiramento, em $1301 \mathrm{~cm}^{-1}$. A tpy possui uma banda intensa, em seus espectros Raman, em $1320 \mathrm{~cm}^{-1}$, atribuída ao estiramento das ligações C-C entre anéis.

O modo normal 1 de Wilson do benzeno corresponde à respiração totalmente simétrica do anel e, em todos os compostos estudados na tabela 3, é atribuído a uma banda Raman intensa próxima de $994 \mathrm{~cm}^{-1}$. Esta banda, para os compostos envolvendo anéis piridínicos, sofre deslocamentos de freqüências bastante característicos quando do comprometimento dos pares de elétrons dos nitrogênios com ligações químicas, tais como coordenação com metais de transição, protonação, formação de óxidos, etc ${ }^{8}$.

Pode-se observar que o modo normal 12 de Wilson do benzeno, correspondente à respiração trigonal do anel (estrela de David), sofre grandes variações de freqüiência com a substituição no anel, passando de $1010 \mathrm{~cm}^{-1}$ no benzeno para $733 \mathrm{~cm}^{-1}$ no difenil. Deslocamento de freqüência semelhante ocorre entre a piridina e a 2,2'-bipiridina. Na tpy esta vibração foi atribuída à banda em $724 \mathrm{~cm}^{-1}$.

O modo normal 8 de Wilson do benzeno, que corresponde aos estiramentos C-C do anel, nos demais compostos da tabela 3 perde a degenerescência, sendo atribuído a duas freqüências típicas entre1500 e $1600 \mathrm{~cm}^{-1}$. Estas bandas, por estarem isoladas em uma região do espectro que é limpa de outras frequiências, são bastante características em todas estas espécies.

Na tabela 4 é apresentada uma atribuição para as freqüências fundamentais da tpy no estado sólido, bem como as intensidades relativas das bandas dos espectros Raman e infravermelho e as medidas de polarização das bandas Raman.

No espectro Raman da tpy, as bandas em $994 \mathrm{~cm}^{-1}$, atribuída à respiração totalmente simétrica do anel, em $1320 \mathrm{~cm}^{-1}$, atribuída ao estiramento C-C entre anéis e em 1563, 1573 e $1593 \mathrm{~cm}^{1}$, atribuídas aos estiramentos C-C dos anéis piridínicos, sendo bastante sensíveis às ligações químicas nas quais os átomos de nitrogênio da molécula estão envolvidos, serão utilizadas neste estudo para identificar-se interações da tpy em diferentes sistemas. As bandas em 994 e $1573 \mathrm{~cm}^{-1}$ sofrem degenerescência acidental que pode ser quebrada quando estas interações ocorrem. 
TABELA 4: Atribuição das bandas dos espectros vibracionais da tpy $\mathrm{em}^{-1}: v \Rightarrow$ estiramento; $\alpha, \beta \Rightarrow$ deformações de ângulo no plano; $\phi, \gamma \Rightarrow$ deformações de ângulo fora do plano; $\chi$ sens $\Rightarrow$ modo sensível à substituição no anel; $\mathrm{p} \Rightarrow$ bandas Raman polarizadas; $\mathrm{sh} \Rightarrow$ ombro; $\mathrm{w} \Rightarrow$ intensidade baixa; vw $\Rightarrow$ intensidade muito baixa; $\mathrm{m} \Rightarrow$ intensidade média; $\mathrm{s} \Rightarrow$ intensidade alta; vs $\Rightarrow$ intensidade muito alta.

\begin{tabular}{|c|c|c|c|c|}
\hline Infravermelho & Raman & Atribuição tentativa & Anel piridínico & Representação \\
\hline & $227(20)$ & $\phi(\mathrm{CC})(\chi$ sens. $)$ & lateral & A" \\
\hline & $245(9)$ & $\phi(\mathrm{CC})(\chi$ sens. $)$ & central & $\mathrm{B}_{1}$ \\
\hline & $283(6)$ & $\alpha($ CCC $)(\chi$ sens. $)$ & central & $\overline{A_{1}}$ \\
\hline & $401(8)$ & $\phi(\mathrm{CC})$ & central & $\overline{\mathrm{B}_{1}}$ \\
\hline $419 \mathrm{w}$ & & $\chi$ sens. & central & $\mathrm{B}_{2}$ \\
\hline \multirow[t]{2}{*}{$509 \mathrm{vw}$} & & $\phi(\mathrm{CC})$ & central & $\mathrm{A}_{2}$ \\
\hline & $522(2)$ & $\alpha(\mathrm{CCC})$ & central & $\overline{\mathrm{B}_{2}}$ \\
\hline $622 \mathrm{w}$ & $622(8) \mathrm{p}$ & $\alpha$ (CCC) $(\chi$ sens. $)$ & lateral & $\mathrm{A}^{\prime}$ \\
\hline $632 \mathrm{~m}$ & $639(5) \mathrm{p}$ & $\alpha(\mathrm{CCC})(\chi$ sens. $)$ & lateral & $\mathrm{A}^{\prime}$ \\
\hline $656 \mathrm{~m}$ & $655(2)$ & $\alpha(\mathrm{CCC})$ & lateral & $\mathrm{A}^{\prime}$ \\
\hline $734 \mathrm{w}$ & $724(15) \mathrm{p}$ & $\alpha$ (CCC) (Resp. trigonal) $(\chi$ sens. $)$ & central/lateral & $\overline{A_{1} / A^{\prime}}$ \\
\hline $765 \mathrm{vs}$ & & $\gamma(\mathrm{CH}) / \phi(\mathrm{CC})$ & central & $\mathrm{B}_{1}$ \\
\hline $771 \mathrm{vs}$ & & $\gamma(\mathrm{CH})$ & central/lateral & $\mathrm{B}_{1} / \mathrm{A}^{\prime \prime}$ \\
\hline $799 \mathrm{vw}$ & $796(5)$ & $\phi(\mathrm{CC})(\chi$ sens. $)$ & lateral & $\mathrm{A}^{\prime}$ \\
\hline $833 \mathrm{~m}$ & $832(11)$ & $\phi(\mathrm{CC})(\chi$ sens. $)$ & central & $\mathrm{B}_{2}$ \\
\hline $897 \mathrm{vw}$ & & $\gamma(\mathrm{CH})$ & central & $\mathrm{B}_{1}$ \\
\hline $962 \mathrm{vw}$ & & $\gamma(\mathrm{CH})$ & lateral & A" \\
\hline $989 \mathrm{~m}$ & $994(98) \mathrm{p}$ & $v(\mathrm{CC}, \mathrm{CN})($ Resp. anel) & central/lateral & $\mathrm{A}_{1} / \mathrm{A}^{\prime}$ \\
\hline $1040 \mathrm{~m}$ & $1041(16) \mathrm{p}$ & $\beta(\mathrm{CH}) / v(\mathrm{CC}, \mathrm{CN})$ & lateral & $\mathrm{A}^{\prime}$ \\
\hline $1078 \mathrm{~m}$ & $1064(4) p$ & $\beta(\mathrm{CH}) / v(\mathrm{CC}, \mathrm{CN})$ & lateral & $\mathrm{A}^{\prime}$ \\
\hline $1104 \mathrm{~m}$ & $1096(5)$ & $\beta(\mathrm{CH}) / v(\mathrm{CC}, \mathrm{CN})$ & central & $\overline{A_{1}}$ \\
\hline $1142 \mathrm{sh}$ & $1152(9)$ & $\beta(\mathrm{CH}) / v(\mathrm{CC}, \mathrm{CN})$ & central & $\mathrm{B}_{2}$ \\
\hline \multirow[t]{2}{*}{$1150 \mathrm{vw}$} & $1152(9)$ & $\beta(\mathrm{CH})$ & central & $\mathrm{B}_{2}$ \\
\hline & $1224(16)$ & $v(\mathrm{CC}, \mathrm{CN}) /($ Kekulé $)$ & central & $\mathrm{B}_{2}$ \\
\hline $1264 \mathrm{~m}$ & $1246(19) \mathrm{p}$ & $v(\mathrm{CC}, \mathrm{CN}) / \beta(\mathrm{CH})(\chi$ sens. $)$ & central/lateral & $\overline{A_{1} / A^{\prime}}$ \\
\hline $1320 \mathrm{vw}$ & $1320(90) \mathrm{p}$ & $v(\mathrm{CC})$ interanéis ( $\chi$ sens.) & lateral & $\mathrm{A}^{\prime}$ \\
\hline 1423 vs & $1406(6)$ & $\nu(\mathrm{CC}, \mathrm{CN}) / \beta(\mathrm{CH})$ & central & $\mathrm{B}_{2}$ \\
\hline $1437 \mathrm{sh}$ & $1438(14) \mathrm{p}$ & $v(\mathrm{CC}, \mathrm{CN}) / \beta(\mathrm{CH})$ & lateral & $A^{\prime}$ \\
\hline $1454 \mathrm{~s}$ & $1453(22)$ & $v(\mathrm{CC}, \mathrm{CN}) / \beta(\mathrm{CH})$ & lateral & $\mathrm{A}^{\prime}$ \\
\hline $1469 \mathrm{~m}$ & $1470(36)$ & $v(\mathrm{CC}, \mathrm{CN}) / \beta(\mathrm{CH})$ & central & $\mathrm{A}_{1}$ \\
\hline $1477 \mathrm{sh}$ & $1475(36)$ & Ressonância Fermi & central & $\mathrm{A}_{1}$ \\
\hline $1550 \mathrm{sh}$ & $1563(\mathrm{sh})$ & $v(C C)$ & lateral & $A^{\prime}$ \\
\hline 1562 vs & $1573(100) \mathrm{p}$ & $v(\mathrm{CC})$ & central/lateral & $\mathrm{B}_{2} / \mathrm{A}^{\prime}$ \\
\hline $1581 \mathrm{vs}$ & $1593(62) \mathrm{p}$ & $v(\mathrm{CC})$ & central & $\mathrm{A}_{1}$ \\
\hline $3012 \mathrm{w}$ & $3016(3)$ & $v(\mathrm{CH})$ & central & $\mathrm{B}_{2}$ \\
\hline $3050 \mathrm{w}$ & $3050(\mathrm{sh})$ & $v(\mathrm{CH})$ & central/lateral & $\mathrm{A}_{1} / \mathrm{A}^{\prime}$ \\
\hline $3065 \mathrm{sh}$ & $3065(10)$ & $v(\mathrm{CH})$ & central/lateral & $\mathrm{A}_{1} / \mathrm{A}^{\prime}$ \\
\hline
\end{tabular}


É interessante notar que as bandas mais intensas nos espectros de absorção no infravermelho são, geralmente menos intensas nos espectros Raman e vice-versa. Alguns deslocamentos são, também, observados. Um exemplo disto é a banda observada em $994 \mathrm{~cm}^{-1}$, bastante intensa no espectro Raman e atribuída à respiração totalmente simétrica do anel piridínico, que se desloca para $989 \mathrm{~cm}^{-1}$ e é bem menos intensa no espectro infravermelho.

A tpy é pouco solúvel em água, dificultando a obtenção dos espectros Raman em solução aquosa. Apenas quando diprotonada sua solubilidade aume nta o suficiente para atingir-se uma concentração na qual a obtenção dos espectros torna-se possível. Foi preparada uma solução aquosa da tpy em pH aproximadamente zero utilizando-se $\mathrm{HCl}$, para que praticamente todas as moléculas de tpy fossem diprotonadas, e seu espectro Raman foi obtido (figura 7-a). Para a obtenção de um padrão espectral da tpy monoprotonada foi sintetizado o composto tpyH $\mathrm{H}^{+} \mathrm{CF}_{3} \mathrm{SO}_{3}{ }^{-}{ }^{9} . \mathrm{O}$ espectro Raman deste composto foi obtido de cristais depositados sobre placa de silício para diminuir sua fluorescência (figura 7-b).

Analisando-se estes espectros nota-se que a banda correspondente ao modo de respiração do anel piridínico é sensível à protonação. $\mathrm{O}$ espectro da tpy no estado sólido apresenta uma banda em $994 \mathrm{~cm}^{-1}$ atribuída à respiração dos três anéis piridínicos (figura 7c). No espectro em solução aquosa com $\mathrm{pH}$ aproximadamente zero (figura 7a), foram observadas, na região da respiração do anel, duas bandas em 1015 e $1000 \mathrm{~cm}^{-1}$, sendo a primeira atribuída à respiração dos anéis laterais protonados e a segunda à respiração do anel central, com os pares de elétrons do nitrogênio comprometido com ligações de hidrogênio (figura 2, seção 1.1). 


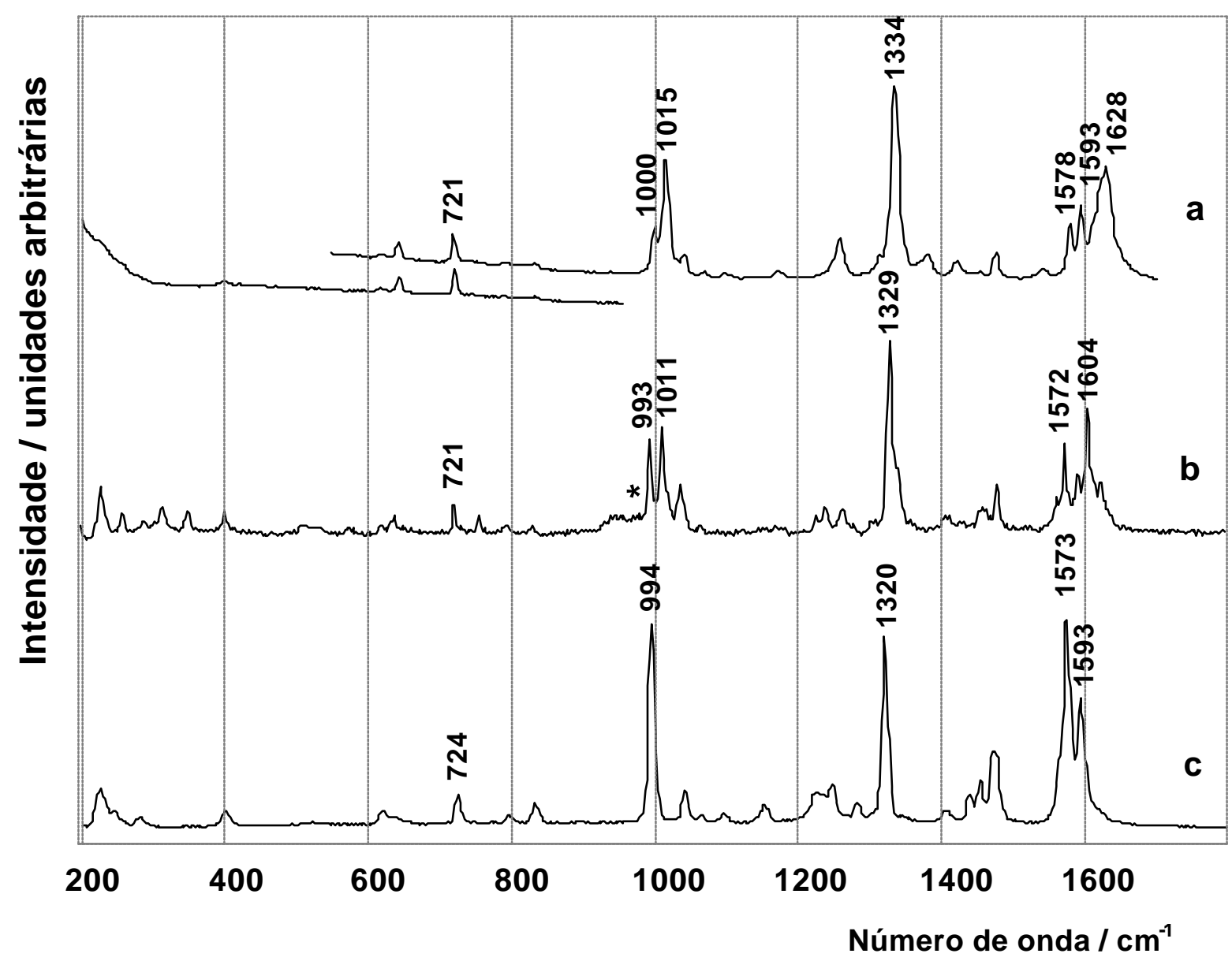

FIGURA 7: Espectros Raman da tpyH ${ }_{2}{ }^{2+}$ em solução aquosa $\mathrm{pH} \sim 0,0, \lambda_{0}=514,5 \mathrm{~nm}$ (a); do tpyH ${ }^{+} \mathrm{CF}_{3} \mathrm{SO}_{3}{ }^{-}$sólido sobre silício (acertada linha base e excluída banda do $\mathrm{Si}$ em $520 \mathrm{~cm}^{-1}$ ), $\lambda_{0}=632,8 \mathrm{~nm}$ (b); e da tpy no estado sólido, $\lambda_{0}=632,8 \mathrm{~nm}$ (c).

$(*)$ banda do Si.

No espectro do composto tpyH $\mathrm{H}^{+} \mathrm{CF}_{3} \mathrm{SO}_{3}^{-}$(figura 7-b) são observadas duas bandas em $993 \mathrm{~cm}^{-1}$ e em $1011 \mathrm{~cm}^{-1}$, sendo a primeira atribuída à respiração do anel lateral e do anel central não protonados e a segunda à respiração do anel lateral protonado.

Outra banda que é sensível à protonação da tpy é observada em $1320 \mathrm{~cm}^{-1}$ no espectro do composto puro no estado sólido, sendo atribuída ao estiramento C-C entre os anéis. No espectro da tpyH ${ }_{2}{ }^{2+}$ (aq) ela é observada em $1334 \mathrm{~cm}^{-1}$ e no espectro do 
composto tpyH $\mathrm{H}^{+} \mathrm{CF}_{3} \mathrm{SO}_{3}^{-}$há duas freqüências: em $1336 \mathrm{~cm}^{-1}$ (ombro) e em $1329 \mathrm{~cm}^{-1}$, sendo esta última atribuída ao estiramento C-C entre os anéis não protonados.

A análise dos espectros na região entre 1550 e $1650 \mathrm{~cm}^{-1}$, onde bandas atribuídas aos estiramentos C-C dos anéis estão presentes, corrobora as afirmações acima, quanto às protonações dos anéis. $\mathrm{O}$ espectro da tpy no estado sólido apresenta três bandas em 1563 (ombro), 1573 e $1593 \mathrm{~cm}^{-1}$, enquanto que o espectro da espécie diprotonada apresenta bandas em freqüências mais altas, comportamento observado sempre que anéis piridínicos são protonados ${ }^{8}$. No caso da espécie monoprotonada, como estão presentes três diferentes tipos de anéis piridínicos na molécula: o lateral protonado na posição cis, o central não protonado e o lateral não protonado na posição trans, seu espectro apresenta um maior número de bandas nesta região, em 1562, 1572, 1590, 1604, 1611 (ombro) e $1623 \mathrm{~cm}^{-1}$.

Como os estudos da tpy adsorvida foram realizados em substratos de $\mathrm{Ag} \mathrm{e} \mathrm{Cu}$ e como a interação da tpy na superfície metálica pode ser considerada como a formação de um complexo de superfície entre a molécula e átomos dos aglomerados metálicos presentes na superfície, foram sintetizados complexos de tpy com os íons $\mathrm{Ag}^{+}$e $\mathrm{Cu}^{2+}$ para auxiliarem na interpretação dos resultados da adsorção. Os espectros Raman destes complexos estão apresentados na figura 8.

Destes espectros pode-se verificar que os deslocamentos de freqüências são semelhantes aos observados quando da protonação da tpy. As bandas em 1008, 1032 e $1045 \mathrm{~cm}^{-1}, \quad$ nos complexos $\left[\mathrm{Ag}(\mathrm{I})\right.$ tpyNO$\left._{3}\right], \quad[\mathrm{Cu}(\mathrm{II}) \operatorname{tpyCl}] \mathrm{Cl}$ e $\left[\mathrm{Cu}(\mathrm{II}) \mathrm{tpyH} \mathrm{H}_{2} \mathrm{OClO}_{4}\right] \mathrm{ClO}_{4}$ respectivamente, são atribuídas ao modo de respiração dos três anéis piridínicos da tpy coordenados ao metal pelos nitrogênios. Pode-se observar um deslocamento sensivelmente maior desta banda quando a tpy coordena ao $\mathrm{Cu}^{2+}$, quando comparado ao complexo de tpy e $\mathrm{Ag}^{+}$. No entanto, nos dois complexos de $\mathrm{Cu}^{2+}$ e tpy seu valor variou em função da coordenação de diferentes ânions ao metal, indicando que a freqüência desta banda é bastante sensível à coordenação de outros ligantes ao íon metálico. Isto foi verificado em diferentes complexos de $\mathrm{Ru}^{2+} \mathrm{e}$ tpy, nos quais variações entre 1011 e $1046 \mathrm{~cm}^{-1}$ nesta banda foram observadas ${ }^{10,11}$. 


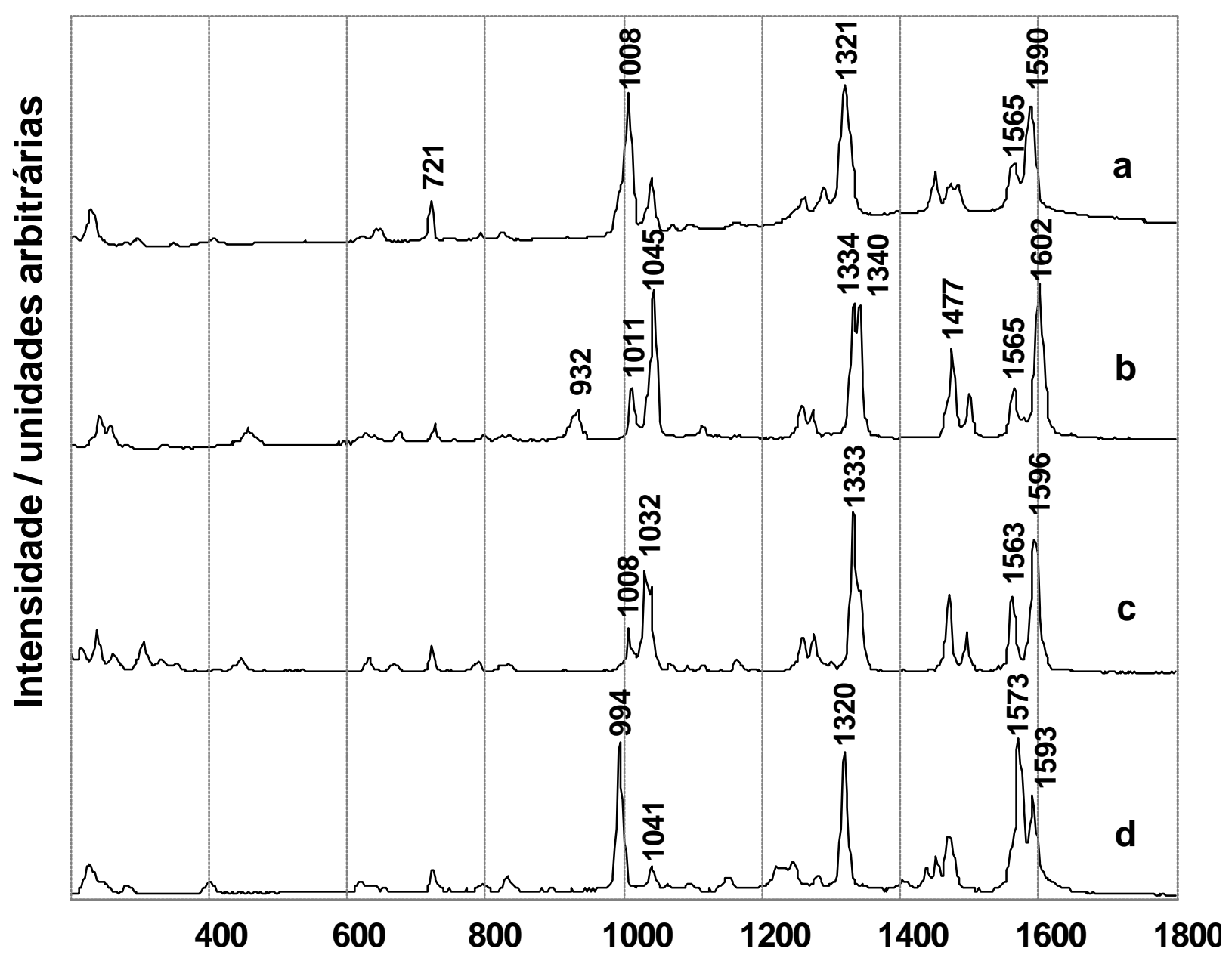

\section{Número de onda $/ \mathrm{cm}^{-1}$}

FIGURA 8: Espectros Raman dos complexos [Ag(I)tpyNO $\left.{ }_{3}\right]$ (a), [Cu(II)tpyH $\left.{ }_{2} \mathrm{OClO}_{4}\right] \mathrm{ClO}_{4}$ (b), $[\mathrm{Cu}(\mathrm{II}) \mathrm{tpyCl}] \mathrm{Cl}$ (c) e da tpy (d). Amostras no estado sólido. $\lambda_{0}=632,8 \mathrm{~nm}$.

As bandas atribuídas à ligação metal-nitrogênio, que caracterizam a coordenação podem ser observadas ao ampliarmos os espectros anteriores na região de baixa freqüência (figura 9).

Considerando-se que as bandas atribuídas aos estiramentos $\mathrm{Cu}-\mathrm{N}$ e $\mathrm{Ag}-\mathrm{N}$ são observadas na região de 300 a $400 \mathrm{~cm}^{-1}{ }^{12}$, pode-se atribuir as bandas em 337 e 352 $\mathrm{cm}^{-1}$ na figura 9-b e 332 e $354 \mathrm{~cm}^{-1}$ na figura 9-c à vibração associada ao estiramento 
$\mathrm{Cu}-\mathrm{N}$. O estiramento $\mathrm{Ag}-\mathrm{N}$ pode, então, ser atribuído às bandas em 350 e $389 \mathrm{~cm}^{-1}$ (figura 9-a).

Como a banda em $305 \mathrm{~cm}^{-1}$ no espectro do composto [CutpyCl]Cl não é observada no espectro do composto $\left[\mathrm{CutpyH}_{2} \mathrm{OClO}_{4}\right] \mathrm{ClO}_{4}$, pode-se atribui-la ao estiramento $\mathrm{Cu}-\mathrm{Cl}^{12}$.

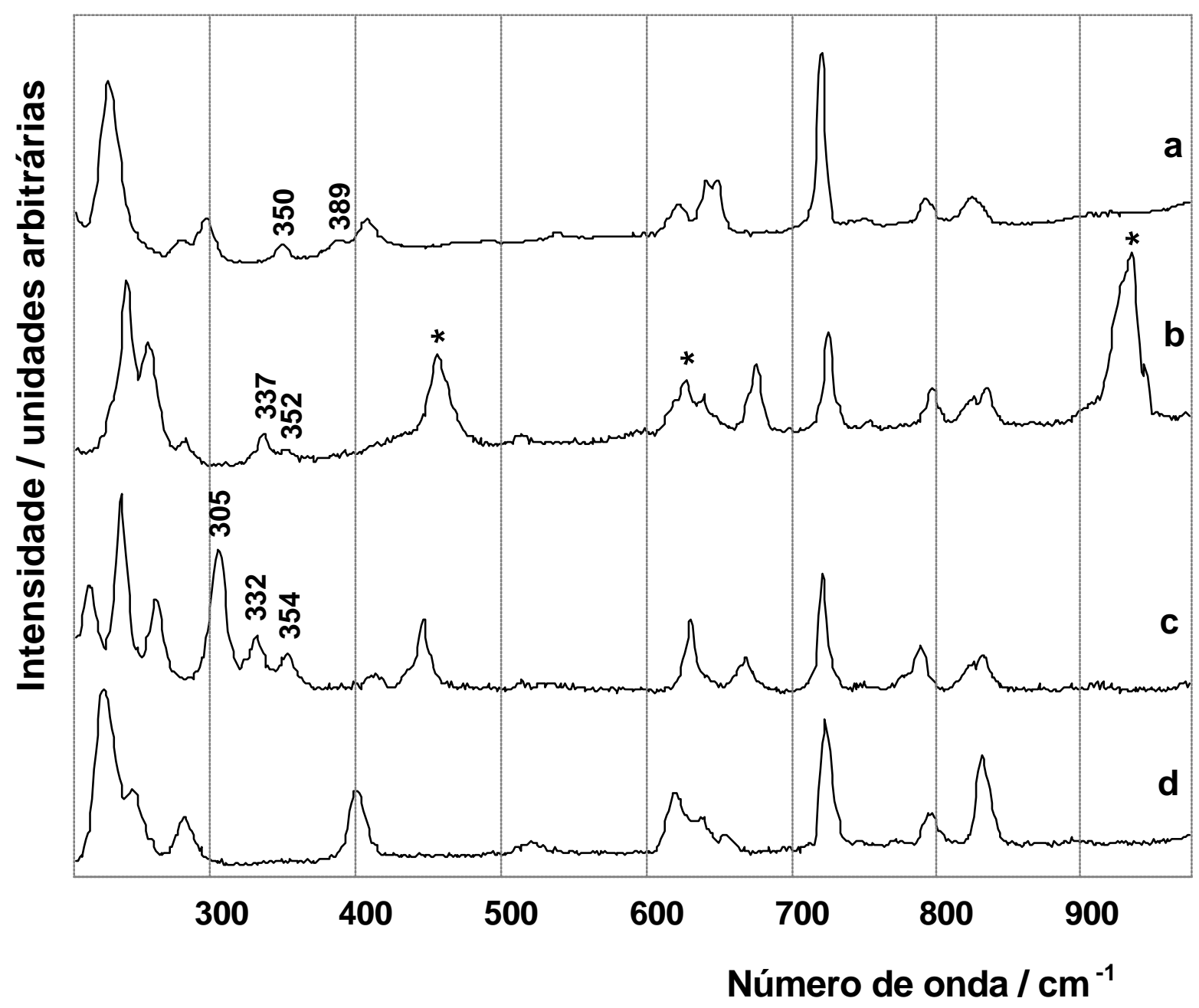

FIGURA 9: Espectros Raman dos complexos [Ag(I)tpyNO $\mathrm{P}_{3}$ (a), [Cu(II)tpyH $\left.\mathrm{OClO}_{4}\right] \mathrm{ClO}_{4}$ (b), $[\mathrm{Cu}(\mathrm{II}) \mathrm{tpyCl}] \mathrm{Cl}$ (c) e da tpy (d). Amostras no estado sólido. $\lambda_{0}=632,8 \mathrm{~nm}$.

(*) Bandas do $\mathrm{ClO}_{4}^{-}$. 
Os espectros Raman da tpy em solução foram obtidos em diferentes solventes para verificar-se possíveis mudanças conformacionais induzidas por diferenças nas constantes dielétricas dos solventes e por interações solvente- molécula (figura 10).

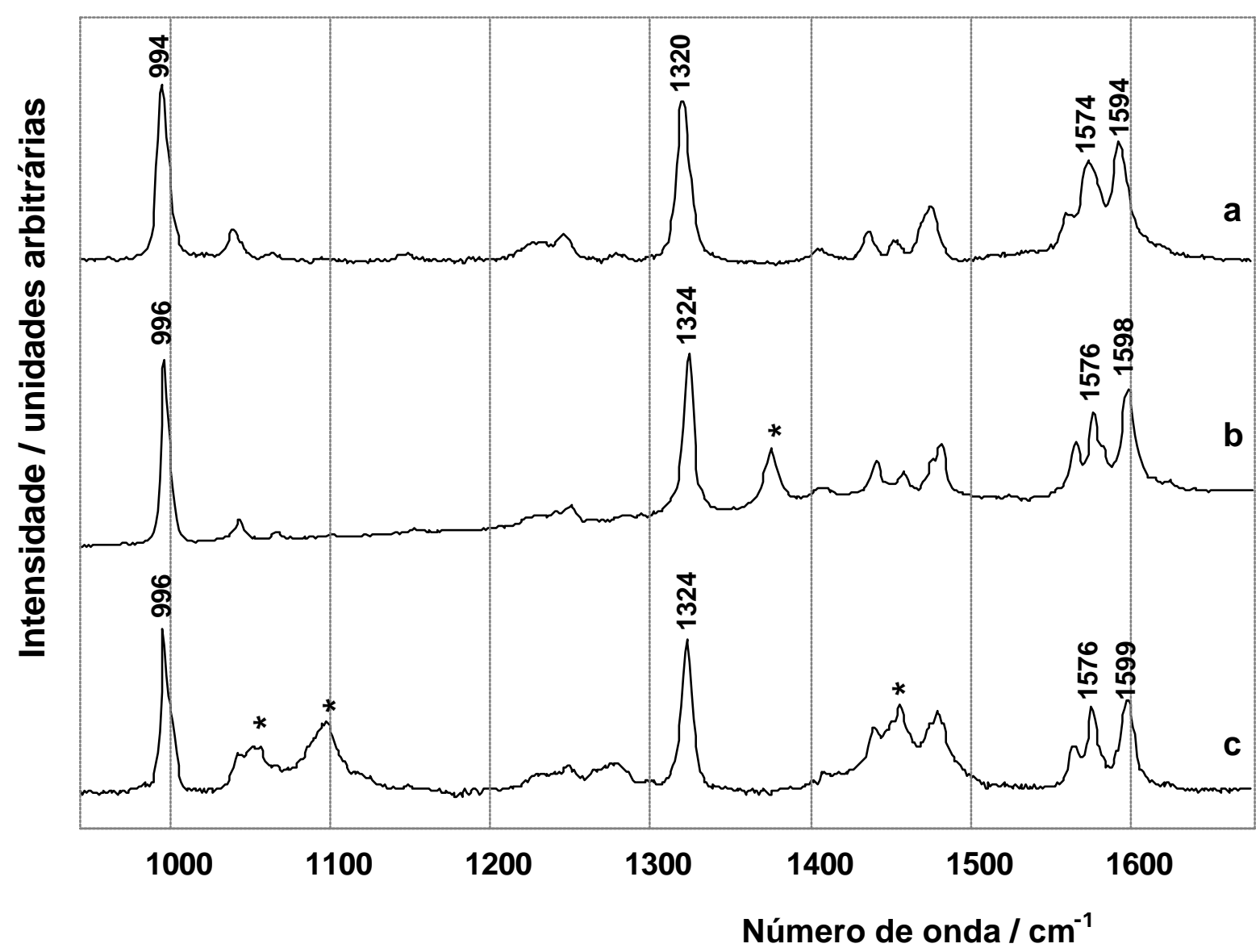

FIGURA 10: Espectros Raman da tpy em diferentes solventes: $\mathrm{CCh}_{4}\left(\lambda_{0}=632,8 \mathrm{~nm}\right)$ (a); $\mathrm{H}_{3} \mathrm{CCN}\left(\lambda_{0}=514,5 \mathrm{~nm}\right)(\mathrm{b}) ; \mathrm{H}_{3} \mathrm{CCH}_{2} \mathrm{OH}\left(\lambda_{0}=514,5 \mathrm{~nm}\right)(\mathrm{c}) ;(*)$ bandas do solvente.

Foram utilizados como solventes o tetracloreto de carbono, por sua baixa constante dielétrica $\left(\varepsilon=2\right.$ a $\left.25^{\circ} \mathrm{C}\right)$, a acetonitrila, por sua alta polaridade $(\varepsilon=36,2$ a $25^{\circ} \mathrm{C}$ ) e o etanol, por formar ligações de hidrogênio com a tpy e possuir constante dielétrica intermediária $\left(\varepsilon=24,3\right.$ a $\left.25^{\circ} \mathrm{C}\right)$.

Nestes espectros podem ser observados deslocamentos de algumas bandas da tpy, e estes são mais pronunciados nas soluções de acetonitrila e de etanol, indicando 
interações químicas mais intensas com solvente polares ou formadores de ligações de hidrogênio. O espectro em etanol apresenta uma banda intensa em $996 \mathrm{~cm}^{-1}$ e um ombro em $1000 \mathrm{~cm}^{-1}$, sendo este atribuído aos anéis piridínicos que possuem o nitrogênio comprometido com ligações de hidrogênio com o solvente. O deslocamento da banda da respiração do anel pode ser associado ao deslocamento da banda do estiramento GC entre anéis, observada em $1324 \mathrm{~cm}^{-1}$, bem como à resolução das bandas na região do estiramento C-C do anel, observadas em 1565, 1576, 1582 (ombro) e $1599 \mathrm{~cm}^{-1}$, pois estas bandas são sensíveis às interações químicas que envolvam pares de elétrons dos nitrogênios dos anéis piridínicos.

Na tabela 5 estão resumidos os comportamentos das bandas da tpy atribuídas à respiração do anel piridínico em função do comprometimento dos pares de elétrons dos nitrogênios com uma ligação química. Fica evidente que tanto a solvatação quanto a protonação e a complexação da tpy geram comportamentos semelhantes nos padrões espectrais obtidos.

TABELA 5: Resumo da variação da freqüência da respiração do anel.

\begin{tabular}{|c|c|c|}
\hline COMPOSTO & ANEL LIVRE & ANEL LIGADO \\
\hline tpy (sólida) & 994 & \\
\hline tpyH $^{+} \mathrm{CF}_{3} \mathrm{SO}_{3}^{-}$ & 993 & 1011 \\
\hline tpyH $_{2}^{2+}(\mathrm{aq})$ & & 1000 e 1015 \\
\hline $\operatorname{Ag}(\mathrm{I}) \operatorname{tpyNO}_{3}$ & & 1008 \\
\hline$\left[\mathrm{Cu}(\mathrm{II}) \mathrm{tpyH}_{2} \mathrm{OClO}_{4}\right] \mathrm{ClO}_{4}$ & & 1011 e 1045 \\
\hline$[\mathrm{Cu}(\mathrm{II}) \mathrm{tpyCl}] \mathrm{Cl}$ & & 1008 e 1032 \\
\hline tpy (etanol) & 996 & 1000 (ombro) \\
\hline
\end{tabular}

Um método para a obtenção de espectros Raman da tpy em diferentes conformações, que não envolvesse formação de ligações químicas com a tpy, seria a formação de diferentes confôrmeros com a variação da temperatura. Com este objetivo foram obtidos os espectros Raman da tpy apresentados na figura 11. 


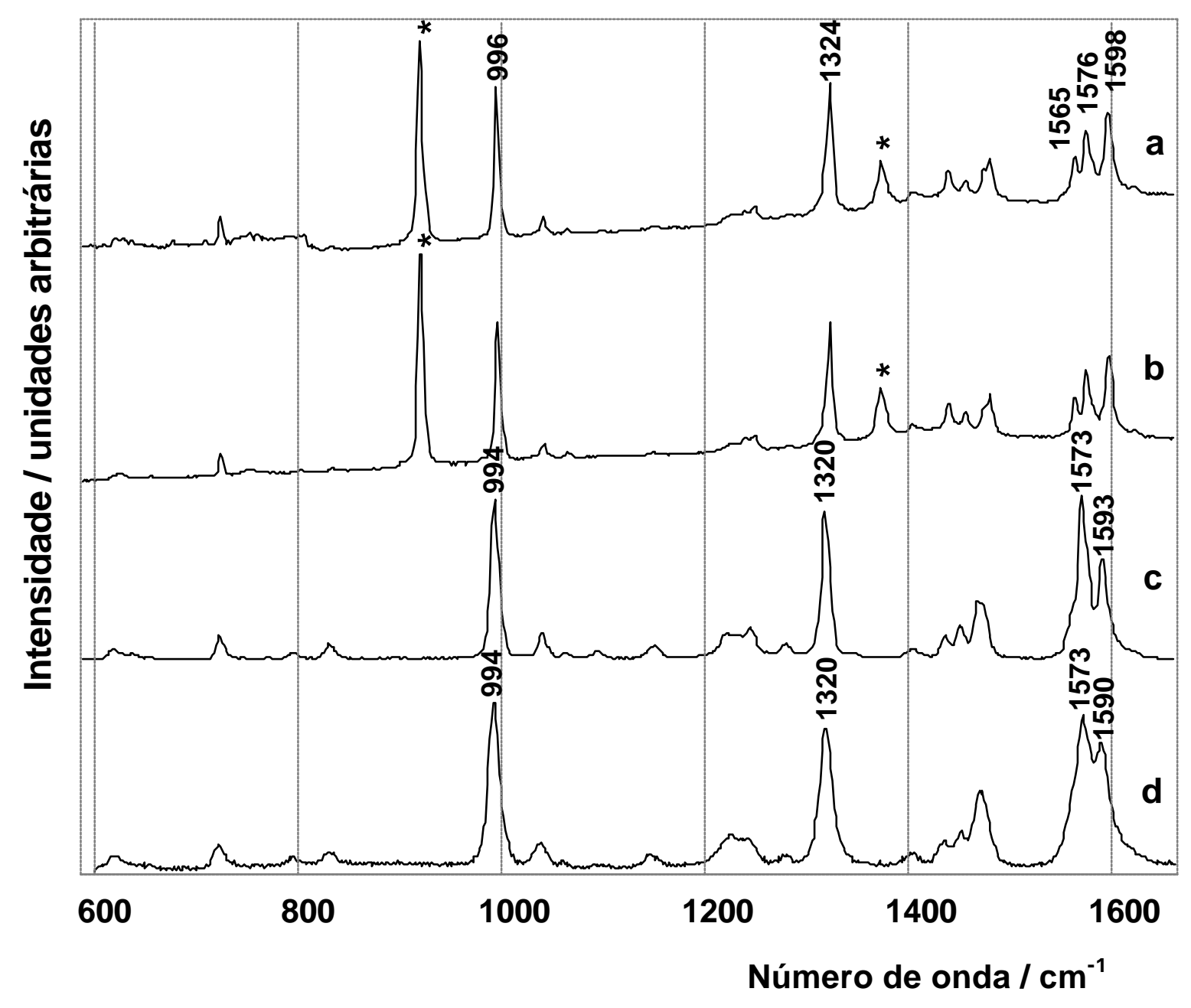

FIGURA 11: Espectros Raman da tpy em solução de acetonitrila a $8^{\circ} \mathrm{C}$ (a) e a $-19^{\circ} \mathrm{C}$ (b) e no estado sólido a $25^{\circ} \mathrm{C}$ (c) e fundida a $140^{\circ} \mathrm{C}$ (d). OBS: Ponto de fusão da tpy $=90^{\circ} \mathrm{C}$.

(*) bandas do solvente. (a) e (b) obtidos com $\lambda_{0}=514,5 \mathrm{~nm}$ e (c) e (d) com $\lambda_{0}=632,8 \mathrm{~nm}$.

A tpy em solução não sofre alterações conformacionais nas temperaturas de $20^{\circ} \mathrm{C}, 8^{\circ} \mathrm{C}$ e $-19^{\circ} \mathrm{C}$, como pode ser observado nos espectros da figura $10-\mathrm{b}, 11$ - a e 11 b, respectivamente, onde o padrão espectral não foi alterado. A tpy fundida possui maior liberdade de rotação ao redor das ligações $\sigma$ existentes entre os anéis piridínicos, logo, confôrmeros diferentes daquele predominante no retículo cristalino da tpy (a $25^{\circ} \mathrm{C}$, no estado sólido) devem estar presentes. Portanto, o espectro da figura 11-d 
obtido da amostra fundida $\left(\mathrm{a} 140^{\circ} \mathrm{C}\right)$ representa uma média dos diferentes confôrmeros presentes. No entanto, pode-se afirmar que alterações espectrais atribuídas a mudanças conformacionais não foram observadas entre a tpy no estado sólido e fundido (figura 11-c e 11-d).

A partir das variações espectrais observadas nos diferentes padrões espectrais conclui-se que as interações químicas envolvendo os pares de elétrons livres dos nitrogênios dos anéis piridínicos são as que geram variações mais acentuadas. Estas observações serão úteis, posteriormente, na análise dos padrões espectrais obtidos nos experimentos Raman intensificados pela superfície.

A adsorção do ânion $\mathrm{ClO}_{4}{ }^{-}$, utilizado como eletrólito nos experimentos SERS, pode ocorrer sobre o substrato através de um ou dois átomos de oxigênio. Para se obter os padrões espectrais desta adsorção foi monitorado o espalhamento Raman do sal perclorato de cobre (II) hexaidratado com a variação da temperatura, pois é sabido que alterações em seu grau de hidratação provocam diferenças na natureza dacoordenação do ânion ${ }^{13}$.

Este sal está normalmente hidratado com quatro moléculas de água coordenadas ao cobre: $\left[\mathrm{Cu}(\mathrm{II})\left(\mathrm{H}_{2} \mathrm{O}\right)_{4}\right]\left(\mathrm{ClO}_{4}\right)_{2} \cdot 2 \mathrm{H}_{2} \mathrm{O}$, onde o ânion perclorato não coordenado pertence ao grupo de ponto $\mathrm{T}_{\mathrm{d}}$. Através de termogravimetria foram obtidas as condições de aquecimento em que se obtém o sal $\left[\mathrm{Cu}(\mathrm{II})\left(\mathrm{H}_{2} \mathrm{O}\right)_{2}\left(\mathrm{ClO}_{4}\right)_{2}\right]$, onde o perclorato está coordenado ao cobre por apenas um átomo de oxigênio, pertencendo ao grupo de ponto $\mathrm{C}_{3 \mathrm{~V}}$ e o sal desidratado $\left[\mathrm{Cu}\left(\mathrm{ClO}_{4}\right)_{2}\right]$, com o perclorato coordenado ao cobre por dois átomos de oxigênio, pertencendo ao grupo de ponto $\mathrm{C}_{2 \mathrm{~V}}{ }^{13}$. Estes espectros são apresentados na figura 12.

Nestes espectros pode-se observar a perda de degenerescência de bandas e os deslocamentos de algumas freqüências atribuídos ao abaixamento da simetria do perclorato em função de sua coordenação ao cobre. 


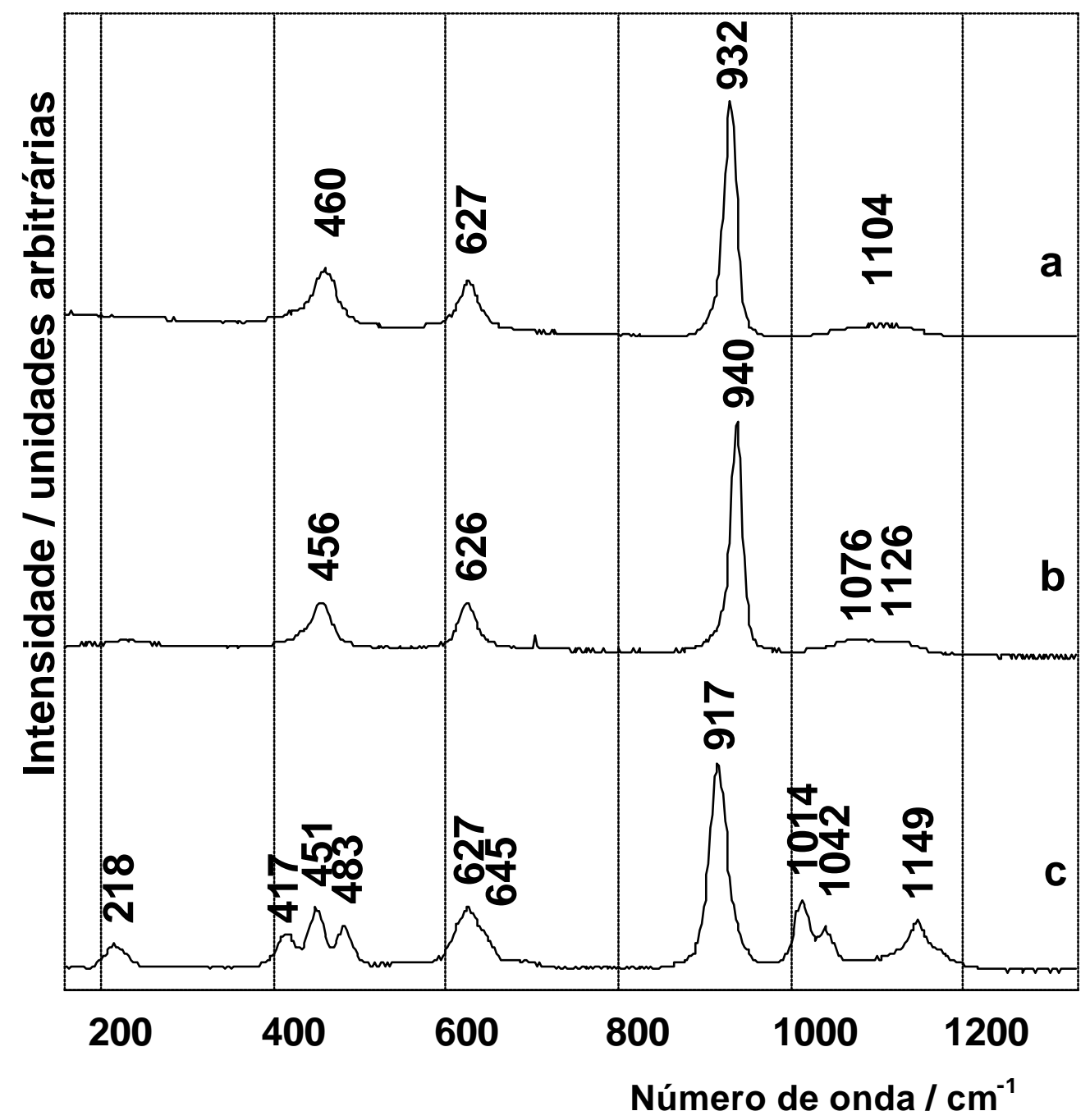

FIGURA 12: Espectros Raman do ânion $\mathrm{ClO}_{4}{ }^{-}$em diferentes simetrias: não coordenado ao metal, $\left[\mathrm{Cu}(\mathrm{III})\left(\mathrm{H}_{2} \mathrm{O}\right)_{4}\right]\left(\mathrm{ClO}_{4}\right)_{2}\left(\mathrm{H}_{2} \mathrm{O}\right)_{2}$, grupo de ponto $\mathrm{T}_{\mathrm{d}}$ (a); coordenado monodentado ao metal, $\left[\mathrm{Cu}(\mathrm{II})\left(\mathrm{H}_{2} \mathrm{O}\right)_{2}\left(\mathrm{ClO}_{4}\right)_{2}\right]$, grupo de ponto $\mathrm{C}_{3 \mathrm{~V}}$ (b) e coordenado bidentado ao metal, $\left[\mathrm{Cu}(\mathrm{II})\left(\mathrm{ClO}_{4}\right)_{2}\right]$, grupo de ponto $\mathrm{C}_{2 \mathrm{~V}}(\mathrm{c}) . \lambda_{0}=632,8 \mathrm{~nm}$.

A correlação entre as espécies de simetria dos diferentes grupos de ponto do perclorato, junto a uma tentativa de atribuição das frequiências fundamentais, está apresentada na tabela 6 . 
TABELA 6: Correlação entre diferentes simetrias e atribuição das frequiências fundamentais do perclorato não coordenado e coordenado monodentado e bidentado ao $\mathrm{Cu}^{2+}$, onde: est.= estiramento; def. âng. $=$ deformação de ângulo; $s .=$ simétrico; $a .=$ anti-simétrico; $\mathrm{O}^{*}=$ oxigênio coordenado ao $\mathrm{Cu}^{2+} ; \mathrm{E}=$ duplamente degenerado; $\mathrm{F}_{2}=$ triplamente degenerado.

$\left.\underline{\mathrm{ClO}}_{4}^{-} \underline{\mathrm{T}}_{\mathrm{d}}\right)$

932

A1 (est. s.)

627

E (def. âng. s.)

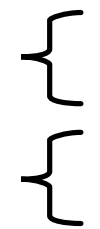

1104

$F_{2}$ (est. a.)

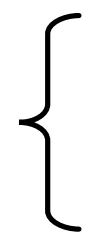

$\underline{\mathrm{ClO}}_{4-\left(\mathrm{C}_{3 \mathrm{~V}}\right)}$

940

$\mathrm{A}_{1}$ (est. ClO s.)

626

E (rocking)

1076

$\mathrm{A}_{1}$ (est. $\mathrm{ClO}_{3}$ s.)

1126

E (def. âng. ClO* a.)

\section{$\underline{\mathrm{ClO}}_{4-}^{-} \quad\left(\mathrm{C}_{2 \mathrm{~V}}\right)$}

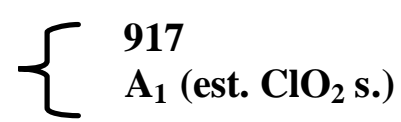

627

$\mathrm{A}_{1}$ (def. âng. $\mathrm{ClO}_{2}$ s.) 645

$A_{2}$ (torção)

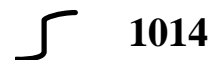

$\mathrm{A}_{1}$ (est. $\mathrm{ClO}_{2}$ s.)

1042

$\mathrm{B}_{1}$ (est. $\mathrm{ClO}_{2}$ a.)

1149

$\mathrm{B}_{2}$ (est. $\mathrm{ClO}_{2} *$ a.)

460

$F_{2}$ (def. âng. a.)

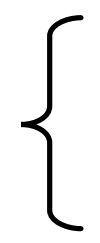

435 (ombro)

$\mathrm{A}_{1}$ (def. âng. $\mathrm{ClO}_{3}$ s.)

456

E (def. âng. $\mathrm{ClO}_{3}$ a.)

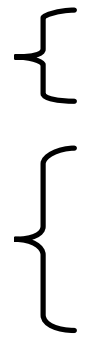

417

$\mathrm{A}_{1}$ (def. âng. $\mathrm{ClO}_{2}$ s.)

451

$B_{1}$ (rocking)

483

B $_{2}$ (rocking)

Pela tabela 6 pode-se notar que é possível, com o espalhamento Raman, monitorar a mudança de coordenação do ânion $\mathrm{ClO}_{4}{ }^{-}$, obtendo-se padrões espectrais para o íon bidentado, monodentado e não coordenado. 


\section{2 - SERS EX SITU DA TPY ADSORVIDA EM Ag}

Foi estudada a adsorção da tpy sobre superfície metálica através de experimentos SERS ex situ variando-se o pH da solução-mãe, o ânion-suporte e o solvente com a finalidade de observar-se como a competição pela superfície entre as diversas espécies presentes nas soluções-mãe influencia na adsorção das espécies.

Experimentos SERS ex situ da tpy adsorvida em Ag foram realizados utilizando-se CI como ânion-suporte e variando-se o solvente e o pH das soluçõesmãe (figura13) .

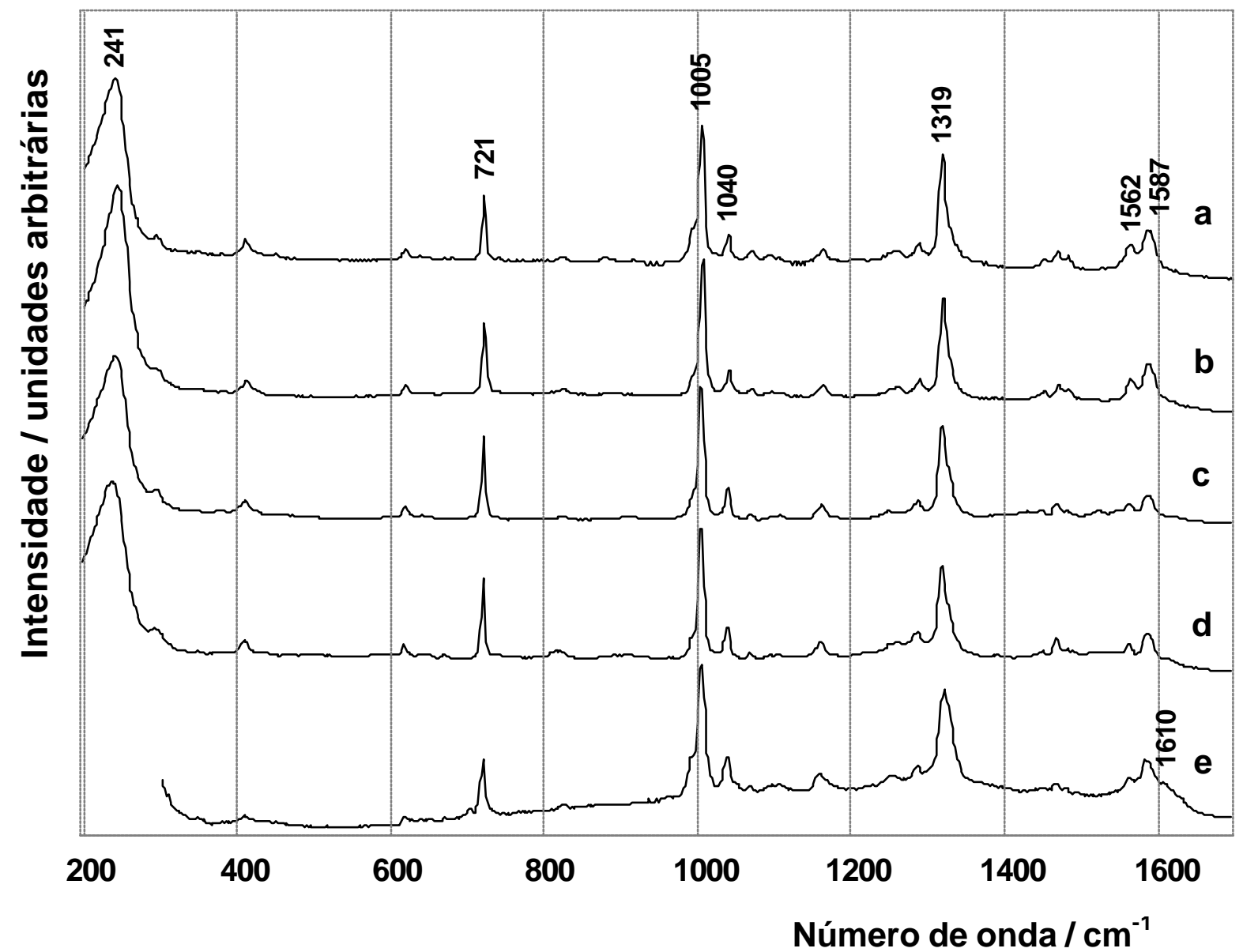

FIGURA 13: Espectros SERS ex situ do sistema tpy/Ag/CI, com as seguintes soluções-mãe: etanólica (a), e aquosa com pH=6 (b), pH=3 (c), pH=1,8 (d) e pH=0 (e). 
Estes espectros são bastante semelhantes, o que permite afirmar que a mesma espécie predomina na superfície metálica quando a tpy adsorve no eletrodo de Ag na presença de $\mathrm{CI}$, independente do $\mathrm{pH}$ da solução-mãe e ou do solvente utilizado. A espécie predominante na superfície metálica possui padrão espectral diferente da tpy protonada (figura 7) e da tpy no estado sólido (figura 5-b), porém, semelhante ao do complexo $\mathrm{Ag}(\mathrm{I}) \operatorname{tpyNO}_{3}$ (figura 8-a). A espécie adsorvida é, portanto, um complexo de superfície. Como em outros estudos SERS verificar-se-á a presença de outro complexo de superfície envolvendo moléculas de tpy na superfície de Ag, esta primeira espécie, que predomina nos espectros da figura 13, será denominada complexo de superfície do tipo I.

Os espectros deste complexo de superfície e do complexo $\mathrm{Ag}(\mathrm{I}) \mathrm{tpyNO}_{3}$ possuem pequenas diferenças, tais como, as intensidades relativas das bandas em 721, 1562 e $1587 \mathrm{~cm}^{-1}$, além de pequenos deslocamentos de frequiências, que podem ser explicadas por diferenças nas geometrias particulares de cada sistema. O primeiro forma uma monocamada que recobre a superfície do eletrodo onde átomos de $\mathrm{Ag}$ com carga elétrica entre zero e um estão presentes como aglomerados, enquanto que o complexo sintetizado possui o cátion $\mathrm{Ag}^{+}$e o ligante tpy coordenado e estruturado em um retículo cristalino.

A partir destas observações conclui-se que em soluções-mãe ácidas a tpy protonada deve estar perdendo o próton para que ocorra a adsorção através de ligações coordenadas entre os nitrogênios dos anéis piridínicos e os átomos de $\mathrm{Ag}$ dos aglomerados superficiais SERS-ativos. Isto é corroborado pela banda em $1005 \mathrm{~cm}^{-1}$ observada nos espectros da figura 13. Portanto, a molécula de tpy deve estar adsorvida em uma posição mais próxima à vertical, facilitando a interação entre os pares de elétrons dos átomos de nitrogênio e a superfície.

$\mathrm{Na}$ figura anterior pode-se observar que a intensificação da banda em 721 $\mathrm{cm}^{-1}$ é mais pronunciada quando ocorre a diminuição na intensidade do ombro em 994 $\mathrm{cm}^{-1}$ sendo este último atribuído a alguma espécie adsorvida que possui anel piridínico cujo átomo de nitrogênio não está coordenado ao metal. A dificuldade na interação 
entre a tpy e a superfície deve-se à existência de geometrias particulares nos centros de adsorção superficiais em função da rugosidade gerada eletroquimicamente durante a ativação do eletrodo. Portanto, a diminuição do ombro em $994 \mathrm{~cm}^{-1}$, associada à intensificação da banda em $721 \mathrm{~cm}^{-1}$ e ao aparecimento da banda em $1005 \mathrm{~cm}^{-1}$ indica a predominância na superfície da tpy adsorvida pelos três átomos de nitrogênio e esta espécie foi denominada complexo de superfície do tipo I.

Outra característica do espectro deste complexo superficial decorre da análise da região espectral correspondente aos modos de estiramento CC dos anéis. Nesta região espectral há dois modos vibracionais atribuídos para cada anel piridínico (ver tabela 4), podendo existir diferenças de freqüência entre as bandas dos anéis laterais e do anel central. Nos espectros SERS ex situ apresentados na figura 13 ocorre a coincidência das frequiências das bandas dos anéis laterais e central, resultando na presença de duas bandas largas e pouco intensas em $1562 \mathrm{~cm}^{-1}$ e em $1587 \mathrm{~cm}^{-1}$.

Outro fator que interfere na geometria local da espécie adsorvida é a presença de ânions $\mathrm{Cl}$, cuja banda atribuída ao estiramento $\mathrm{Ag}-\mathrm{Cl}$ ocorre em $241 \mathrm{~cm}^{-1}$. Este íon compete com a tpy pela superfície metálica e a necessidade de sua presença para a estabilidade do complexo de superfície será discutida posteriormente, nos experimentos in situ.

É importante ressaltar que os espectros Raman obtidos representam uma média das espécies espalhadoras presentes na área da superfície metálica atingida pelo feixe de laser, pois este possui diâmetro da ordem de $1 \mu \mathrm{m}$. Assim, pela observação dos espectros da figura 13 conclui-se que a tpy coordenada à Ag pelos três nitrogênios, formando o complexo de superfície do tipo I, é a espécie que prevalece na superfície do eletrodo, pois o ombro em $994 \mathrm{~cm}^{-1}$ é, sempre, menos intenso que a banda em 1005 $\mathrm{cm}^{-1}$.

A partir desta análise observa-se que em $\mathrm{pH}$ zero (figura 13-e) o complexo de superfície do tipo I continua sendo a espécie predominante no eletrodo, porém, existem outras espécies adsorvidas, fato este associado à baixa intensidade da banda em $721 \mathrm{~cm}^{-1}$ e ao ombro em $994 \mathrm{~cm}^{-1}$ bastante pronunciado. A tpy diprotonada, 
caracterizada pelas bandas em $1330 \mathrm{~cm}^{-1}$ (ombro) e $1610 \mathrm{~cm}^{-1}$ (larga), também está adsorvida em quantidade significativa na superfície do eletrodo. A adsorção desta espécie deve ocorrer através da formação de par iônico entre o ânion CI adsorvido na superfície e os prótons da molécula.

A hipótese levantada acima sobre a formação de um complexo superficial é corroborada pela presença nos espectros SERS ex situ das bandas em 351 e $380 \mathrm{~cm}^{-1}$ atribuídas aos estiramentos das ligações $\mathrm{Ag}-\mathrm{N}$, como pode ser observado na figura 14, onde os mesmos espectros da figura 13 estão apresentados ampliando-se a região de baixas freqüências. Estas bandas são, também, observadas no espectro do complexo $\mathrm{Ag}(\mathrm{I}) \mathrm{tpyNO} \mathrm{N}_{3}$ (ver figura 9-a).

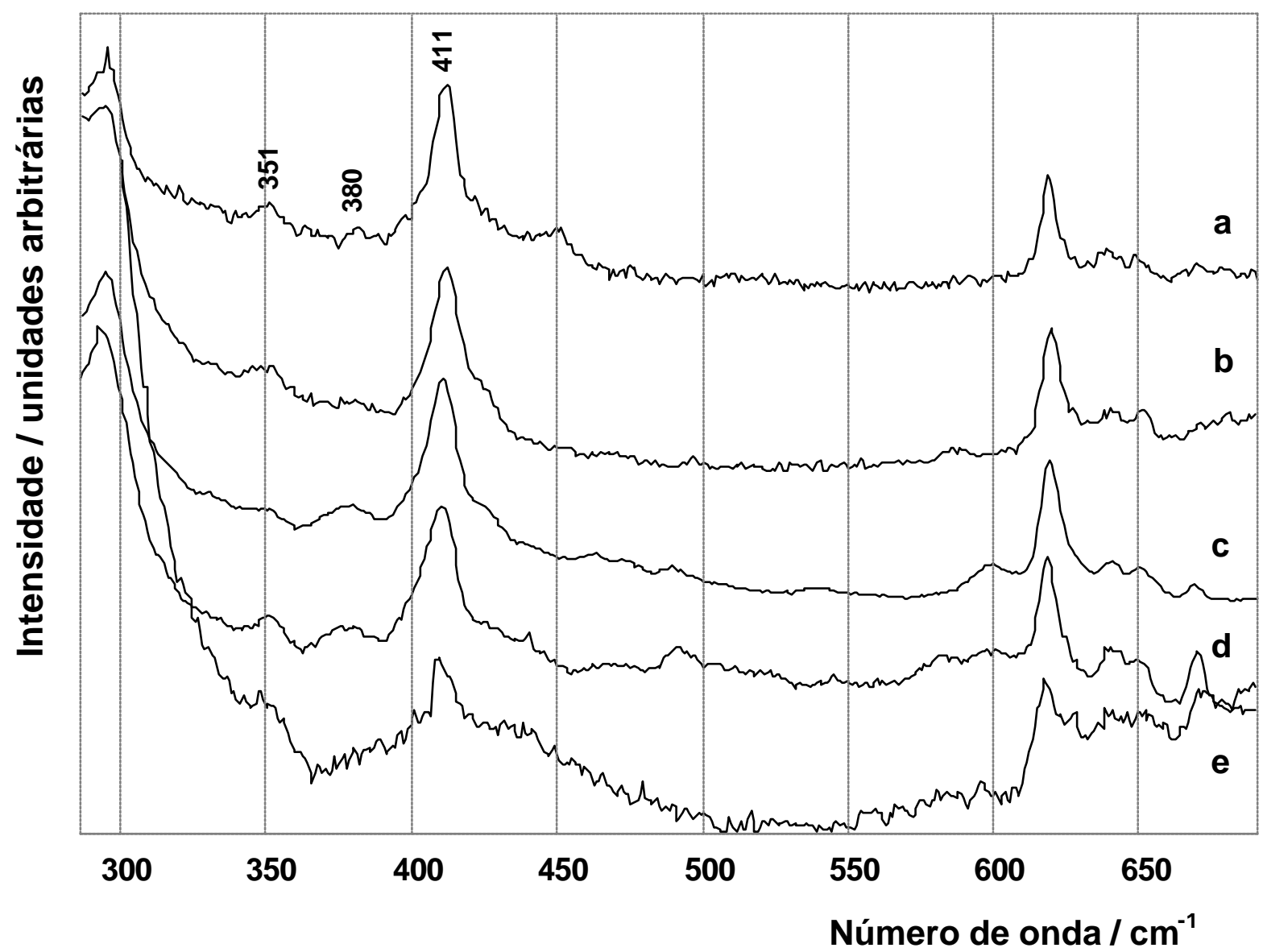

FIGURA 14: Espectros SERS ex situ do sistema tpy/Ag/CI, com as seguintes soluções-mãe: em etanol (a), e em água com pH=6 (b), $\mathrm{pH}=3$ (c), $\mathrm{pH}=1,8$ (d) e pH=0 (e). 
O estudo da influência do ânion eletrolítico na adsorção da tpy foi complementado com experimentos em iodeto e perclorato. É sabido que a capacidade de adsorção dos ânions em prata ocorre na seguinte ordem decrescente $\mathrm{I}>\mathrm{Cl}>\mathrm{ClO}_{4}{ }^{-}{ }^{14}$. Os espectros apresentados na figura 15 foram obtidos de soluções aquosas contendo tpy, em $\mathrm{pH}=6$ e variando-se o ânion-suporte.

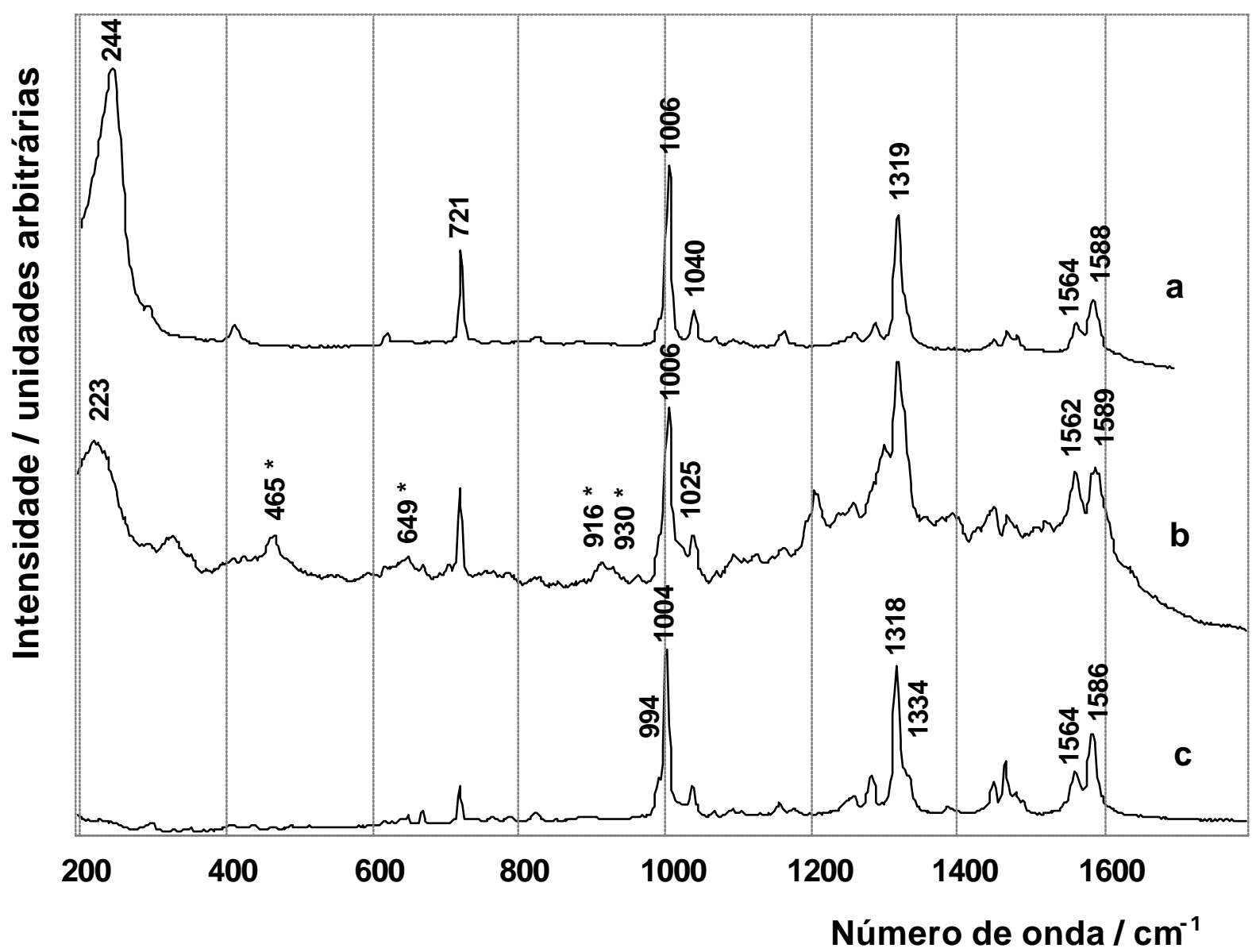

FIGURA 15: Espectros SERS ex situ do sistema tpy/Ag com soluções-mãe aquosas em pH 6, variando-se os ânions-suporte: $\mathrm{Cl}^{-}(\mathrm{a}), \mathrm{ClO}_{4}^{-}$(b) e $\mathrm{I}^{-}$(c). (*) bandas do $\mathrm{ClO}_{4}^{-}$.

Destes espectros pode-se concluir que o complexo de superfície do tipo I é a espécie que prevalece na superfície do eletrodo, independente do ânion-suporte 
utilizado. Esta espécie é caracterizada pelas bandas em 721, 1006, 1319, 1564 e 1588 $\mathrm{cm}^{-1}$.

Quando o I é o ânion-suporte utilizado, a baixa intensidade da banda em 721 $\mathrm{cm}^{-1}$ associada à resolução e à intensificação da banda em $994 \mathrm{~cm}^{-1}$ indicam que na superfície outras espécies, além do complexo de superfície, são formadas. Isto se deve a um maior recobrimento da superfície por este ânion.

Após a formação da monocamada auto-organizada da tpy sobre a superfície metálica, mesmo lavando-se copiosamente a superfície do eletrodo com água deionizada, os ânions-suporte permanecem adsorvidos. Quando o ânion-suporte utilizado é o $\mathrm{Cl}$, observa-se a presença nos espectros da banda em $244 \mathrm{~cm}^{-1}$, atribuída ao estiramento $\mathrm{Ag}-\mathrm{Cl}$ (figura $15-\mathrm{a}$ ).

Mesmo quando o ânion- suporte utilizado é o $\mathrm{ClO}_{4}^{-}$(figura 15-b), que é menos eficiente na adsorção, pode-se observar sua coordenação à superfície metálica através dos átomos de oxigênios. Considerando os resultados apresentados na figura 12 e na tabela 6, as bandas observadas nos espectros da figura 15-b, em 465 e $930 \mathrm{~cm}^{-1}$ podem ser atribuídas ao $\mathrm{ClO}_{4}{ }^{-}$adsorvido por um oxigênio, enquanto que as bandas em $649 \mathrm{e}$ 916 são atribuídas ao $\mathrm{ClO}_{4}{ }_{4}^{-}$adsorvido por dois oxigênios. A banda em $223 \mathrm{~cm}^{-1}$ pode ser atribuída ao estiramento $\mathrm{Ag}$ - $\mathrm{O}$. A frequiência atribuída ao estiramento Ag-I está abaixo de $150 \mathrm{~cm}^{-1}$ e nesta região espectral o espectrômetro utilizado não fornece dados confiáveis.

Os espectros SERS ex situ da adsorção da tpy em Ag, obtidos em $\mathrm{pH}=1,8$, variando-se os ânions-suporte, são apresentados na figura 16. Estes mostram diferenças relevantes em função do ânion-suporte utilizado.

Quando o $\mathrm{Cl}$ está presente, forma-se sobre a superfície metálica o mesmo complexo de superfície do tipo I observado nos espectros em $\mathrm{pH}=6$ obtidos anteriormente. Esta também é a espécie que prevalece no eletrodo quando I é o ânionsuporte utilizado (figuras 16-a e 16-c, respectivamente). Novamente, a baixa intensidade da banda em $721 \mathrm{~cm}^{-1}$ e o ombro observado em $994 \mathrm{~cm}^{-1}$ indicam que outras espécies estão presentes na superfície. A tpy protonada também está adsorvida, 
provavelmente pela formação de par iônico com o I, como pode ser observado pelas bandas em 1335 e 1615 (ombro) $\mathrm{cm}^{-1}$.

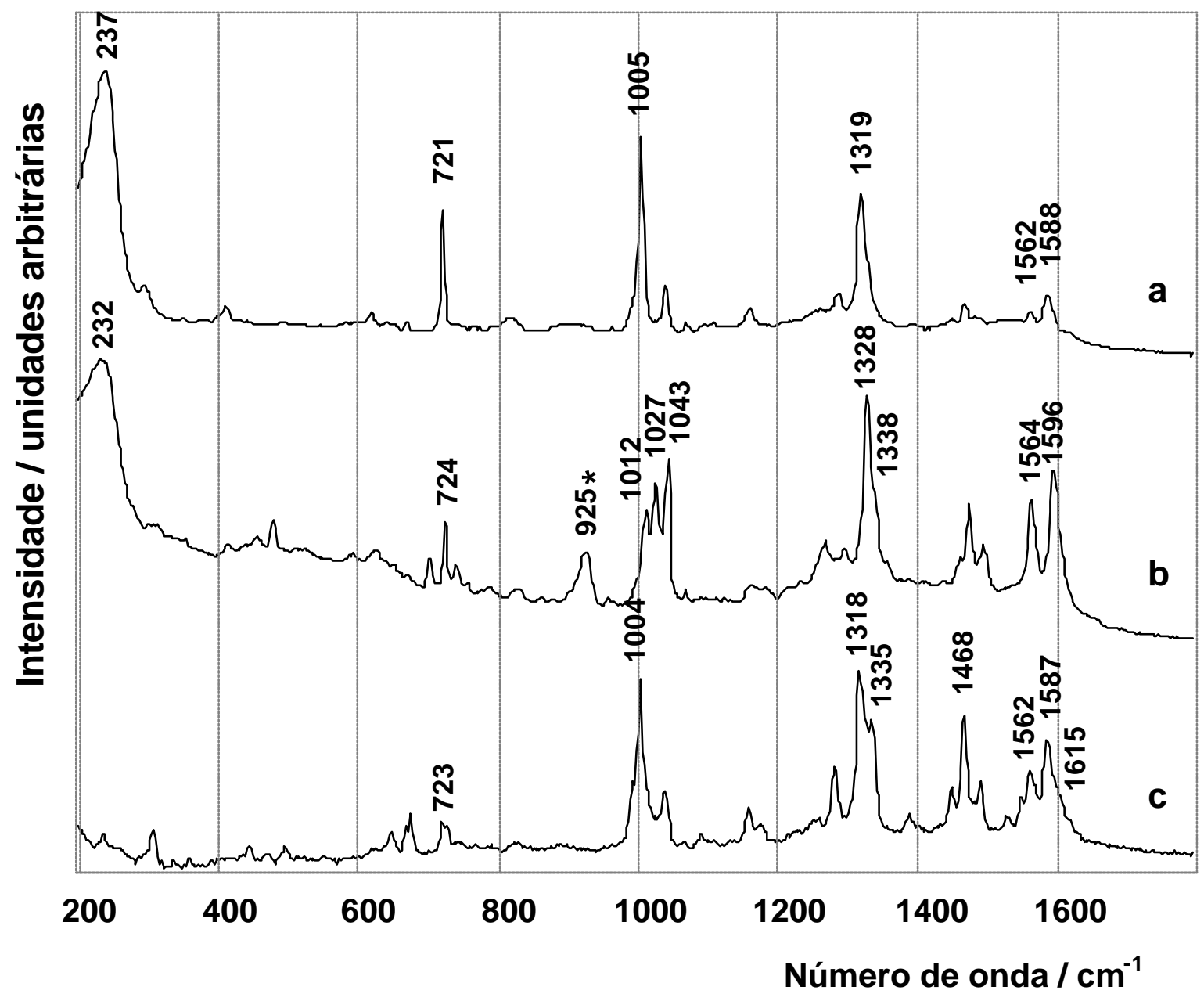

FIGURA 16: Espectros SERS ex situ do sistema tpy/Ag com soluções-mãe aquosas em pH 1,8, variando-se os ânions-suporte: $\mathrm{Cl}^{-}$(a), $\mathrm{ClO}_{4}^{-}$(b) e I (c). (*) banda do $\mathrm{ClO}_{4}^{-}$.

Quando o ânion-suporte utilizado é $\mathrm{ClO}_{4}{ }^{-}$o padrão espectral é bastante alterado (figura 16-b), já que o complexo de superfície do tipo I, presente em todos os espectros SERS ex situ anteriores, não é observado na superfície metálica.. A presença de $\mathrm{ClO}_{4}{ }^{-}$coordenado monodentado e bidentado à $\mathrm{Ag}$ é verificada pela banda larga em $925 \mathrm{~cm}^{-1}$. 
As bandas atribuídas à respiração dos anéis piridínicos presentes neste espectro são 1012, 1027 e $1043 \mathrm{~cm}^{-1}$. A ausência da banda em $994 \mathrm{~cm}^{-1}$ indica que a presença da tpy adsorvida com todos os átomos de nitrogênios coordenados predomina na superfície. A banda em $1012 \mathrm{~cm}^{-1}$ pode ser atribuída aos anéis centrais das moléculas de tpy que, devido à geometria molecular, devem estar mais afastados da superfície, sofrendo menor variação na freqüência vibracional. As bandas em 1027 e $1043 \mathrm{~cm}^{-1}$ podem ser atribuídas a dois tipos de coordenação da tpy associados a duas novas espécies presentes na superfície metálica, que não foram descritas anteriormente.

A banda em $1027 \mathrm{~cm}^{-1}$ será atribuída a um novo complexo de superfície que será chamado do tipo II para diferenciá-lo do anteriormente descrito (complexo de superfície do tipo I, figura 13). Esta banda aparece em experimentos SERS da piridina adsorvida em superfície de $\mathrm{Ag}^{15}$, surgindo também em experimentos SERS da 2,2'bipiridina adsorvida em $\mathrm{Ag}{ }^{14}, 16,17$. Nestes trabalhos, esta banda foi atribuída à respiração do anel piridínico que forma uma ligação coordenada do tipo ácido-base de Lewis envolvendo o par de elétrons livre do nitrogênio e a superfície de Ag. M. Kim e K. Itoh observaram esta banda no composto 2,2'-bipiridina-N,N'-dióxido ${ }^{16}$. Esta banda, apesar de pouco intensa, também pode ser observada nos espectros SERS ex situ da tpy adsorvida em $\mathrm{Ag}$ com o $\mathrm{ClO}_{4}{ }^{-}$como ânion-suporte e solução eletrolítica com $\mathrm{pH}=6$ (figura15-b).

$\mathrm{Na}$ figura 17 são apresentados os espectros SERS ex situ do sistema $\mathrm{Ag} / \mathrm{tpy} / \mathrm{ClO}_{4}{ }^{-}$em $\mathrm{pH}=1,8$ em função do tempo de exposição à radiação excitante. A banda em $1043 \mathrm{~cm}^{-1}$ é a sobreposição de uma banda atribuída à vibração $\beta(\mathrm{C}-\mathrm{H})$ da tpy (ver tabela 4) e de outra banda atribuída à respiração do anel piridínico que possui o nitrogênio coordenado à superfície, estando sujeito a fortes interações químicas. Esta espécie é instável e sofre decomposição térmica com a incidência do laser, como pode ser observado na figura 17-I.

A decomposição desta espécie ocorre associada a alterações na coordenação do ânion $\mathrm{ClO}_{4}^{-}$na superfície, como pode ser observado na figura 17-II. Este ânion está 
inicialmente adsorvido à superfície por dois átomos de oxigênio e com a incidência do laser perde uma das coordenações. Esta hipótese é comprovada pela diminuição da meia-largura das bandas em $925 \mathrm{~cm}^{-1}$ e por seu deslocamento para $928 \mathrm{~cm}^{-1}$, além do desaparecimento das demais bandas deste ânion em função do aumento de simetria na sua adsorção (ver, também, figura 12 e tabela 6).

$\mathrm{O}$ desaparecimento da banda em $1043 \mathrm{~cm}^{-1}$ associado à perda de uma coordenação do ânion $\mathrm{ClO}_{4}{ }^{-}$sugere que esta banda pode ser atribuída à coordenação de um oxigênio do ânion com o nitrogênio do anel piridínico. No entanto, uma banda que pudesse ser atribuída ao estiramento $\mathrm{N}-\mathrm{O}$ não foi observada.

Com a incidência do laser sobre um mesmo ponto do eletrodo, a espécie instável caracterizada pela banda em $1043 \mathrm{~cm}^{-1}$ sofre decomposição e o complexo de superfície do tipo II, caracterizado pelas bandas em 1025, 1327, 1475, 1494, 1563 (intensificada) e $1594 \mathrm{~cm}^{-1}$, que é estável com o laser, passa a ser a espécie que predomina na superfície metálica (figura 17-I-d). A banda em $354 \mathrm{~cm}^{-1}$, atribuída ao estiramento $\mathrm{Ag}-\mathrm{N}$, é observada em todos os espectros da figura 17-II, indicando que anéis piridínicos coordenados ao metal estão sempre presentes. 

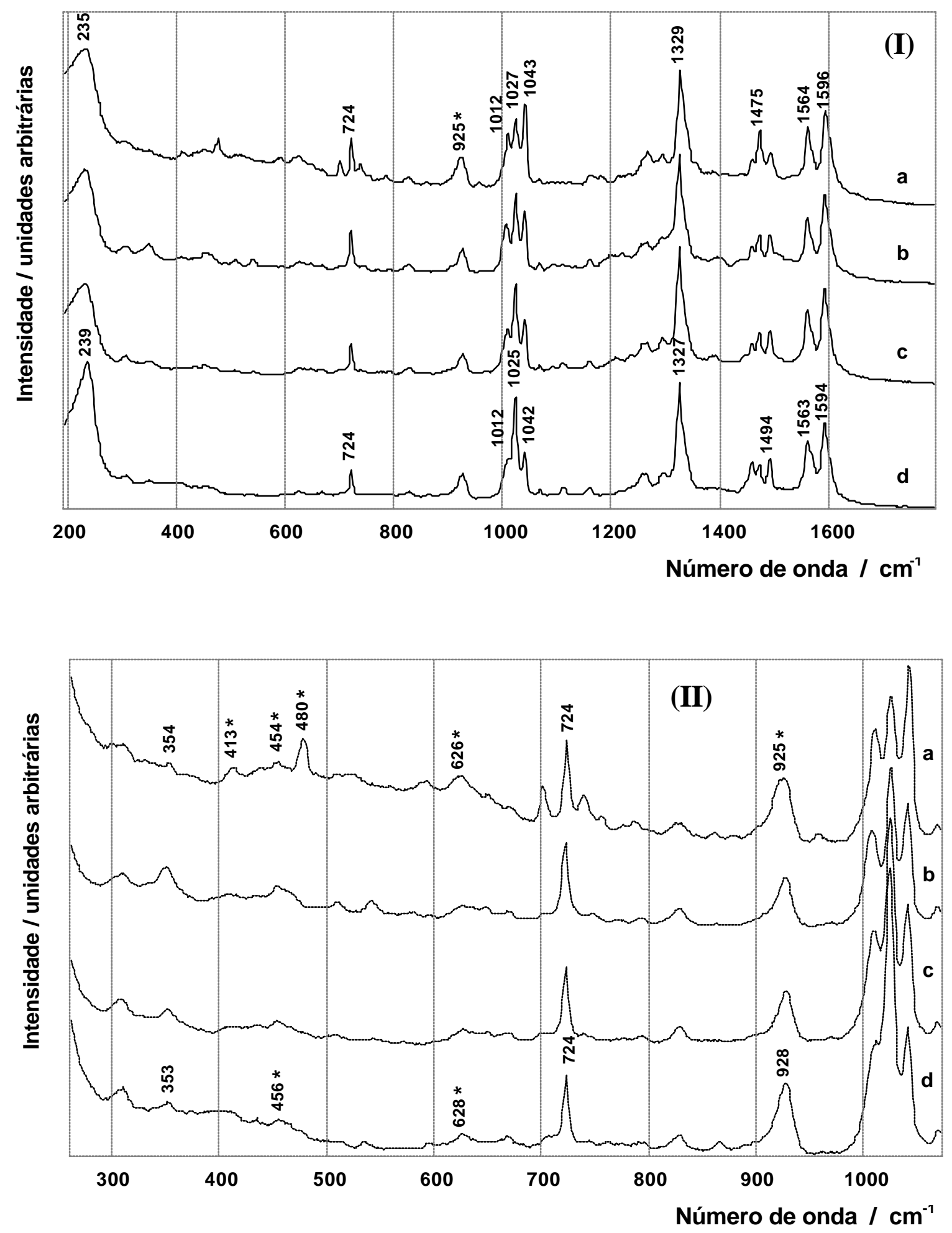

FIGURA 17: Evolução dos espectros SERS ex situ do sistema $\mathrm{Ag} /$ tpy $/ \mathrm{ClO}_{4}^{-}$, em $\mathrm{pH}=1,8$ entre 200 e $1800 \mathrm{~cm}^{-1}$ (I) e entre $250 \mathrm{e} 1100 \mathrm{~cm}^{-1}$ (II), com o tempo de exposição ao laser: $1 \mathrm{~min}$ (a), $3 \mathrm{~min}(\mathrm{~b}), 6 \mathrm{~min}$ (c) e $10 \mathrm{~min}(\mathrm{~d}) . \quad \lambda_{0}=632,8 \mathrm{~nm}$, potência do laser $=3 \mathrm{~mW}$. $\left(^{*}\right)$ bandas $\mathrm{ClO}_{4}$. 


\section{3 - SERS IN SITU DA TPY ADSORVIDA EM Ag}

Espectros SERS in situ da tpy adsorvida sobre a superfície metálica de Ag foram obtidos variando-se o potencial do eletrodo.

A figura 18 apresenta os espectros SERS in situ da tpy (aq) em Ag tendo o $\mathrm{CI}$ como ânion-suporte e o pH=6 na solução eletrolítica.

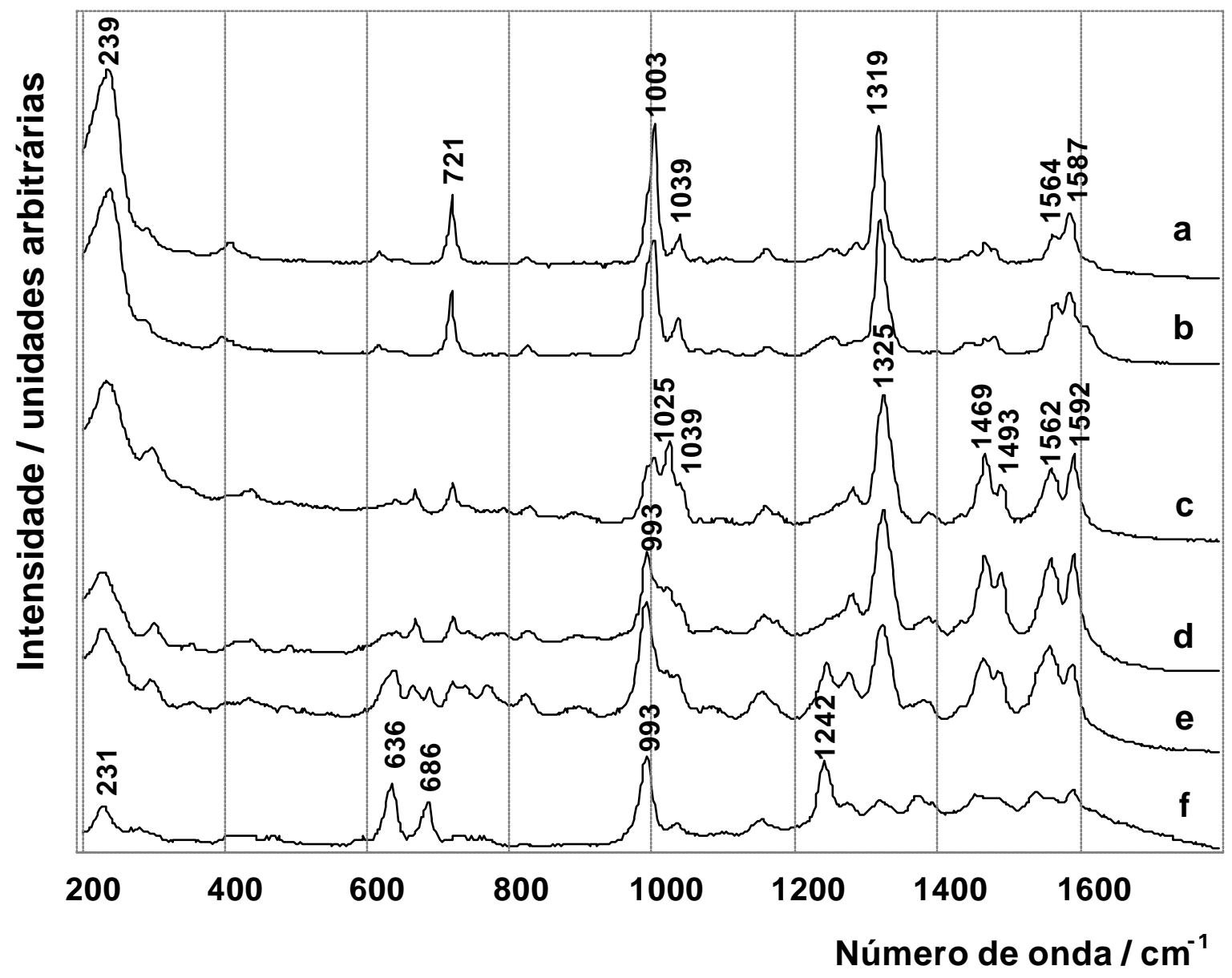

FIGURA 18: Espectros SERS in situ do sistema $\mathrm{Ag} / \mathrm{tpy}(\mathrm{aq}) / \mathrm{Cl}$ em $\mathrm{pH}=6$, em vários potenciais: repouso $=0,0 \mathrm{~V}(\mathrm{a}),-0,1 \mathrm{~V}(\mathrm{~b}),-0,2 \mathrm{~V}(\mathrm{c}),-0,5 \mathrm{~V}(\mathrm{~d}),-0,8 \mathrm{~V}(\mathrm{e}),-1,1 \mathrm{~V}$ (f).

No potencial de repouso, aproximadamente $0,0 \mathrm{~V}$, a espécie que predomina na superfície metálica é o complexo de superfície do tipo I, caracterizado pelas bandas em 721, 1003, 1319, 1564 e $1587 \mathrm{~cm}^{-1}$. Esta espécie é semelhante à 
observada nos espectros ex situ para o mesmo sistema tpy (aq) adsorvida em Ag, tendo CI como ânion-suporte (figura 13).

Em potencial -0,2V (figura 18-c) ocorre alteração das espécies presentes na superfície do eletrodo, passando a predominar o complexo de superfície do tipo II, caracterizado pelas bandas em 1025, 1325, 1469, 1493, 1562 (intensificada) e 1592 $\mathrm{cm}^{-1}$. Uma explicação possível é que à medida que potenciais mais negativos são aplicados, ocorre a diminuição da carga elétrica positiva presente nos aglomerados superficiais de Ag e com isto a ligação química entre o átomo de nitrogênio e do metal passa a possuir um maior caráter ácido-base de Lewis.

Outro experimento SERS in situ da tpy (aq) adsorvida em Ag realizado em condições iniciais diferentes, e que vem ao encontro desta idéia, é apresentado a seguir (figura 19). Após os ciclos de oxidação e redução do eletrodo de Ag para a ativação da superfície, o potencial foi mantido em $-0,2 \mathrm{~V}$ e à solução eletrolítica foi adicionada tpy. Nestas condições as moléculas de tpy adsorveram sobre uma superfície onde estavam presentes os ânions $\mathrm{Cl}$ adsorvidos sobre aglomerados metálicos cuja carga elétrica média já estava menos positiva que no potencial de repouso. O primeiro espectro obtido após alguns minutos indica a predominância no eletrodo do complexo de superfície do tipo II (figura 19-a), caracterizado pelas bandas em 1027, 1328, 1473, 1493, 1563 e $1593 \mathrm{~cm}^{-1}$. Este espectro é muito semelhante ao obtido em SERS ex situ da tpy (aq) adsorvida em $\mathrm{Ag}$ com $\mathrm{ClO}_{4}^{-}$ utilizado como ânion-suporte, quando o $\mathrm{pH}=1,8$ foi mantido na solução-mãe (figura 17-I-d). Pode-se afirmar que em ambos experimentos é o mesmo complexo de superfície que prevalece sobre o eletrodo. 


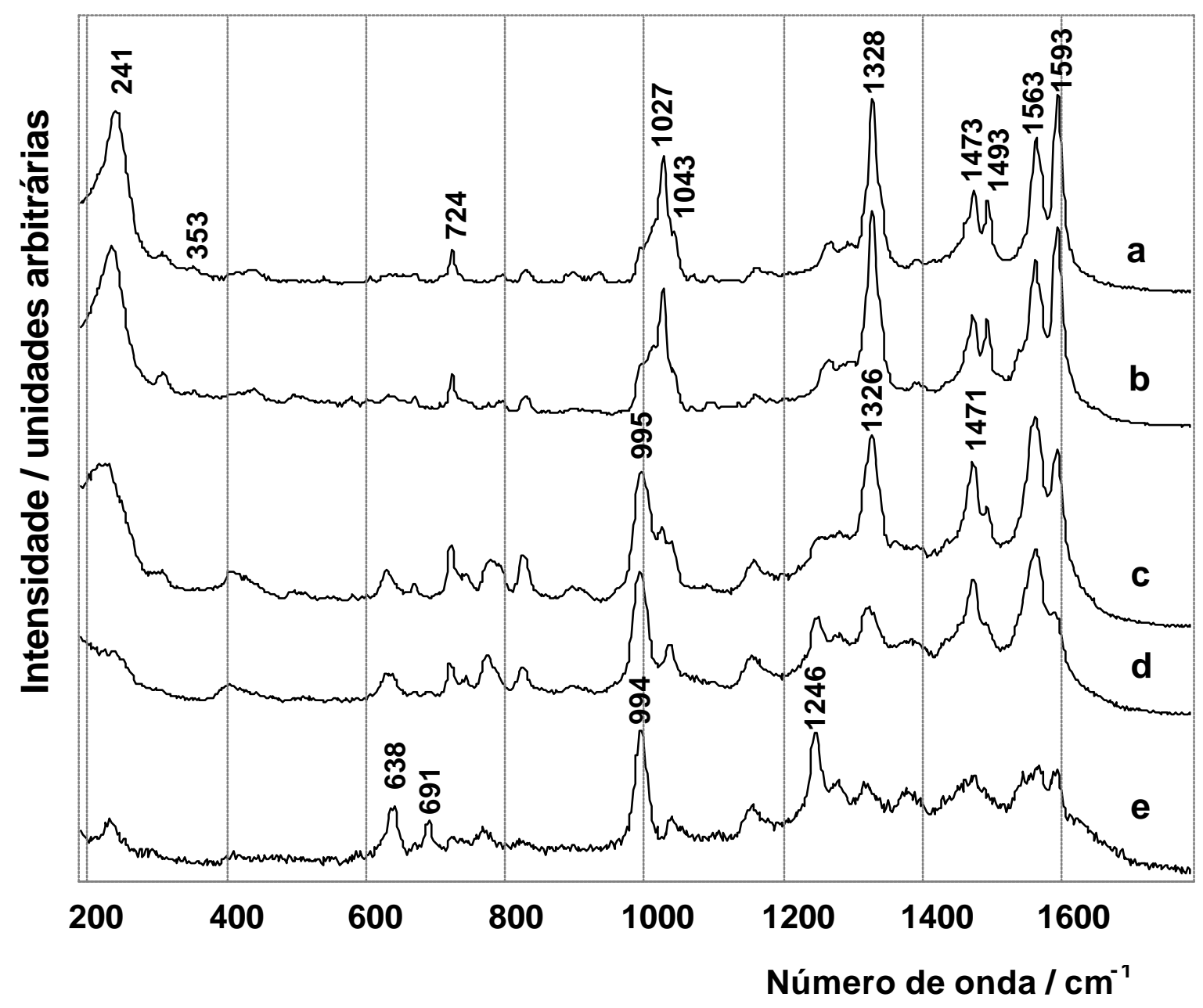

FIGURA 19: Espectros SERS in situ do sistema $\mathrm{Ag} / \mathrm{tpy}(\mathrm{aq}) / \mathrm{Cl}^{-} \mathrm{em} \mathrm{pH}=6$, em vários potenciais: $-0,2 \mathrm{~V}$ (a), $-0,4 \mathrm{~V}$ (b), $-0,6 \mathrm{~V}$ (c), $-0,8 \mathrm{~V}$ (d) e $-1,2 \mathrm{~V}$ (e).

Nos experimentos SERS in situ, apresentados nas figuras 18 e 19, quando o potencial está em aproximadamente $-0,8 \mathrm{~V}$ praticamente não há mais $\mathrm{CI}$ na superfície do eletrodo, como pode ser verificado pela brusca diminuição da intensidade da banda associada ao estiramento $\mathrm{Ag}-\mathrm{Cl}$ em $241 \mathrm{~cm}^{-1}$. Com isso, ocorre uma segunda variação no padrão espectral da tpy adsorvida e na região de respiração do anel piridínico é observada uma única banda em $993 \mathrm{~cm}^{-1}$, indicativa da não coordenação dos nitrogênios com o me tal. Outra evidência disso é a ausência 
da banda atribuída ao estiramento da ligação $\mathrm{Ag}-\mathrm{N}$ em $353 \mathrm{~cm}^{-1}$, que pode ser observada ampliando-se estes espectros na região de baixas freqüências (figura 20).

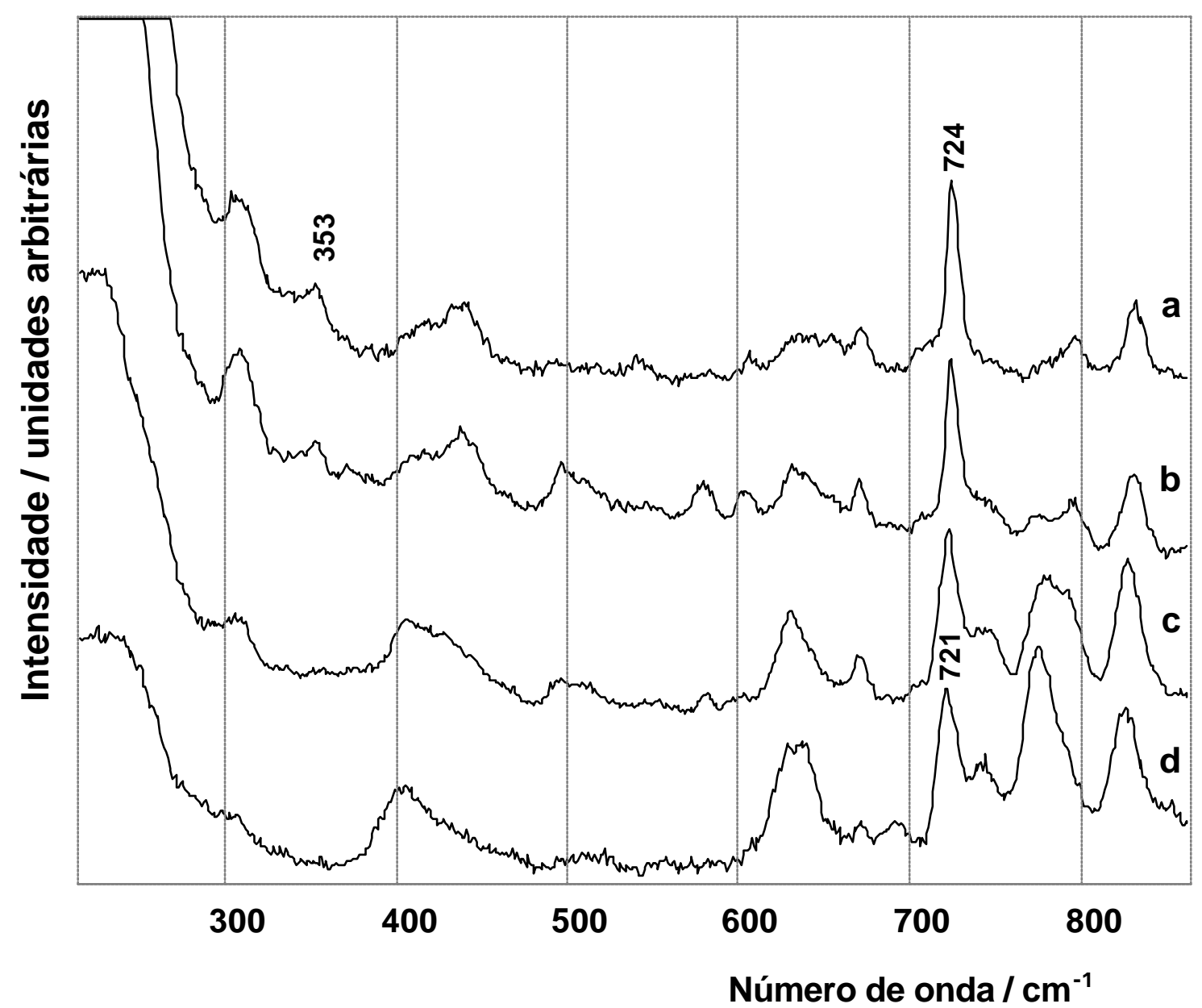

FIGURA 20: Espectros SERS in situ do sistema $\mathrm{Ag} / \mathrm{tpy}(\mathrm{aq}) / \mathrm{Cl}$ em $\mathrm{pH}=6$, em vários potenciais: $-0,2 \mathrm{~V}(\mathrm{a}),-0,4 \mathrm{~V}$ (b), $-0,6 \mathrm{~V}$ (c) e $-0,8 \mathrm{~V}$ (d).

Portanto, pode-se concluir que nesta segunda transição, em que os potenciais aplicados são mais negativos que $-0,8 \mathrm{~V}$, a tpy passa a interagir com a superfície metálica através dos elétrons $\pi$ dos anéis piridínicos, com a molécula adsorvida em uma posição mais próxima da horizontal, sendo caracterizada pelas bandas em 638, 691, 994 e $1246 \mathrm{~cm}^{-1}$. Esta hipótese é reforçada por outra evidência experimental obtida destes espectros quando analisa-se a região de freqüências mais 
altas. É sabido que anéis aromáticos, quando adsorvidos em uma posição perpendicular à superfície, apresentam espectros Raman em que as bandas dos estiramentos C-H estão evidentes e quando estes anéis estão adsorvidos horizontalmente à superfície, estas bandas não aparecem nos espectros ${ }^{18,19}$. Da análise dos espectros in situ do sistema tpy $(\mathrm{aq}) / \mathrm{Ag} / \mathrm{Cl} / \mathrm{pH}=6$ (figura 18), especialmente nesta região espectral, estas evidências podem ser observadas (figura 21).

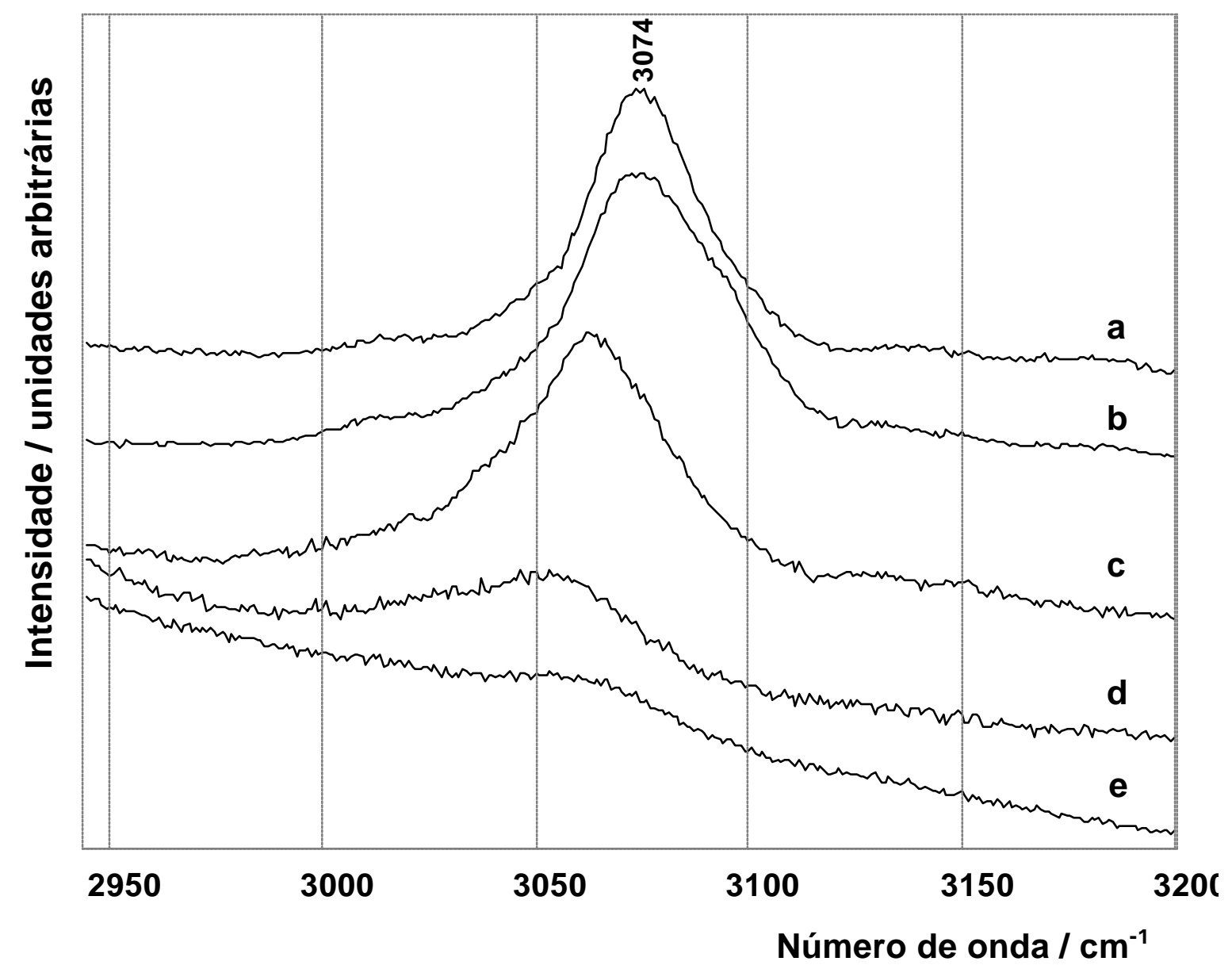

FIGURA 21: Espectros SERS in situ do sistema $\mathrm{Ag} / \mathrm{tpy}(\mathrm{aq}) / \mathrm{Cl}^{-} \mathrm{em} \mathrm{pH}=6$, em vários potenciais: repouso $=0,0 \mathrm{~V}(\mathrm{a}),-0,1 \mathrm{~V}(\mathrm{~b}),-0,5 \mathrm{~V}(\mathrm{c}),-0,9 \mathrm{~V}(\mathrm{~d}),-1,1 \mathrm{~V}(\mathrm{e})$. 
Foram obtidos os espectros SERS in situ da tpy adsorvida em eletrodo de Ag, em $\mathrm{pH}=3,0$ e utilizando-se $\mathrm{Cl}^{-}$como ânion-suporte. Os resultados são apresentados na figura 22.

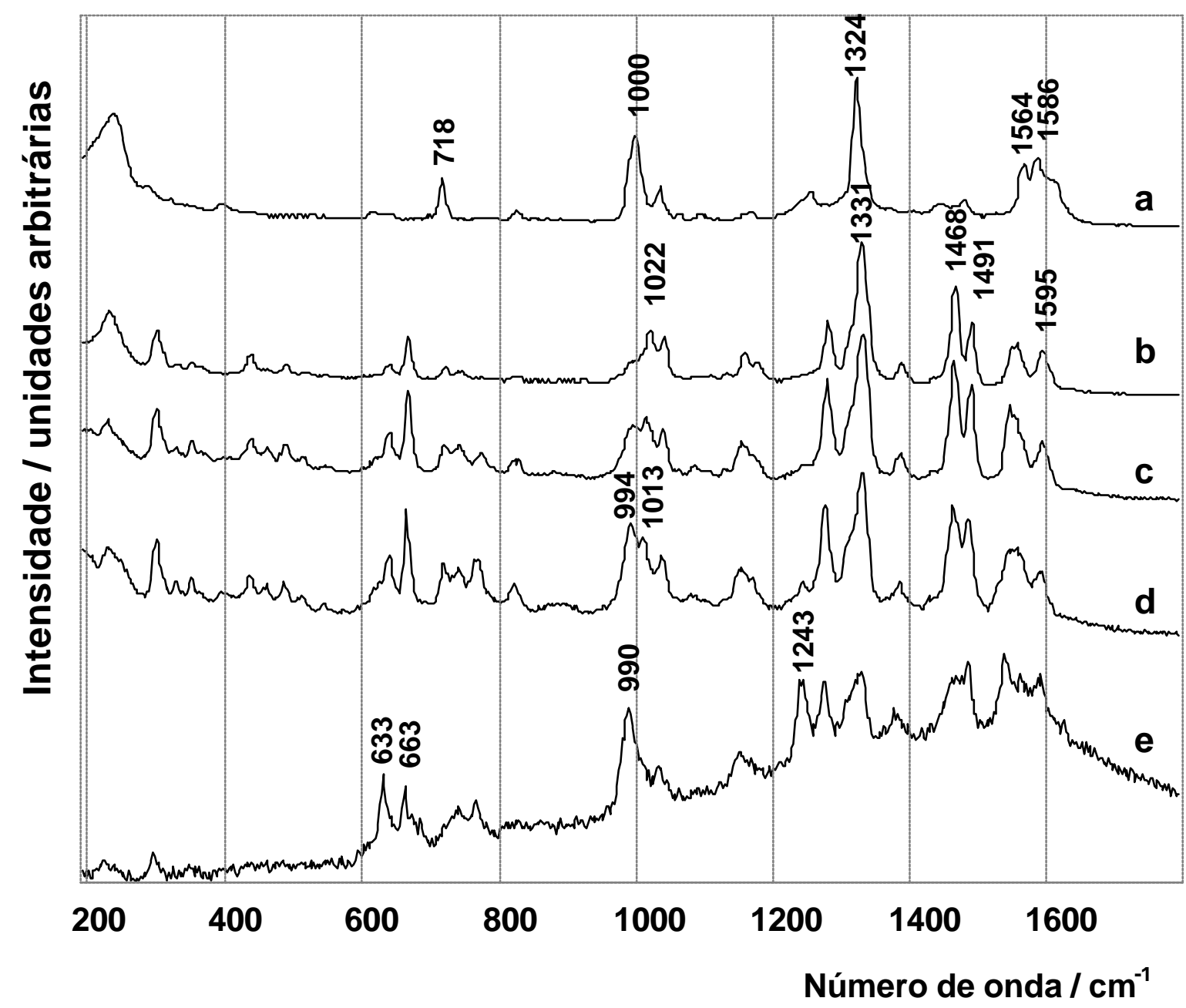

FIGURA 22: Espectros SERS in situ do sistema $\mathrm{Ag} / \mathrm{tpy}(\mathrm{aq}) / \mathrm{Cl}^{\top} \mathrm{em} \mathrm{pH}=3$, em vários potenciais: repouso $=+0,04 \mathrm{~V}(\mathrm{a}),-0,2 \mathrm{~V}(\mathrm{~b}),-0,6 \mathrm{~V}(\mathrm{c}),-0,8 \mathrm{~V}(\mathrm{~d}),-1,0 \mathrm{~V}(\mathrm{e})$.

Nestes espectros pode-se observar que no potencial de repouso (figura 22a) o complexo de superfície do tipo I é a espécie que prevalece na superfície do eletrodo, caracterizado pelas bandas em 1000, 1324, 1564 e $1586 \mathrm{~cm}^{-1}$. Porém, outras espécies estão presentes, pois o ombro em $994 \mathrm{~cm}^{-1}$ indica a presença de 
anéis piridínicos livres e a banda em $1610 \mathrm{~cm}^{-1}$ indica que anéis protonados também estão presentes na superfície metálica.

Quando o potencial aplicado é de $-0,2 \mathrm{~V}$, novamente, observa-se a presença do complexo de superfície do tipo II, caracterizado pelas bandas em 1022, 1331, 1468, 1491 e $1595 \mathrm{~cm}^{-1}$. Para potenciais mais negativos que $-0,8 \mathrm{~V}$ o ânion $\mathrm{CI}$ dessorve (banda $241 \mathrm{~cm}^{-}$diminui), a banda em $994 \mathrm{~cm}^{-1}$ intensifica e a diminuição das intensidades das bandas em 353 e $3070 \mathrm{~cm}^{-1}$ também pode ser verificada. Estas observações caracterizam a adsorção da tpy pelos elétrons $\pi$, em uma posição mais próxima à horizontal.

Os espectros SERS in situ obtidos para a tpy adsorvida em Ag com ânionsuporte $\mathrm{Cl}^{-}$e solução eletrolítica aquosa em $\mathrm{pH}=1,8$ são apresentados na figura 23. Neste $\mathrm{pH}$, quando o sistema está no potencial de repouso, a espécie que predomina na superfície metálica é o complexo de superfície do tipo I, com a tpy desprotonando para adsorver coordenada à $\mathrm{Ag}$, como pode ser observado pela presença das bandas em 718, 1006, 1324 e $1584 \mathrm{~cm}^{-1}$. Porém, outras espécies estão presentes na superfície do eletrodo em quantidades relevantes, tais como, a tpy diprotonada, caracterizada pelas bandas em 1334 (ombro) e 1613 (larga) $\mathrm{cm}^{-1}$ e espécies com anéis piridínicos livres, isto é, com átomos de nitrogênio não comprometidos com uma ligação química, sendo estes caracterizados pela banda da respiração do anel em $994 \mathrm{~cm}^{-1}$.

Ao variar-se o potencial no sentido catódico ocorre intensificação das bandas em 1334 (ombro) e 1604 (ombro) $\mathrm{cm}^{-1}$, atribuídas à tpy protonada, aumentando sua presença na superfície do eletrodo em detrimento do complexo superficial do tipo I, inicialmente predominante.

A partir de $-0,6 \mathrm{~V}$ ocorre a liberação de $\mathrm{H}_{2}$ na superfície do eletrodo devido à redução dos prótons presentes na solução e, com isto, a obtenção de espectros fica comprometida. 


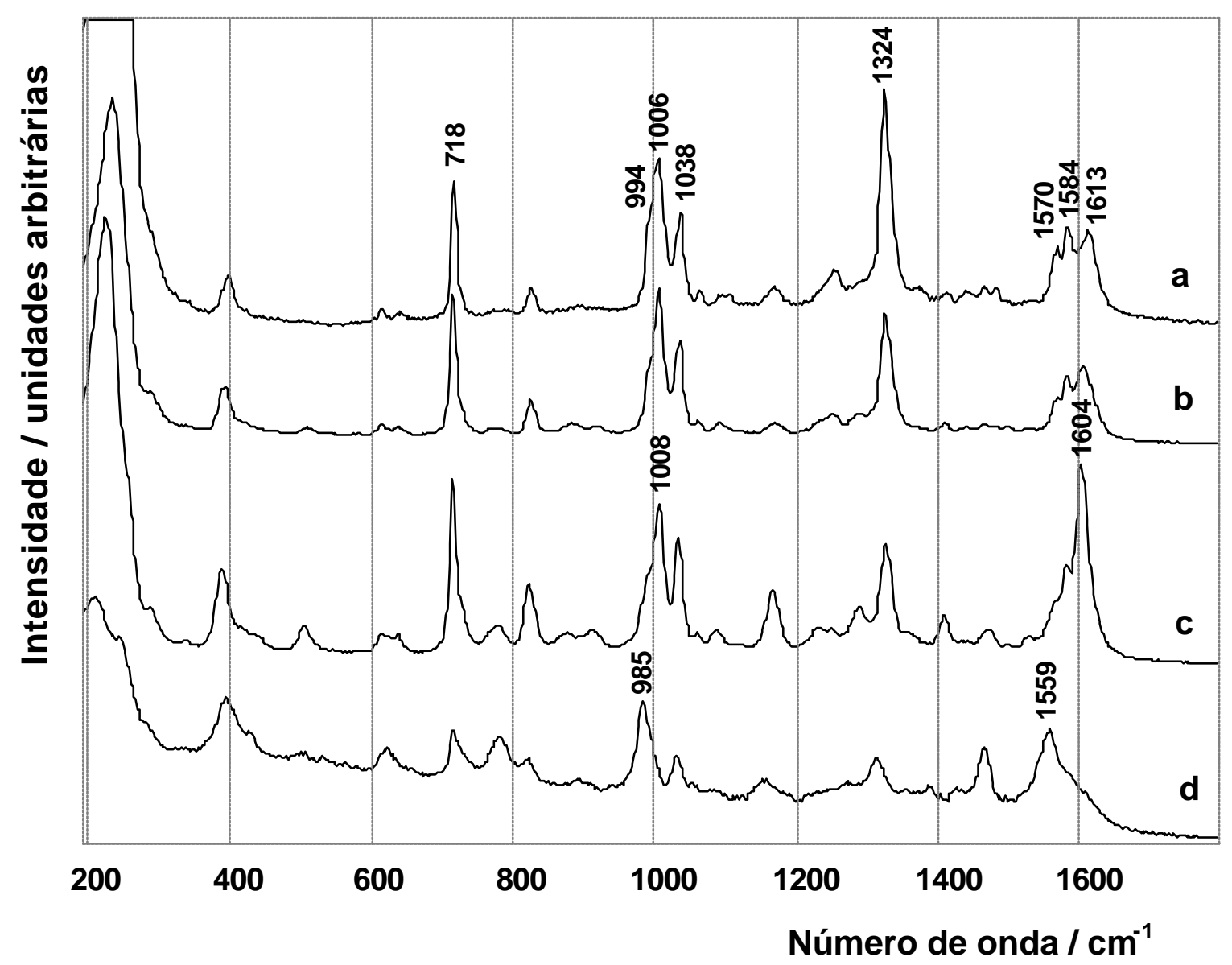

FIGURA 23: Espectros SERS in situ do sistema $\mathrm{Ag} / \mathrm{tpy}(\mathrm{aq}) / \mathrm{Cr}$ em $\mathrm{pH}=1,8$, em vários potenciais: repouso $=+0,15 \mathrm{~V}(\mathrm{a}),-0,2 \mathrm{~V}(\mathrm{~b}),-0,4 \mathrm{~V}(\mathrm{c}),-0,6 \mathrm{~V}$.

Quando os espectros da tpy adsorvida em eletrodo de Ag, na presença de Cl e em $\mathrm{pH}=6$ e $\mathrm{pH}=1,8$ são comparados, fica evidente a ausência da banda em $1027 \mathrm{~cm}^{-1}$ em meio ácido. De alguma forma, a presença dos cátions $\mathrm{H}_{3} \mathrm{O}^{+}$nas proximidades dos sítios de adsorção favorece a adsorção da tpy diprotonada e diminui a possibilidade de formação do complexo de superfície do tipo II.

Para uma melhor avaliação das hipóteses propostas até aqui foram realizados experimentos SERS in situ da tpy adsorvida em eletrodo de Ag, em solução aquosa, variando-se o ânion-suporte. Os espectros obtidos, utilizando-se o I como ânion-suporte, mantido o pH=6, estão apresentados na figura 24. 
Mantendo-se o sistema no potencial de repouso, a espécie que predomina na superfície é, novamente, o complexo de superfície do tipo I, caracterizado pelas bandas em 720, 1004, 1318, 1562 e $1586 \mathrm{~cm}^{-1}$. Pode-se observar que o ombro em $994 \mathrm{~cm}^{-1}$, associado à baixa intensidade da banda em $720 \mathrm{~cm}^{-1}$, indica a presença de anéis piridínicos não coordenados ao metal, fato já observado anteriormente nos espectros SERS ex situ contendo I' na superfície.

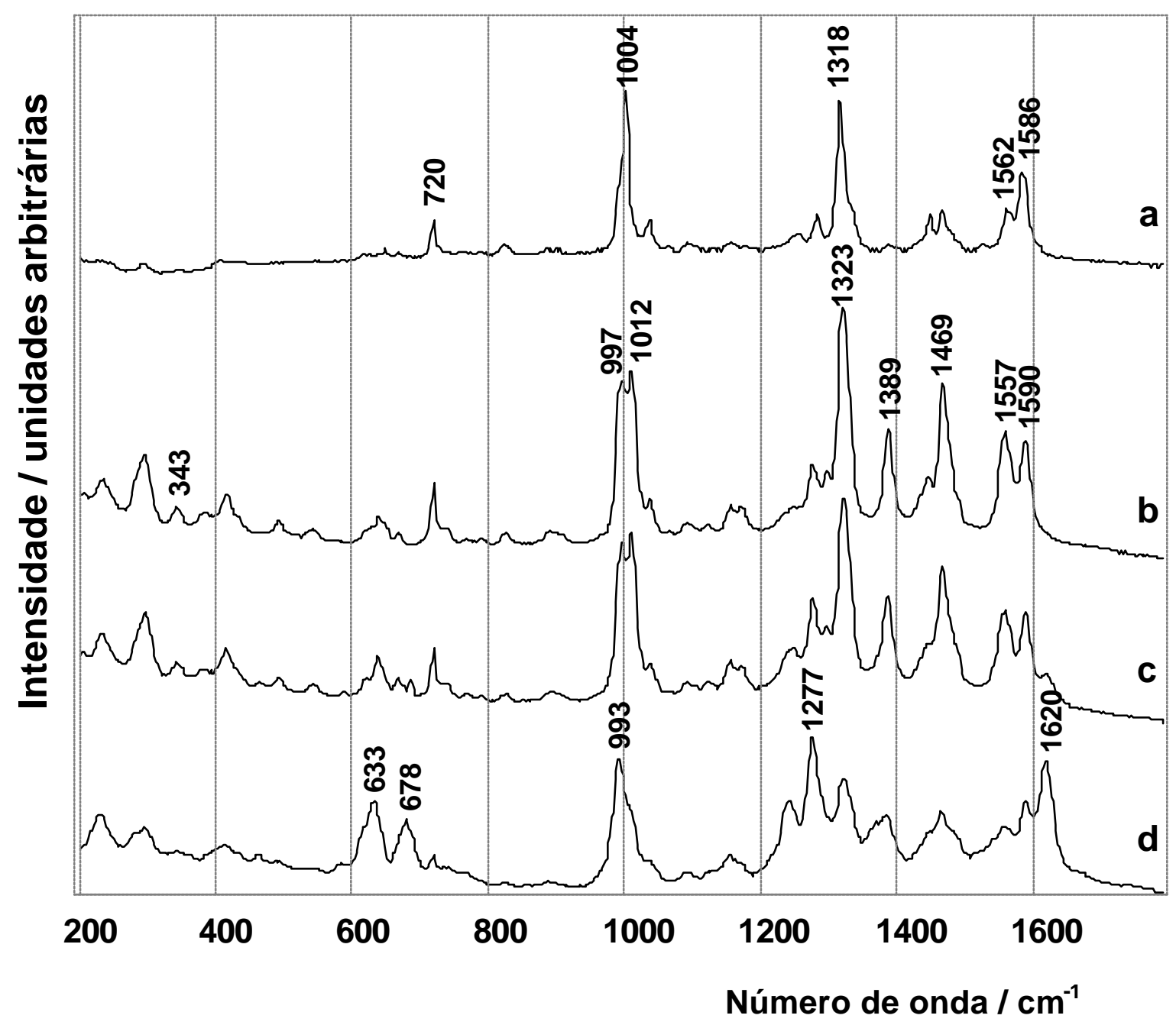

FIGURA 24: Espectros SERS in situ do sistema $\mathrm{Ag} / \mathrm{tpy}(\mathrm{aq}) / \mathrm{I}^{-} \mathrm{em} \mathrm{pH}=6$, em vários potenciais: repouso $=-0,26 \mathrm{~V}(\mathrm{a}),-0,4 \mathrm{~V}(\mathrm{~b}),-0,9 \mathrm{~V}(\mathrm{c}),-1,2 \mathrm{~V}(\mathrm{~d})$. 
Quando o potencial aplicado é de $-0,4 \mathrm{~V}$ ocorre uma transição e nova espécie passa a predominar na superfície do eletrodo. Esta espécie corresponde ao complexo de superfície do tipo II, cujos átomos de nitrogênios da tpy coordenam como bases de Lewis sobre a superfície do eletrodo, podendo ser caracterizado pelas bandas em 1012, 1323, 1469, 1488 e $1590 \mathrm{~cm}^{-1}$.

$\mathrm{O}$ valor da freqüência correspondente à respiração do anel piridínico, observado para esta espécie em $1012 \mathrm{~cm}^{-1}$, está abaixo do observado para o complexo superficial do tipo II nos sistemas anteriormente estudados, tipicamente próximo de $1026 \mathrm{~cm}^{-1}$ (ver figuras 17, 18 e 19). Isto indica que há uma interação menos intensa entre a tpy e a superfície metálica. $O$ maior recobrimento da superfície pelo ânion I, bem como o maior raio iônico desta espécie, dificultam a interação do adsorbato com o metal. Isto leva ao deslocamento da freqüência da respiração dos anéis piridínicos deste complexo superficial para valores mais baixos, bem como, à intensificação da banda em $997 \mathrm{~cm}^{-1}$ atribuída aos anéis piridínicos não coordenados ao metal.

Da mesma forma que nos sistemas anteriores, quando o potencial aplicado é mais negativo que o potencial de repouso há diminuição da carga elétrica média dos aglomerados metálicos superficiais aumentando o caráter ácido-base de Lewis das ligações entre o adsorbato e os átomos de $\mathrm{Ag}$.

Para potenciais aplicados mais negativos que $-0,9 \mathrm{~V}$ ocorre uma alteração progressiva na adsorção das moléculas do adsorbato, e em $-1,2 \mathrm{~V}$ observa-se a predominância da tpy interagindo com a superfície pelos elétrons $\pi$, em uma posição mais próxima da horizontal. Esta espécie pode ser caracterizada pelas bandas em 633, 678, 993 e $1277 \mathrm{~cm}^{-1}$ e pela diminuição de intensidade das bandas em 343, 385 e $3065 \mathrm{~cm}^{-1}$.

Foram, também, realizados experimentos SERS in situ da tpy (aq) adsorvida em $\mathrm{Ag}$ utilizando-se $\mathrm{ClO}_{4}{ }^{-}$como ânion-suporte, mantido o $\mathrm{pH}=6$ na solução eletrolítica. Os espectros obtidos estão apresentados na figura 25. 
$\mathrm{O}$ ânion $\mathrm{ClO}_{4}^{-}$é de difícil adsorção na superfície metálica, diminuindo a estabilidade dos centros SERS-ativos e, por isso, os espectros obtidos no potencial de repouso tiveram baixa relação sinal/ruído (figura 25-a).

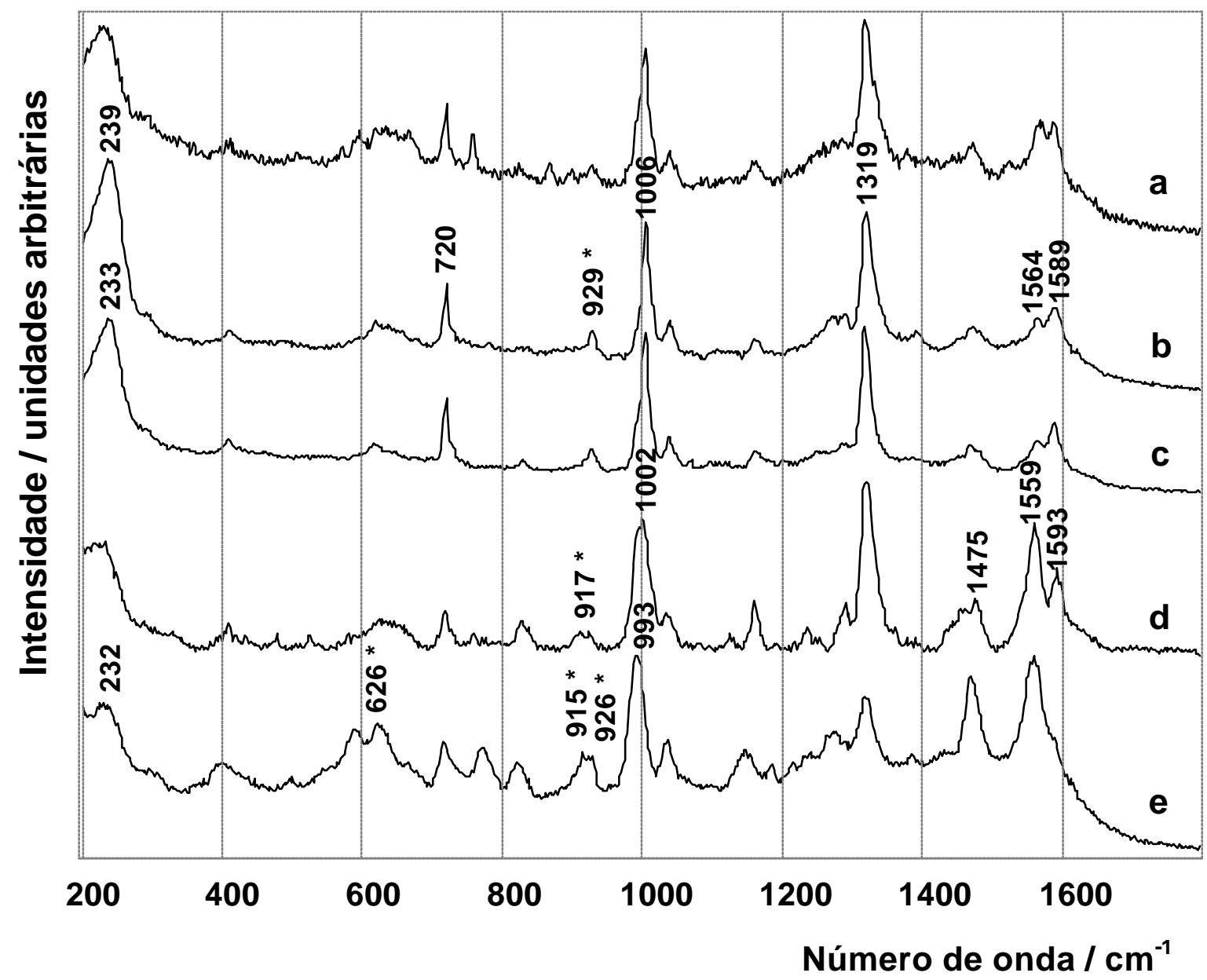

FIGURA 25: Espectros SERS in situ do sistema $\mathrm{Ag} / \mathrm{tpy}(\mathrm{aq}) / \mathrm{ClO}_{4}{ }^{-} \mathrm{em} \mathrm{pH}=6$, em vários potenciais: repouso $=+0,07 \mathrm{~V}(\mathrm{a}),+0,3 \mathrm{~V}(\mathrm{~b}), 0,0 \mathrm{~V}(\mathrm{c}),-0,1 \mathrm{~V}$ (d) e $-0,7 \mathrm{~V}$ (e).

(*) bandas do $\mathrm{ClO}_{4}$.

Quando é aplicado ao eletrodo um potencial de $+0,3 \mathrm{~V}$, a relação sinal/ruído aumenta e o espectro se assemelha ao obtido anteriormente no potencial de repouso, sendo ambos atribuídos ao complexo de superfície do tipo I, caracterizado pelas bandas em 720, 1006, 1319, 1564 e $1589 \mathrm{~cm}^{-1}$ (figura 25-b). A banda em $929 \mathrm{~cm}^{-1}$, observada em ambos os espectros, pode ser atribuída tanto ao $\mathrm{ClO}_{4}{ }^{-}$presente na 
solução quanto ao ânion coordenado monodentado na superfície metálica, já que ambas as espécies possuem freqüências muito próximas para este modo vibracional (ver figura 12).

Variando-se o potencial aplicado ao eletrodo no sentido catódico, surge uma transição das espécies adsorvidas em $-0,1 \mathrm{~V}$. O complexo de superfície do tipo I predomina na superfície, caracterizado pelas bandas em 1002 (larga) e $1319 \mathrm{~cm}^{-1}$, mas também o complexo de superfície do tipo II adsorve, como pode ser caracterizado pelas bandas 1015 (ombro), 1330 (ombro), 1475, 1559 (intensificada) e $1593 \mathrm{~cm}^{-1}$ (ver esta região ampliada na figura 26-d).

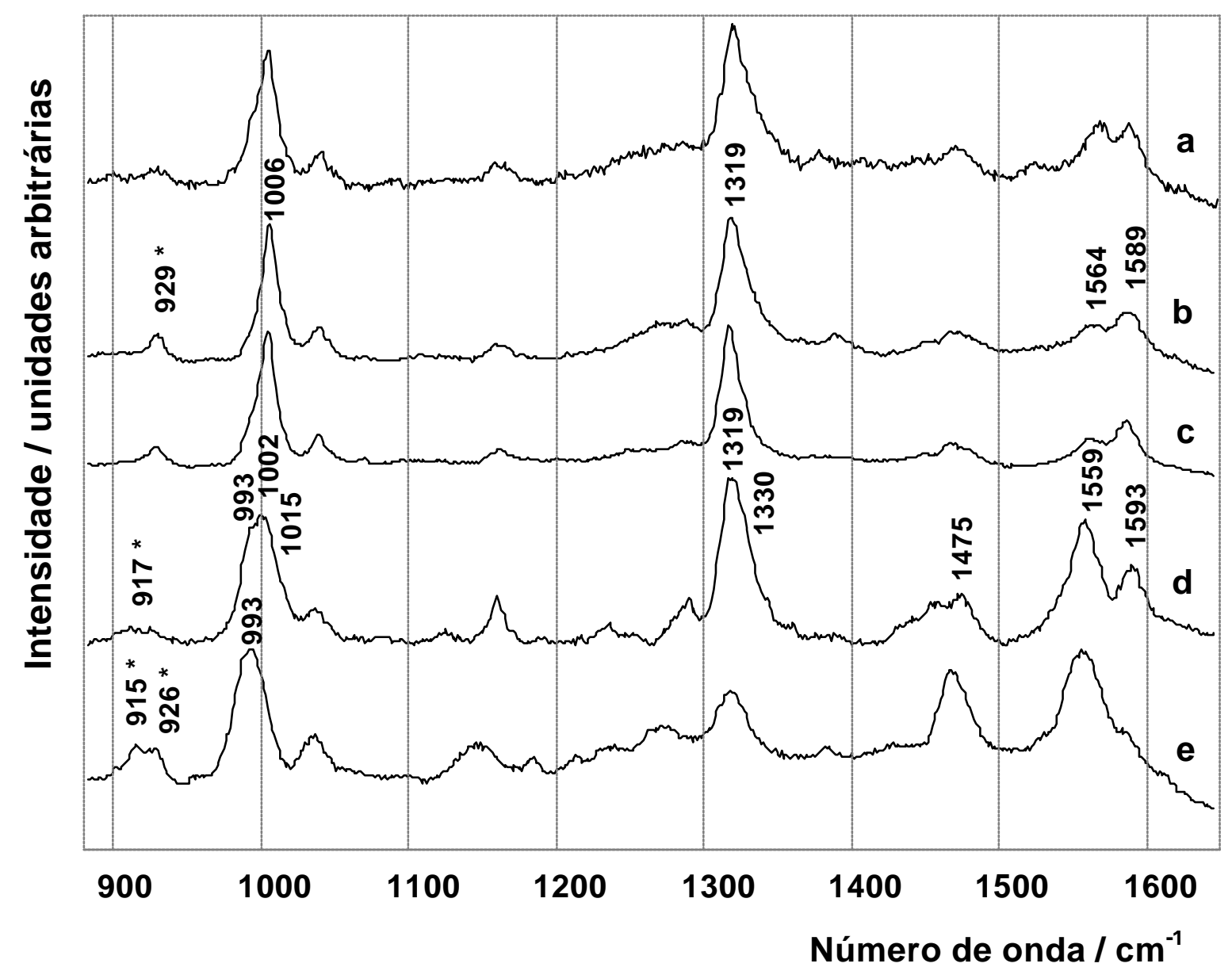

FIGURA 26: Espectros SERS in situ do sistema $\mathrm{Ag} / \mathrm{tpy}(\mathrm{aq}) / \mathrm{ClO}_{4}{ }^{-} \mathrm{em} \mathrm{pH}=6$, em vários potenciais: repouso $=+0,07 \mathrm{~V}(\mathrm{a}),+0,3 \mathrm{~V}(\mathrm{~b}), 0,0 \mathrm{~V}(\mathrm{c}),-0,1 \mathrm{~V}$ (d) e $-0,7 \mathrm{~V}$ (e).

(*) bandas do $\mathrm{ClO}_{4}{ }^{*}$. 
Analisando-se, ainda, o espectro obtido em potencial -0,1V (figura 26-d), o aumento da intensidade do ombro em $994 \mathrm{~cm}^{-1}$ indica a presença no eletrodo de espécies com anéis piridínicos cujos átomos de nitrogênio não estão coordenados à superfície. Neste potencial, a presença de ânions $\mathrm{ClO}_{4}{ }^{-}$adsorvidos por um ou dois átomos de oxigênio à Ag pode ser inferida pelo surgimento de uma banda larga em $917 \mathrm{~cm}^{-1}$. O complexo de superfície do tipo II não é a espécie predominante na superfície como observado anteriormente, quando outros íons foram utilizados, devido à dificuldade de adsorção do $\mathrm{ClO}_{4}{ }^{-}$, caracterizada pela baixa intensidade da banda Ag-O em $232 \mathrm{~cm}^{-1}$ (figura 25-d).

Quando o potencial aplicado é de $-0,7 \mathrm{~V}$, a presença nos espectros das bandas em 915 e $926 \mathrm{~cm}^{-1}$ indica que íons $\mathrm{ClO}_{4}{ }^{-}$estão adsorvidos, respectivamente, por dois ou um átomo de oxigênio à superfície metálica. Neste potencial a banda da respiração dos anéis em $993 \mathrm{~cm}^{-1}$ indica que a tpy adsorvida à superfície através dos elétrons $\pi$ dos anéis piridínicos, em uma posição mais próxima da horizontal é a espécie que predomina.

A dependência da formação destes complexos superficiais com a presença do ânionsuporte adsorvido na superfície metálica é confirmada pelo experimento SERS in situ descrito a seguir, no qual a tpy foi adsorvida sobre a superfície do eletrodo de Ag utilizando-se $\mathrm{Cl}^{-}$como ânion-suporte e mantido o $\mathrm{pH}=3$ na solução eletrolítica (figura 27).

Neste experimento a ativação eletroquímica do eletrodo não foi realizada a contento. Isto pode ser observado nos espectros, pela baixa intensidade da banda atribuída ao estiramento $\mathrm{Ag}-\mathrm{Cl}$ em $240 \mathrm{~cm}^{-1}$. Nestas condições a formação do complexo do tipo I é observada no potencial de repouso, porém as bandas que caracterizam-no, em $721 \mathrm{~cm}^{-1}$ (pouco intensa) e $1003 \mathrm{~cm}^{-1}$ associadas ao intenso ombro em $994 \mathrm{~cm}^{-1}$ indicam que esta espécie não recobriu a superfície com a mesma eficiência observada anteriormente, em experimentos SERS envolvendo tpy adsorvida em Ag na presença de CI (figuras 18, 19, 22 e 23). 


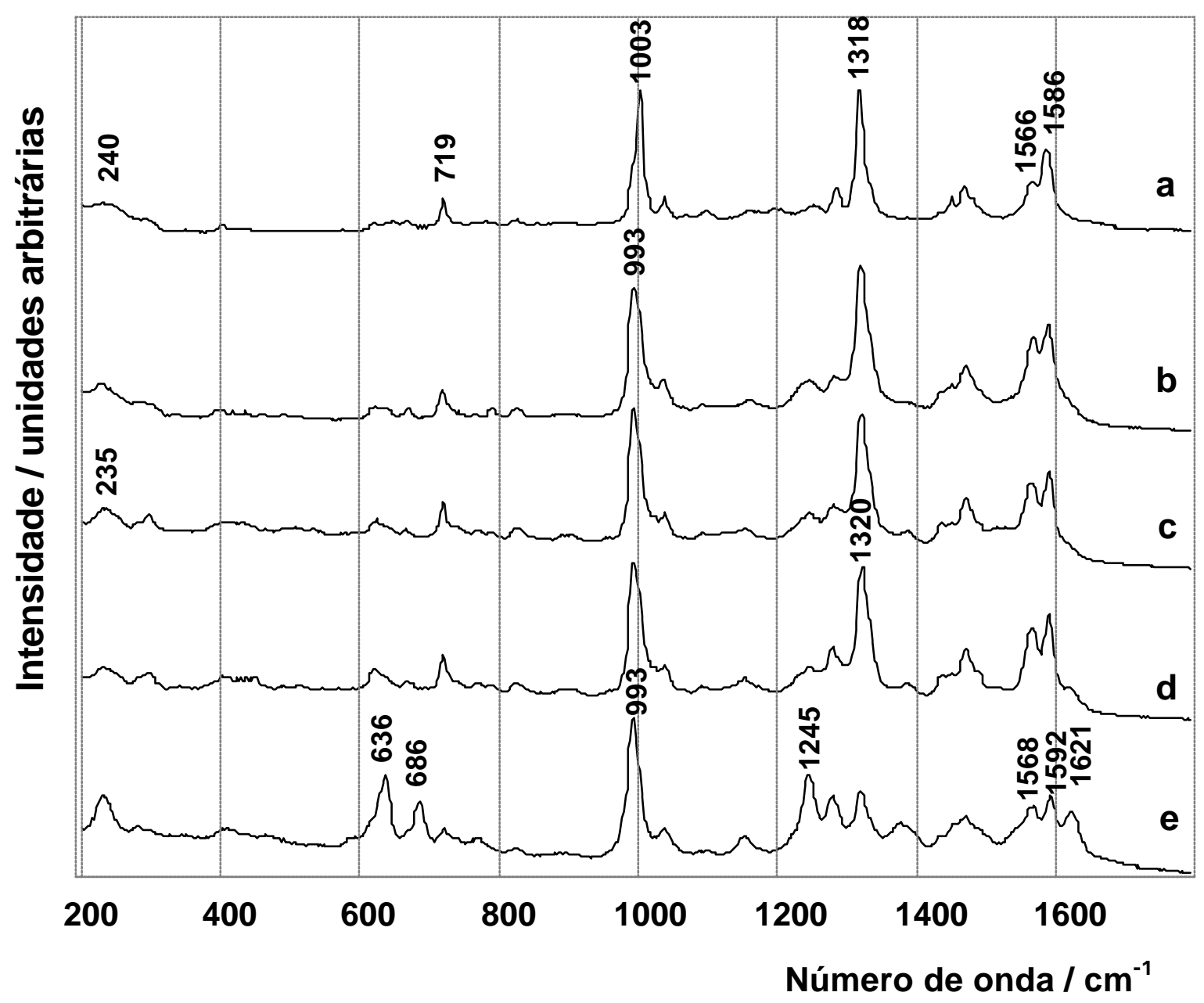

FIGURA 27: Espectros SERS in situ do sistema $\mathrm{Ag} / \mathrm{tpy}(\mathrm{aq}) / \mathrm{Cl}^{-} \mathrm{em} \mathrm{pH}=3$, em vários potenciais: repouso $=+0,02 \mathrm{~V}(\mathrm{a}),-0,2 \mathrm{~V}(\mathrm{~b}),-0,6 \mathrm{~V}(\mathrm{c}),-0,8 \mathrm{~V}(\mathrm{~d}) \mathrm{e}-1,1 \mathrm{~V}(\mathrm{e})$.

Com o potencial aplicado em $-0,2 \mathrm{~V}$ observa-se, na superfície do eletrodo, a presença da tpy não coordenada à $\mathrm{Ag}$ pelos átomos de nitrogênio, cujo padrão espectral assemelha-se ao da tpy no estado sólido (figura 5), caracterizado pelas bandas em 993 e $1320 \mathrm{~cm}^{-1}$, bem como pela intensificação da banda em $1566 \mathrm{~cm}^{-1}$. A ausência da espécie protonada na superfície é, também, explicada pela baixa densidade superficial de ânions adsorvidos, o que dificulta a adsorção por par iônico. Para potenciais aplicados mais negativos que $-0,8 \mathrm{~V}$ os espectros 
assemelham-se aos obtidos anteriormente em sistemas semelhantes (figuras 18, 19, 22 e 23), atribuídos às moléculas adsorvidas sobre a superfície metálica em uma posição próxima à horizontal.

A influência do metal na adsorção da tpy foi investigada utilizando-se eletrodo de $\mathrm{Cu}$ e os espectros obtidos em solução aquosa em $\mathrm{pH}=6,0$, utilizando-se como ânion-suporte $\mathrm{Cl}^{-}$são apresentados na figura 28.

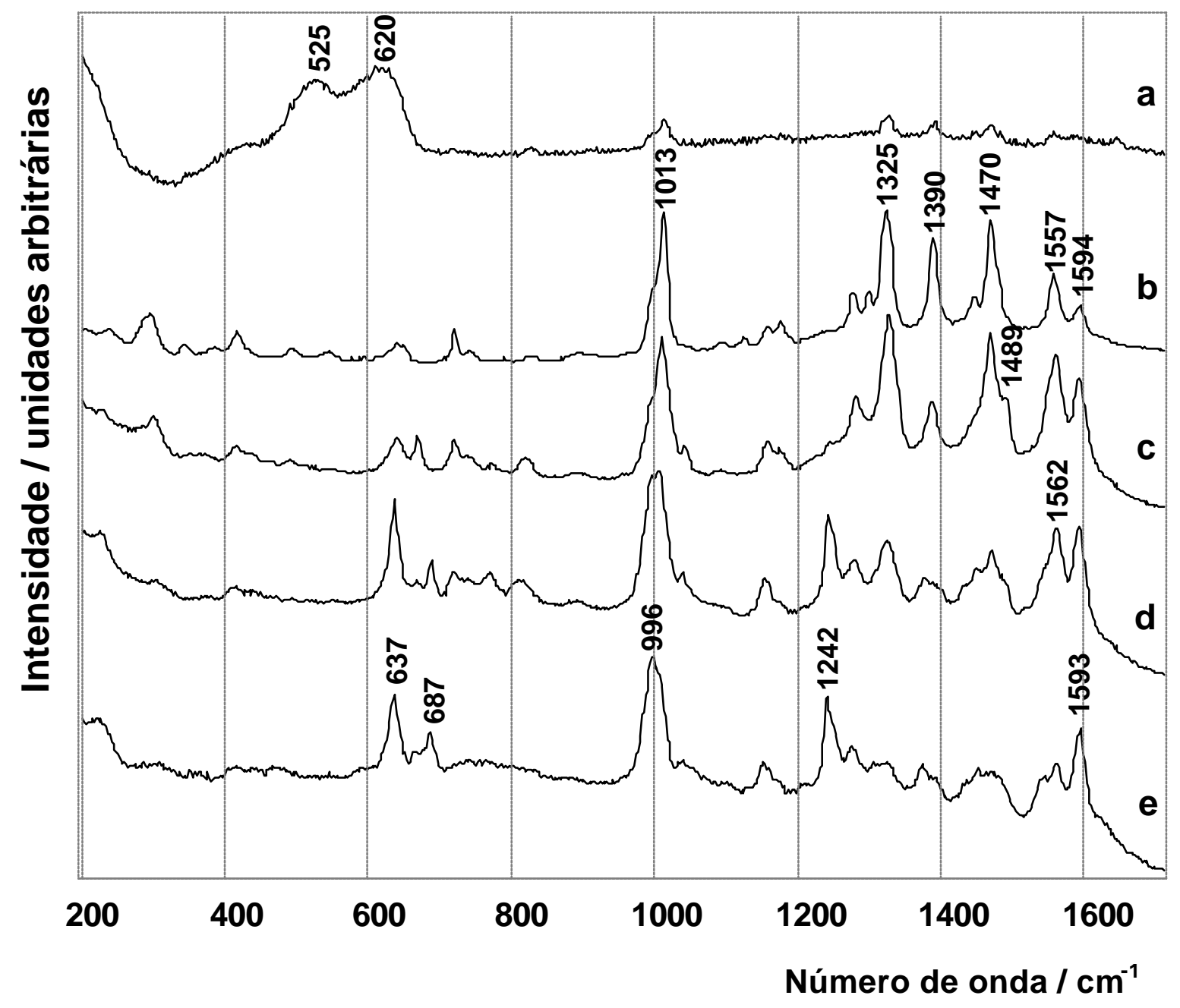

FIGURA 28: Espectros SERS in situ do sistema $\mathrm{Cu} / \mathrm{tpy}(\mathrm{aq}) / \mathrm{Cl}$, em $\mathrm{pH}=6,0$ e em vários potenciais: $-0,3 \mathrm{~V}(\mathrm{a}),-0,5 \mathrm{~V}$ (b), $-0,7 \mathrm{~V}(\mathrm{c}),-0,9 \mathrm{~V}$ (d) $\mathrm{e}-1,2 \mathrm{~V}$ (e). 
No potencial de repouso, em $-0,125 \mathrm{~V}$, a tpy adsorve muito pouco, sendo difícil obter-se o espectro em experimentos SERS. Esta dificuldade permanece até quando o potencial aplicado no sentido catódico chega a $-0,3 \mathrm{~V}$. Nesta faixa de potencial podem ser observadas duas bandas largas em 525 e $620 \mathrm{~cm}^{-1}$, atribuídas ao $\mathrm{Cu}_{2} \mathrm{O}$ que se forma sobre a superfície do eletrodo ${ }^{20,21}$.

Os espectros obtidos em potenciais mais negativos mostram que a tpy adsorve sobre a superfície de $\mathrm{Cu}$. A ausência das bandas do $\mathrm{Cu}_{2} \mathrm{O}$ indicam sua redução.

Para os potenciais aplicados em $-0,5$ e $-0,7 \mathrm{~V}$ observa-se a adsorção da tpy na forma do complexo de superfície do tipo II, caracterizado pelas bandas em 1013, 1325, 1470, 1489, 1562 e $1594 \mathrm{~cm}^{-1}$. Com a aplicação de potenciais mais negativos que $-0,9 \mathrm{~V}$ a tpy passa a adsorver na superfície do eletrodo pelos elétrons $\pi$ dos anéis piridínicos, em uma posição próxima da horizontal, caracterizada pelas bandas em 637, 687, 996 e $1242 \mathrm{~cm}^{-1}$. Este comportamento é semelhante ao observado em eletrodo de Ag.

Na figura 29 são comparados os espectros SERS in situ da tpy adsorvida em eletrodo de $\mathrm{Cu}$ e Ag com o espectro Raman do complexo [Cu(II)tpyCl]Cl. O espectro do sistema $\mathrm{Cu} / \mathrm{tpy}(\mathrm{aq}) / \mathrm{CI} / \mathrm{pH}=6,0$ no potencial de $-0,5 \mathrm{~V}$ (figura 29-a) e o espectro do sistema $\mathrm{Ag} / \mathrm{tpy}(\mathrm{aq}) / \mathrm{CI} / \mathrm{pH}=6,0$ no potencial de $-0,2 \mathrm{~V}$ (figura 29-c) foram escolhidos por representarem os melhores espectros do complexo de superfície do tipo II. Nestes, são atribuídas as bandas da respiração do anel em 1013 e $1027 \mathrm{~cm}^{-1}$, respectivamente.

Apesar das diferenças nas intensidades relativas das bandas nos espectros da figura 29-a e 29-c, as freqüências que caracterizam este complexo superficial estão presentes. São elas 1013, 1325, 1470 e $1594 \mathrm{~cm}^{-1}$ para a tpy adsorvida em $\mathrm{Cu}$ e $1027,1328,1473,1493$ e $1593 \mathrm{~cm}^{-1}$ para a tpy adsorvida em Ag.

Comparando-se os padrões espectrais destes complexos superficiais com o do complexo $[\mathrm{Cu}(\mathrm{II}) \mathrm{tpyCl}] \mathrm{Cl}$ é observada grande semelhança. As bandas que caracterizam este último são observadas em 1032, 1333, 1470, 1495 e $1596 \mathrm{~cm}^{-1}$. 
Isto permite afirmar que as interações metal-ligante neste complexo levam a mudanças nas vibrações moleculares da parte tpy semelhantes às observadas no complexo de superfície do tipo II.

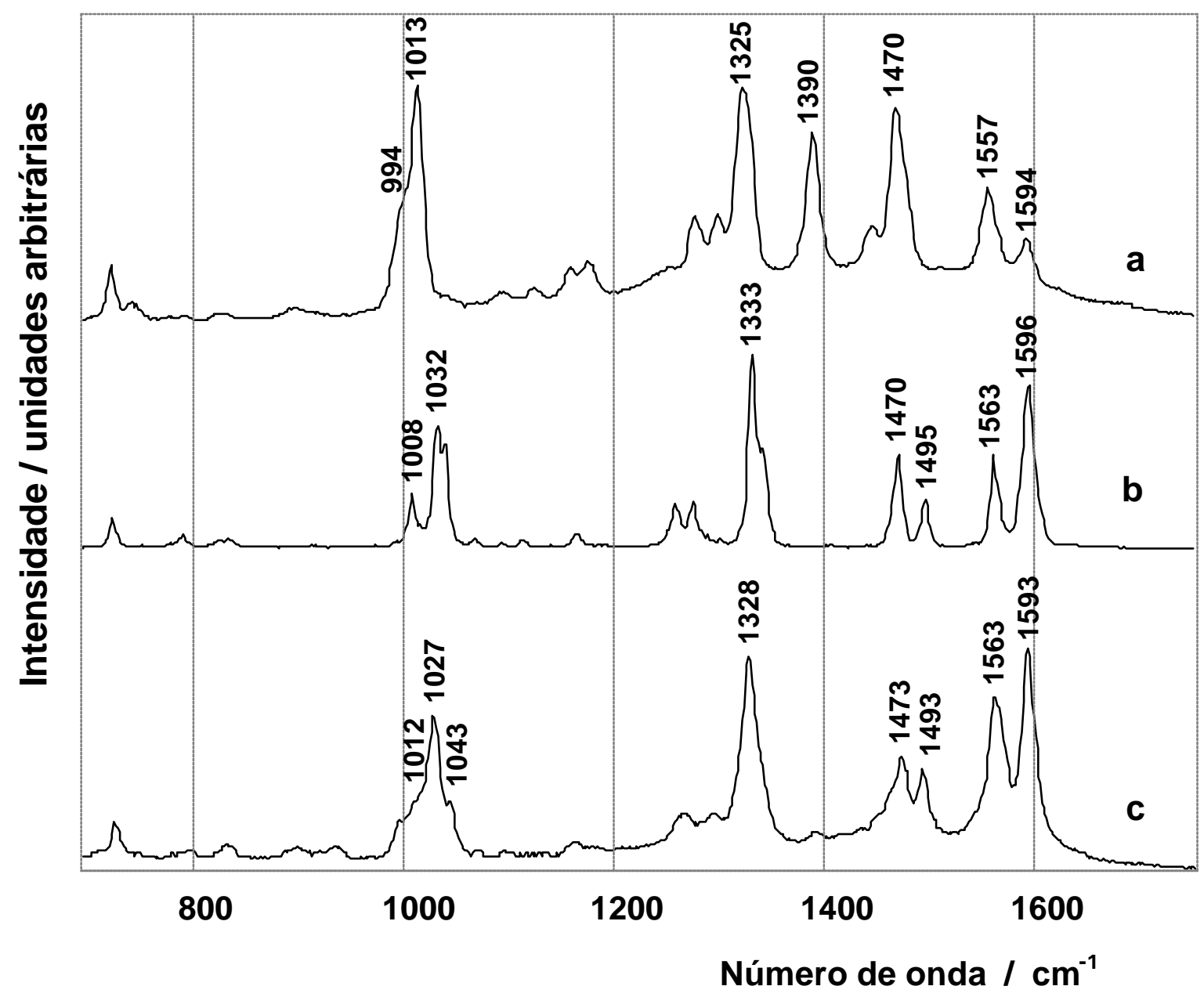

FIGURA 29: Espectros SERS in situ dos sistemas $\mathrm{Cu} / \mathrm{tpy}(\mathrm{aq}) / \mathrm{Cl} / \mathrm{pH}=6,0, \mathrm{~V}_{\mathrm{ap}}=-0,5 \mathrm{~V}$ (a), $\mathrm{Ag} / \mathrm{tpy}(\mathrm{aq}) / \mathrm{Cl} / \mathrm{pH}=6,0, \mathrm{~V}_{\text {ap }}=-0,2 \mathrm{~V}$ (c) e espectro Raman do complexo [Cu(II)tpyCl]Cl (b).

Uma análise mais detalhada da região de baixas freqüências dos espectros anteriores é apresentada na figura 30. As bandas atribuídas ao estiramento $\mathrm{Cu}-\mathrm{Cl}$ podem ser observadas, no espectro SERS da tpy adsorvida em $\mathrm{Cu}$, em $297 \mathrm{~cm}^{-1}$ (figura 30-a) e no espectro Raman do complexo [Cu(II)tpyCl]Cl em $305 \mathrm{~cm}^{-1}$ (figura 30-b). As bandas localizadas em 345 e $384 \mathrm{~cm}^{-1}$ (figura 30-a) e em 332 e $354 \mathrm{~cm}^{-1}$ 
(figura 30-b) podem ser atribuídas aos estiramentos $\mathrm{Cu}$ N. No espectro da tpy adsorvida em Ag (figura 30-c), a banda intensa observada em $240 \mathrm{~cm}^{-1}$ é atribuída ao estiramento $\mathrm{Ag}-\mathrm{Cl}$ e as bandas em 354 e $383 \mathrm{~cm}^{-1}$ são atribuídas ao estiramento Ag-N.

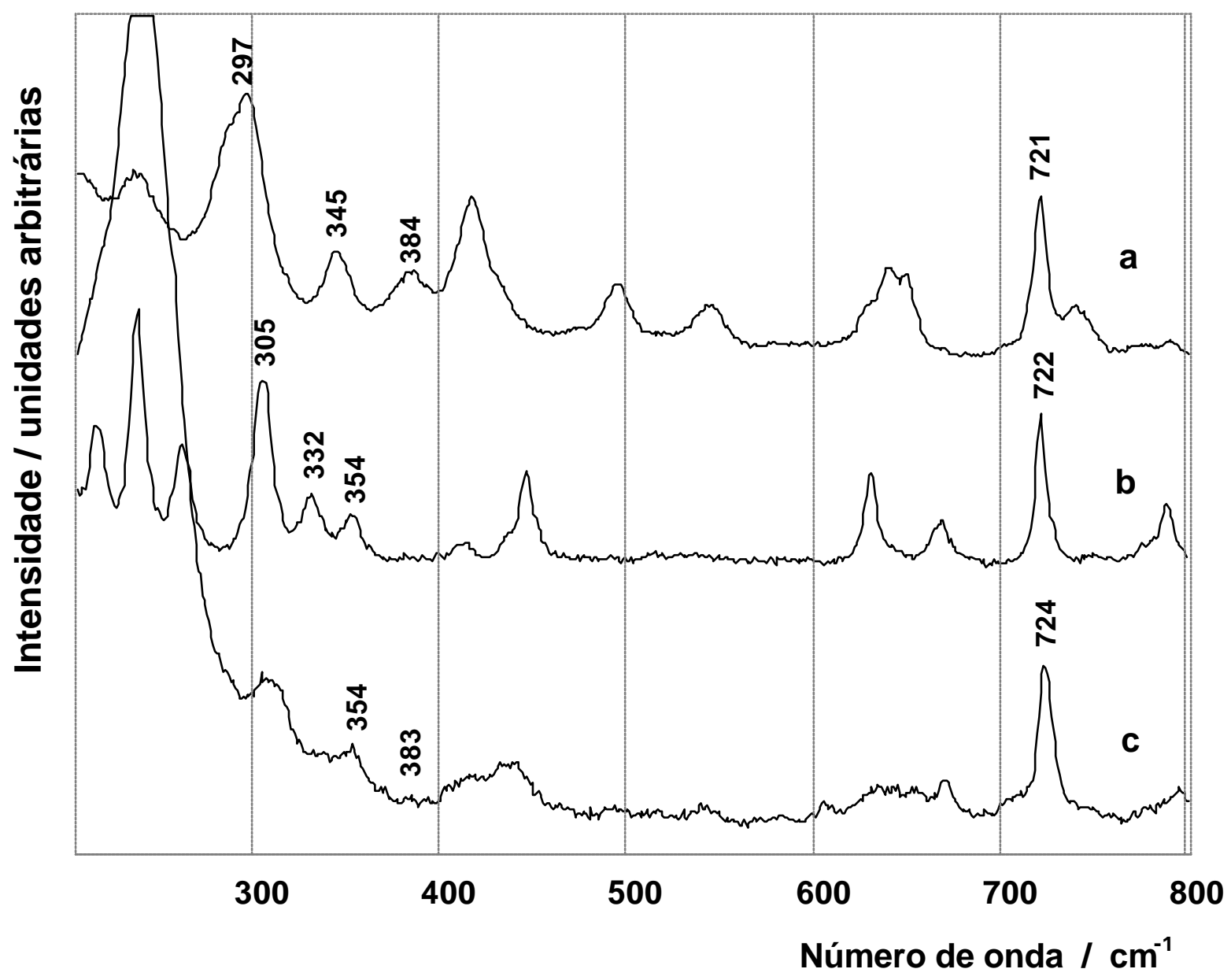

FIGURA 30: Espectros SERS in situ dos sistemas $\mathrm{Cu} / \mathrm{tpy}(\mathrm{aq}) / \mathrm{Cl} / \mathrm{pH}=6,0, \mathrm{~V}_{\mathrm{ap}}=-0,5 \mathrm{~V}$ (a), $\mathrm{Ag} / \mathrm{tpy}(\mathrm{aq}) / \mathrm{Cl}^{-} / \mathrm{pH}=6,0, \mathrm{~V}_{\text {ap }}=-0,2 \mathrm{~V}$ (c) e espectro Raman do complexo [Cu(II)tpyCl] $\mathrm{Cl}$ no estado sólido, $\lambda_{0}=632,8 \mathrm{~nm}$ (b). 


\section{4 - SERS EX SITU DA TPY-SH ADSORVIDA EM Ag}

É sabido que o composto 4'-(5-mercaptopentil)-2,2':6',2'-terpiridina (tpy-SH) adsorve sobre superfícies metálicas através do átomo de enxofre ${ }^{22}$, portanto o estudo deste composto por SERS trará, além de novos dados sobre a adsorção de um tiol, a possibilidade de comparar esses resultados com os da adsorção da tpy.

Na figura 31 são apresentados os espectros Raman da tpy e da tpy-SH no estado sólido.

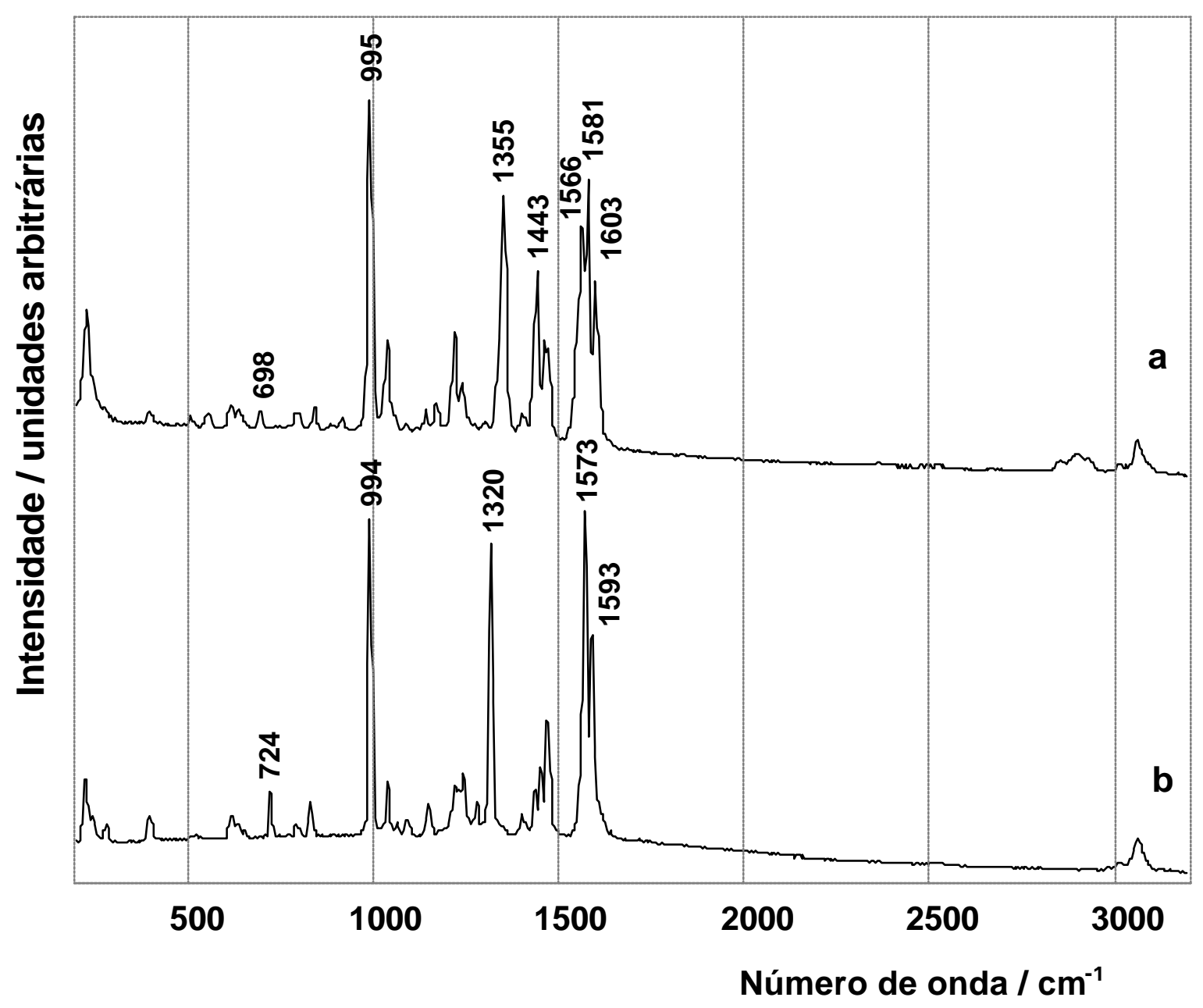

FIGURA 31: Espectros Raman da tpy-SH sólida (a) e da tpy sólida (b). $\lambda_{0}=.632,8 \mathrm{~nm}$. 
Comparando-se estes espectros observa-se o deslocamento de algumas freqüências, tais como: o estiramento C-C entre anéis de $1320 \mathrm{~cm}^{-1}$ (tpy) para 1355 $\mathrm{cm}^{-1}$ (tpy-SH) e a respiração trigonal dos anéis de $724 \mathrm{~cm}^{-1}$ (tpy) para $559 \mathrm{~cm}^{-1}$ (tpy$\mathrm{SH})$. A banda em $1573 \mathrm{~cm}^{-1}$, atribuída ao modo estiramento C-C dos anéis laterais e central da tpy (tabela 4), dá origem a duas bandas no espectro da tpy-SH, em 1566 e em $1581 \mathrm{~cm}^{-1}$. Bandas atribuídas aos modos vibracionais dos estiramentos $\mathrm{C}-\mathrm{H}$ da parte alifática da molécula de tpy-SH são observadas em 2851, 2900 e $2931 \mathrm{~cm}^{-1}$.

Observando-se os espectros anteriores na região entre 200 e $1700 \mathrm{~cm}^{-1}$ (figura 32) verificam-se mudanças nas intensidades relativas de algumas bandas nas regiões entre 1200 e $1300 \mathrm{~cm}^{-1}$ e entre 1400 e $1500 \mathrm{~cm}^{-1}$, porém, todas são bandas da parte tpy da molécula tpy-SH.

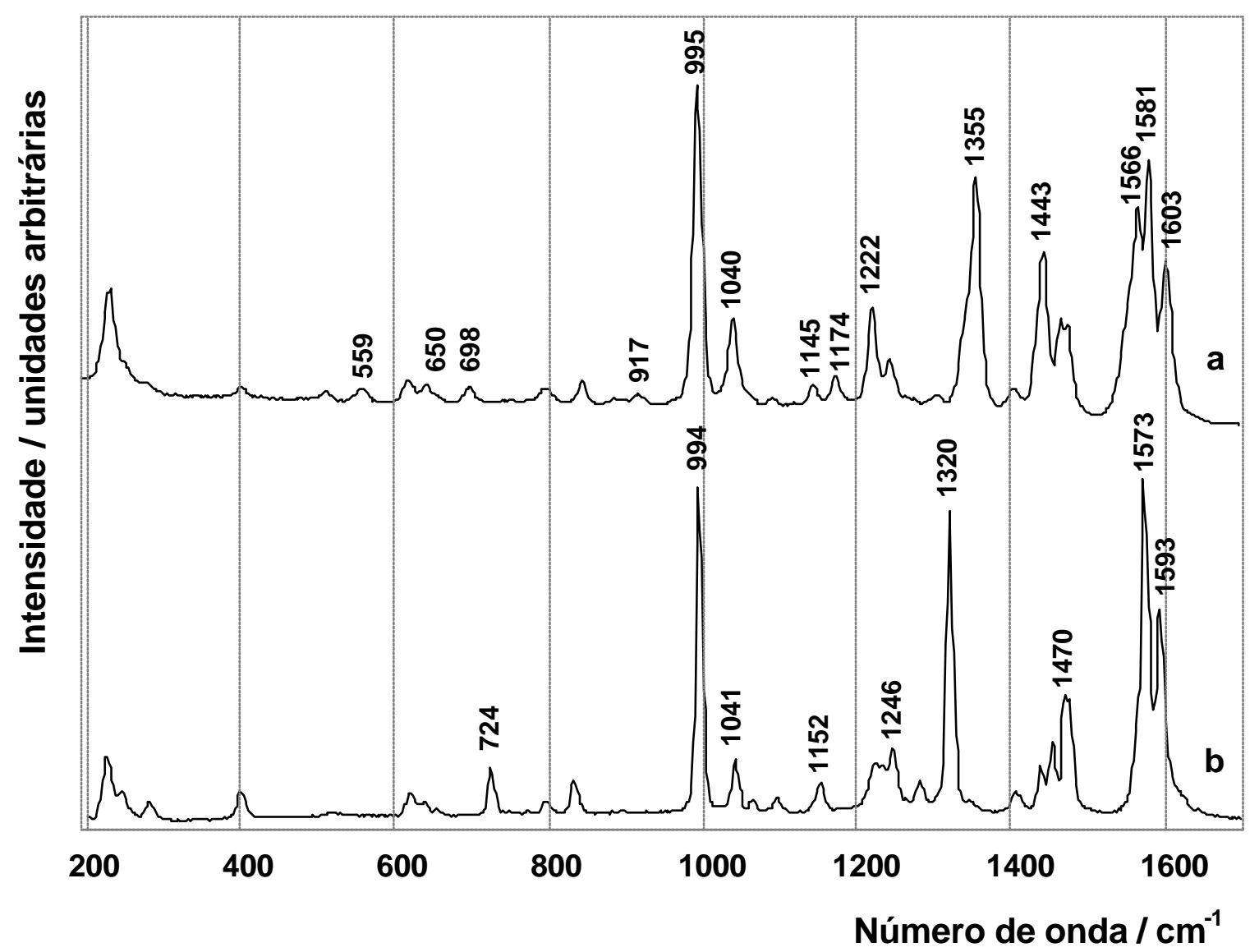

FIGURA 32: Espectros Raman da tpy-SH sólida (a) e da tpy sólida (b). $\lambda_{0}=632,8 \mathrm{~nm}$. 
No espectro da tpy-SH novas freqüências foram observadas e comparandose com o espectro da tpy foi feita a seguinte atribuição: a banda em $1152 \mathrm{~cm}^{-1}$ (tpy dois modos $\beta \mathrm{CH}$ ), deu origem às bandas em 1145 e $1174 \mathrm{~cm}^{-1}$ (tpy-SH), a banda em $962 \mathrm{~cm}^{-1}$ (tpy, ativa no infravermelho), deu origem à banda em $917 \mathrm{~cm}^{-1}$ e, por fim, no espectro da tpy-SH há duas novas bandas em 650 e $698 \mathrm{~cm}^{-1}$, atribuídas ao estiramento C-S dos confôrmeros gauche e trans, respectivamente (frequiências obtidas em estudos de tiois derivados ${ }^{23}, 24$ ). A banda do estiramento $\mathrm{S}-\mathrm{H}$ não foi observada.

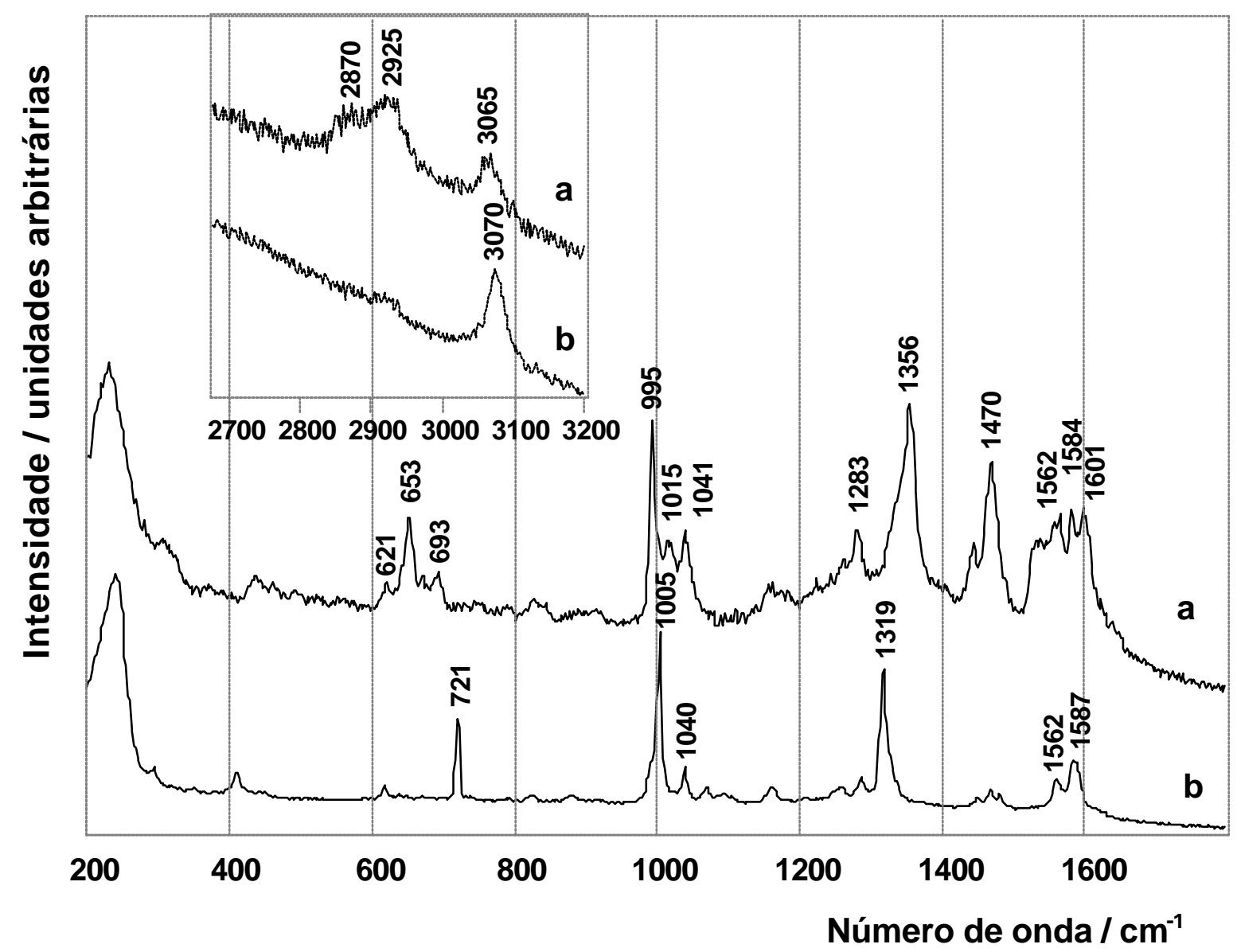

FIGURA 33: Espectros SERS ex situ dos sistemas Ag/tpy-SH/Cl, solução-mãe etanólica (a), e $\mathrm{Ag} / \mathrm{tpy} / \mathrm{Cl}$, solução-mãe etanólica (b). No destaque região espectral dos estiramentos $\mathrm{C}-\mathrm{H}$. 
O espectro SERS ex situ do composto tpy-SH adsorvido sobre eletrodo de $\mathrm{Ag}$ foi obtido na presença do ânion-suporte $\mathrm{Cl}$, em solução-mãe etanólica e está apresentado na figura 33, junto com o espectro da tpy adsorvida sobre Ag, obtido nas mesmas condições experimentais.

No espectro da tpy-SH adsorvida podem ser observadas intensificações das bandas atribuídas à parte alifática da espécie devido sua maior proximidade com a superfície (figura 34), tais como: a banda em $653 \mathrm{~cm}^{-1}$, atribuída ao estiramento C-S do confôrmero gauche, as bandas em 1015, 1023 e 1050 (ombro) $\mathrm{cm}^{-1}$, atribuídas aos estiramentos C-C, a banda em $1283 \mathrm{~cm}^{-1}$, atribuída ao wagging $\mathrm{CH}_{2}$ e as bandas em 2870 e $2925 \mathrm{~cm}^{-1}$, atribuídas aos estiramentos C-H. A banda em $310 \mathrm{~cm}^{-1}$ pode ser atribuída ao estiramento Ag- $\mathrm{S}^{25}$.

Outro resultado importante é a observação de uma única banda da respiração do anel da tpy em $995 \mathrm{~cm}^{-1}$, indicando que nessa geometria de adsorção não existe interação dos anéis piridínicos com a superfície. Este resultado reforça a afirmação anterior, em que na adsorção da tpy sobre Ag há interação da molécula com a superfície, com essa banda deslocando-se para freqüências maiores.

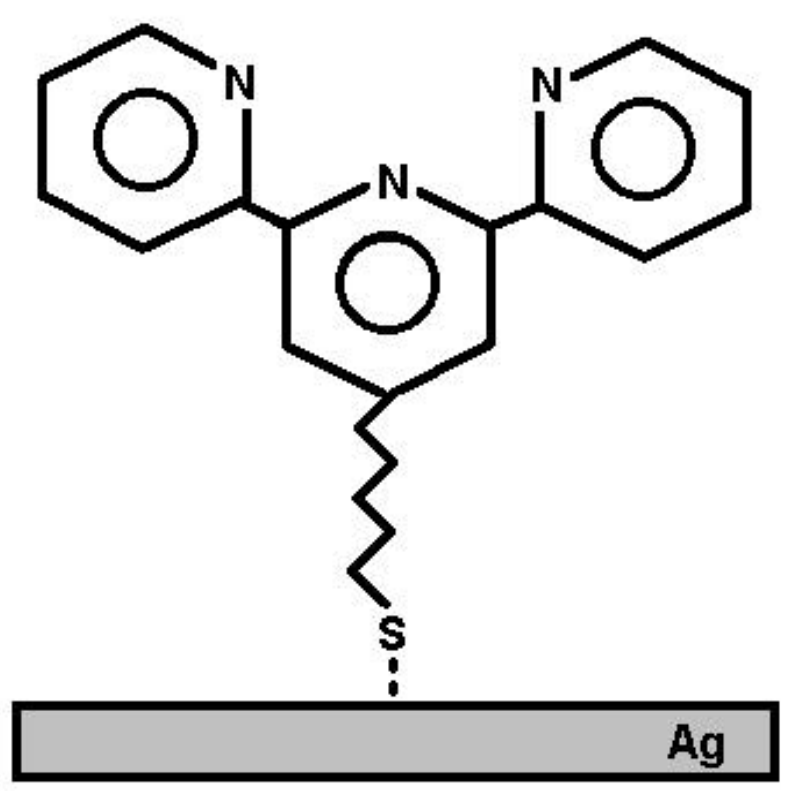

FIGURA 34: tpy-SH adsorvida sobre eletrodo de Ag. 
Um fato interessante a ser ressaltado é a intensificação seletiva de algumas bandas atribuídas a modos totalmente simétricos, tais como 721, 1005 e $1319 \mathrm{~cm}^{-1}$, observada no espectro da tpy adsorvida (comparar figuras 32-b e 33-b), enquanto que no espectro da tpy-SH adsorvida isto não ocorre (figura 33-a). Estas observações são explicadas pelo modelo químico de intensificação SERS, segundo o qual há intensificação das bandas cujos modos vibracionais correspondem aos sítios envolvidos na adsorção da molécula.

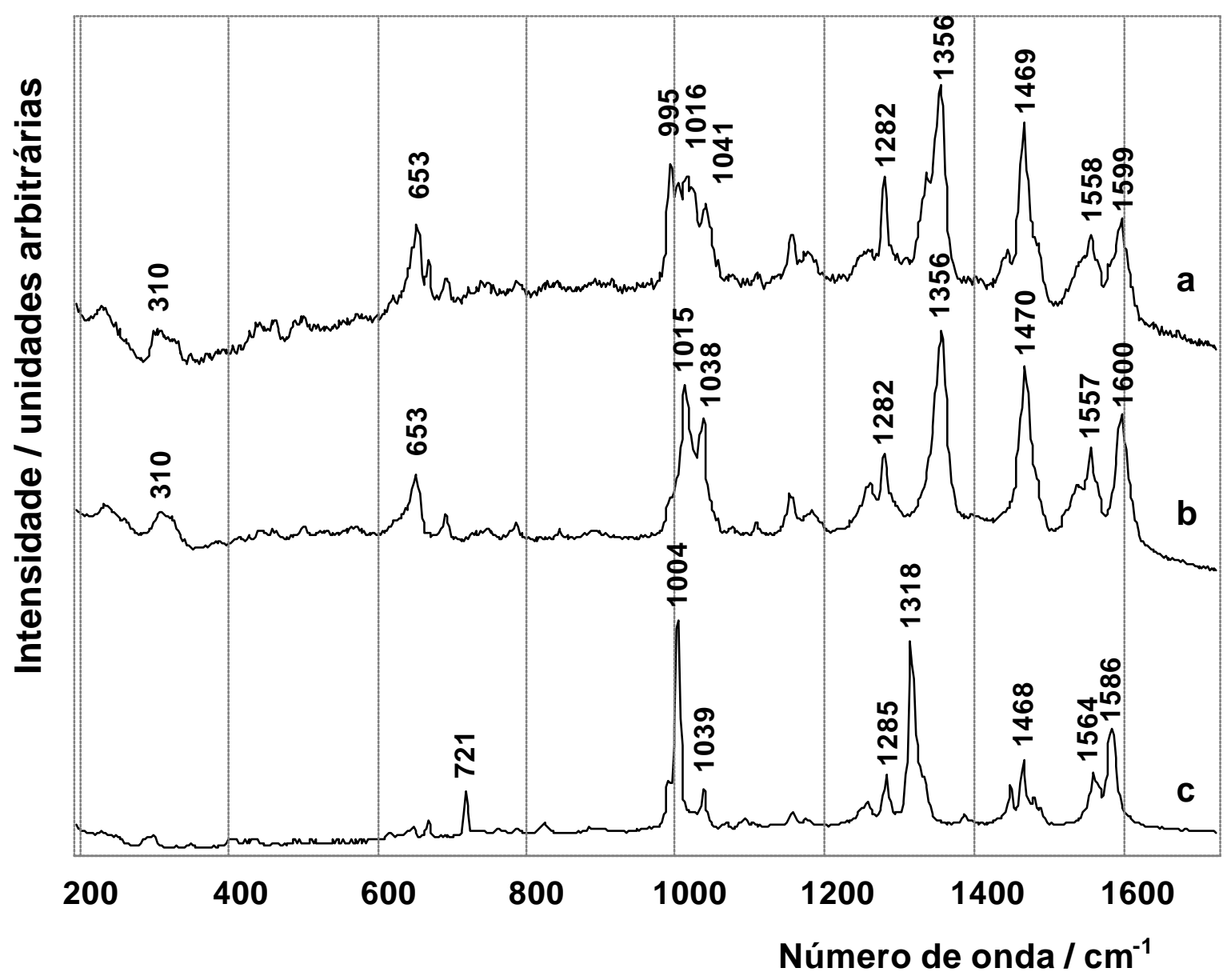

FIGURA 35: Espectros SERS ex situ dos sistemas Ag/tpy-SH/I', solução-mãe etanólica) (a), $\mathrm{Ag} / \mathrm{tpy}-\mathrm{SH}, \mathrm{Cu}^{2+} / \mathrm{I}^{-}, \mathrm{Br}^{-}$, solução-mãe etanólica (b) e Ag/tpy/I, solução-mãe aquosa, pH=6,0) (c). 
Na figura 35-a está apresentado o espectro SERS ex situ da tpy-SH adsorvida sobre Ag, obtido de solução-mãe etanólica onde se utilizou I' para verificar-se a influência do ânion-suporte na adsorção. Posteriormente, este eletrodo foi imerso em uma solução-mãe etanólica com $\mathrm{Cu}(\mathrm{II}) \mathrm{Br}_{2}$ e o espectro ex situ obtido é apresentado na figura 35-b.

Os espectros SERS da tpy-SH obtidos em I (figura 35-a) e em CI (figura 33-a) são semelhantes, estando presentes, em ambos, as bandas em: $310 \mathrm{~cm}^{-1}$ (estiramento Ag-S), $653 \mathrm{~cm}^{-1}$ (estiramento C-S gauche), 1004, 1016, 1024 e 1050 (ombro) $\mathrm{cm}^{-1}$ (estiramentos C-C alifático) e $1282 \mathrm{~cm}^{-1}$ (wagging $\mathrm{CH}_{2}$ ). Estas bandas, bem como a banda intensa em $995 \mathrm{~cm}^{-1}$ (respiração dos anéis piridínicos não comprometidos com uma ligação química), permitem afirmar que a adsorção da tpy-SH ocorre pelo átomo de enxofre. Isto difere do observado com a tpy adsorvida sobre eletrodo de Ag na presença de I (figura 35-c), onde a banda em $1004 \mathrm{~cm}^{-1}$ corresponde à respiração dos anéis piridínicos coordenados pelos nitrogênios aos átomos dos aglomerados metálicos superficiais.

No espectro da superfície do eletrodo com a tpy-SH adsorvida, após imersão deste em solução de $\mathrm{Cu}(\mathrm{II}) \mathrm{Br}_{2}$ (figura 35-b), pode ser observado o deslocamento da banda atribuída à respiração dos anéis piridínicos para $1015 \mathrm{~cm}^{-1}$. Isto indica que houve a coordenação da parte tpy com o $\mathrm{Cu}(\mathrm{II})$ através dos seus átomos de nitrogênio e, portanto, no adsorbato a parte tpy está voltada para a solução. Não há grandes alterações nas intensidades relativas e nas freqüências das demais bandas após esta coordenação, o que indica que as moléculas de tpy-SH continuam adsorvidas à superfície metálica pelo átomo de enxofre.

O procedimento descrito acima é usado na literatura para a construção de dispositivos moleculares utilizando-se a tpy- $\mathrm{SH}^{22}$. Portanto, pode-se concluir que a técnica SERS é uma ferramenta que poderá ser útil na caracterização destes dispositivos. 


\section{5 - SERS EX SITU DA TPY E MPY COADSORVIDAS EM Ag}

A adsorção simples da 2-mercaptopirimidina (mpy) e da tpy sobre superfícies de $\mathrm{Au}$, bem como a competição pela superfície entre estas espécies, foram estudadas pela técnica STM (scanning tunneling microscopy) por L. S. Pinheiro e M. L. A. Temperini ${ }^{26,27}$. Neste estudo observou-se que a tpy adsorve em uma posição próxima da vertical quando sozinha na superfície metálica e próxima à horizontal quando na presença da mpy. Com o objetivo de verificar se estas observações poderiam ser corroboradas pela técnica Raman intensificada pela superfície foram realizados experimentos SERS ex situ com os compostos adsorvidos sobre eletrodo de Ag.

Inicialmente, foram obtidos o espectro Raman da mpy no estado sólido e o espectro SERS ex situ da mpy adsorvida na superfície do eletrodo de Ag, utilizandose $\mathrm{Cl}^{-}$como ânion-suporte (figura 36). Como soluções-mãe foram utilizadas soluções etanólica e aquosa em pH 1,8 para que as mesmas condições experimentais pudessem ser utilizadas, posteriormente, com a tpy, já que esta é pouco solúvel em solução aquosa com pH neutro.

Os padrões espectrais da mpy no estado sólido e adsorvida na superfície de $\mathrm{Ag}$ são diferentes, indicando variação da espécie com a adsorção. Isto está em concordância com trabalho anterior de Y. S. Pang e col. ${ }^{18}$. O solvente e o pH não causam variação na natureza do adsorbato, pois em soluções-mãe etanólica ou aquosa em $\mathrm{pH}$ 1,8 predomina a mesma espécie sobre o eletrodo. 


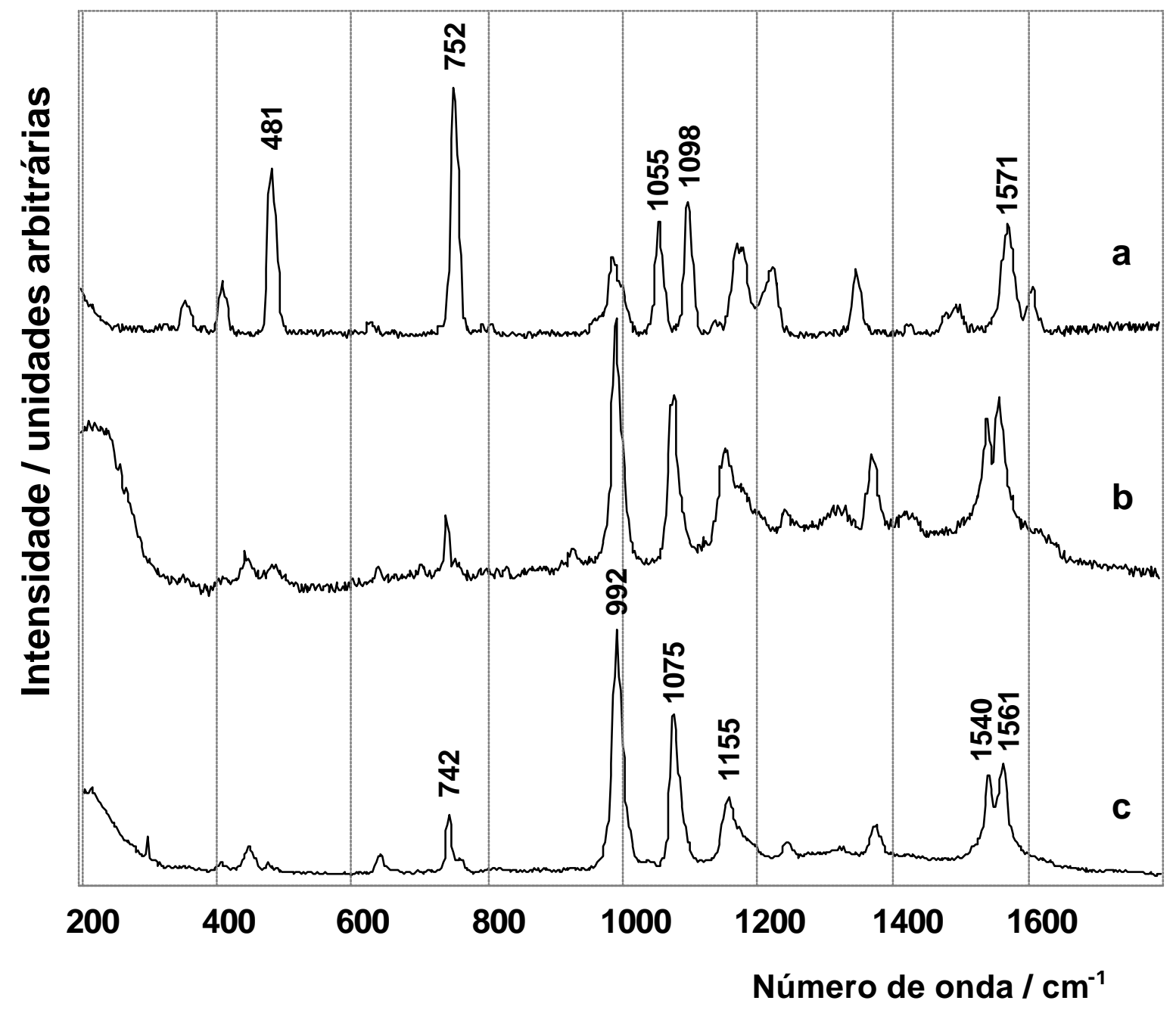

FIGURA 36: Espectros Raman da mpy no estado sólido (a) e SERS ex situ dos sistemas $\mathrm{Ag} / \mathrm{mpy} / \mathrm{Cl}$ em solução-mãe aquosa, $\mathrm{pH}=1,8$ (b) e $\mathrm{Ag} / \mathrm{mpy} / \mathrm{Cl}$ solução-mãe etanólica, (c). $\lambda_{0}=632,8 \mathrm{~nm}$.

Os espectros obtidos dos experimentos SERS ex situ em que foi estudada a coadsorção da tpy e da mpy em solução-mãe aquosa, com pH=1,8 e utilizando-se $\mathrm{Cl}$ como ânion-suporte, são apresentados na figura 37, juntamente com os espectros da mpy e da tpy adsorvidas sozinhas em eletrodo de Ag, nas mesmas condições experimentais, e o espectro da tpy no estado sólido. 


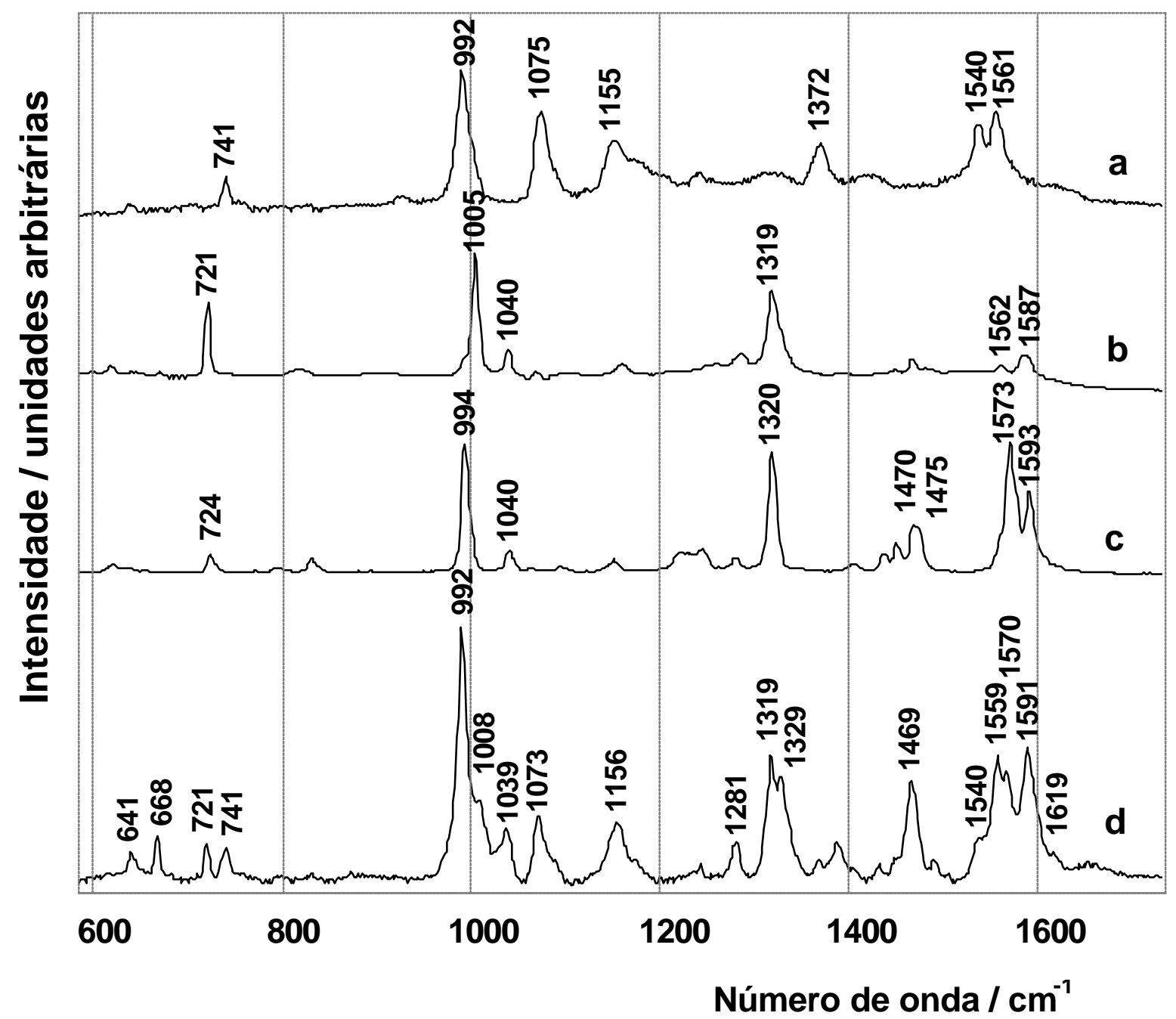

FIGURA 37: Espectros SERS ex situ dos sistemas $\mathrm{Ag} / \mathrm{mpy} / \mathrm{Cl}$ (a), $\mathrm{Ag} / \mathrm{tpy} / \mathrm{Cl}^{-}$(b) e $\mathrm{Ag} / \mathrm{tpy}, \mathrm{mpy} / \mathrm{Cl}^{-}$(d), utilizando-se em todos solução-mãe aquosa em $\mathrm{pH}=1,8$. Espectro Raman da tpy no estado sólido (c). $\lambda_{0}=632,8 \mathrm{~nm}$.

As bandas da mpy em 741, 992, 1075, 1155 e $1540 \mathrm{~cm}^{-1}$ estão presentes nos espectros da sua adsorção sozinha (figura 37-a) e da sua adsorção com a tpy (figura 37-d), indicando que, em ambos, a mesma espécie está presente na superfície.

No espectro em que a tpy coadsorve na presença da mpy pode-se verificar uma mudança nas intensidades relativas das bandas da mpy em 992 e $1075 \mathrm{~cm}^{-1}$, estando a primeira muito mais intensa devido à contribuição da banda da tpy em 994 
$\mathrm{cm}^{-1}$. Isto indica que a tpy está presente na superfície do eletrodo como uma espécie diferente da observada em sua adsorção simples (figura 37-b), onde a banda da respiração dos anéis piridínicos está deslocada para $1005 \mathrm{~cm}^{-1}$. Outras bandas da tpy presentes na coadsorção, tais como, 721 (pouco intensa), 1319, 1469 (larga) e 1591 $\mathrm{cm}^{-1}$ apresentam intensidades relativas mais próximas do observado no espectro da tpy no estado sólido. A observação destas bandas indica que a tpy está adsorvida pelos elétrons $\pi$ dos anéis piridínicos em uma posição próxima à horizontal, com os átomos de nitrogênio não coordenados ao metal. Isto é corroborado pela presença das bandas em 641, 668 e $1281 \mathrm{~cm}^{-1}$ atribuídas à tpy adsorvida próxima à posição horizontal, que também são observadas nos espectros SERS in situ da tpy em potenciais mais negativos (figuras 18-f e 19-e).

A presença das bandas em 1008 (ombro), 1329 e $1619 \mathrm{~cm}^{-1}$ indica que a tpy protonada está presente na superfície do eletrodo, fato associado à não coordenação dos nitrogênios dos anéis piridínicos com o metal. Isto não ocorre na adsorção simples da tpy, quando são observadas sua desprotonação e coordenação ao metal (figura 37-b).

Os espectros obtidos dos experimentos SERS ex situ em que foi estudada a coadsorção da tpy e da mpy em superfície de Ag, com solução-mãe etanólica, utilizando-se $\mathrm{Cl}^{-}$como ânion-suporte, são apresentados na figura 38.

Estes resultados são semelhantes aos obtidos com solução-mãe aquosa em pH=1,8, com exceção das bandas em 1008, 1329 e $1619 \mathrm{~cm}^{-1}$, atribuídas à tpy protonada adsorvida na superfície. As bandas da tpy, observadas em 721 e 1040 $\mathrm{cm}^{-1}$ no espectro da tpy coadsorvida com a mpy (figura 38-d), mantêm a mesma relação de intensidades observada no espectro da tpy no estado sólido (figura 38-c), porém, muito diferente da observada no espectro da adsorção simples da tpy (figura 38-b), indicando que a adsorção da tpy na presença da mpy ocorre de modo diferente. 


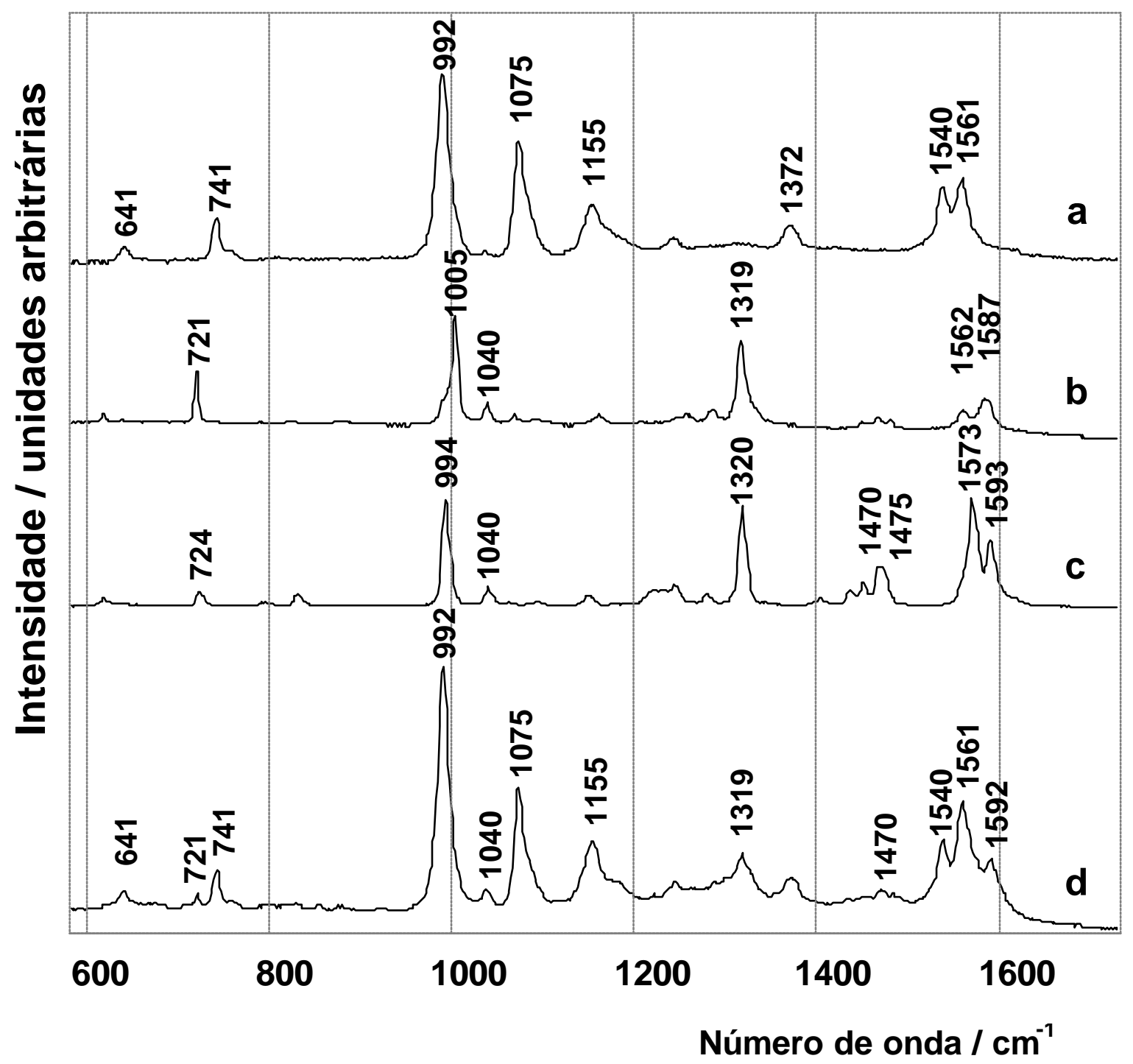

FIGURA 38: Espectros SERS ex situ dos sistemas Ag/mpy/Cl (a), Ag/tpy/Cl- (b) e $\mathrm{Ag} / \mathrm{tpy}, \mathrm{mpy} / \mathrm{Cl}^{-}$(d), utilizando-se em todos solução-mãe etanólica. Espectro Raman da tpy no estado sólido (c). $\lambda_{0}=632,8 \mathrm{~nm}$.

A mudança nas intensidades relativa das bandas da mpy em 992 e 1075 $\mathrm{cm}^{-1}$ nos espectros de sua adsorção simples (figura 38-a) e quando coadsorvida com a tpy (figura 38-d), mostra que há contribuição da banda da tpy em $994 \mathrm{~cm}^{-1}$. Estes fatos indicam que a tpy coadsorve com a mpy sobre a superfície metálica através 
dos elétrons $\pi$ dos anéis piridínicos em uma posição mais próxima da horizontal, não coordenando ao metal pelos nitrogênios.

Comparando-se nestes mesmos espectros as intensidades relativas das bandas da mpy em 1540 e $1561 \mathrm{~cm}^{-1}$ esta conclusão é endossada. A intensificação da banda em $1561 \mathrm{~cm}^{-1}$ no espectro das espécies coadsorvidas (figura 38-d) pode ser explicada pela sobreposição da banda da tpy em $1573 \mathrm{~cm}^{-1}$, sendo esta hipótese confirmada pela presença da banda da tpy em $1592 \mathrm{~cm}^{-1}$.

Embora as bandas Raman da mpy e da tpy sejam muito próximas, é possível, dos experimentos SERS com a adsorção simultânea e separada dessas espécies, concluir que a adsorção da tpy na presença da mpy ocorre com a molécula paralela à superfície do eletrodo. Para este sistema a técnica STM leva a resultados mais evidentes que a técnica SERS. 


\section{6 - ESTUDO DO COMPLEXO [Cu(II)tpy $\left.\mathrm{H}_{2} \mathrm{OClO}_{4}\right] \mathrm{ClO}_{4}$}

$\mathrm{O}$ complexo $\left[\mathrm{Cu}(\mathrm{II}) \mathrm{tpyH}_{2} \mathrm{OClO}_{4}\right] \mathrm{ClO}_{4}$ apresenta um comportamento espectral diferente dos demais compostos estudados nesta dissertação. Por este motivo este composto foi estudado mais detalhadamente e os resultados deste estudo estão relatados nesta seção.

\subsection{1 - ESTRUTURA DO COMPLEXO $\left[\mathrm{Cu}(\mathrm{II}) \mathrm{tpyH}_{2} \mathrm{OClO}_{4}\right]_{\mathrm{ClO}}$}

Os espectros Raman e infravermelho deste complexo são apresentados na figura 39. No espectro infravermelho, a banda larga observada em $1100 \mathrm{~cm}^{-1}$ é característica do ânion $\mathrm{ClO}_{4}^{-}$não coordenado ao metal ${ }^{13}$. Admitindo-se que o íon $\mathrm{Cu}^{2+}$ possua, além da tpy coordenada tridentada, uma água coordenada cuja presença é sugerida pela análise elementar, existem duas possibilidades para o número de coordenação (NC) deste íon: $\mathrm{NC}=4$, caso os dois ânion $\mathrm{ClO}_{4}^{-}$não estejam coordenados ao $\mathrm{Cu}^{2+}$, ou $\mathrm{NC}=5$, caso um ânion $\mathrm{ClO}_{4}{ }^{-}$esteja coordenado ao íon $\mathrm{Cu}^{2+}$ através de um átomo de oxigênio. A banda larga em $932 \mathrm{~cm}^{-1}$, observada no espectro Raman deste complexo, pode ser atribuída tanto ao $\mathrm{ClO}_{4}{ }^{-}$coordenado monodentado ao $\mathrm{Cu}^{2+}\left(\mathrm{C}_{3 \mathrm{~V}}\right)$, quanto ao $\mathrm{ClO}_{4}{ }^{-}$livre $\left(\mathrm{T}_{\mathrm{d}}\right)$ (figuras 12 e tabela 6).

Como discutido no estudo dos padrões para a caracterização da adsorção da tpy, a banda da respiração do anel piridínico varia de freqüência em função da natureza do outro ligante coordenado ao metal. Portanto, a banda Raman em 1045 $\mathrm{cm}^{-1}$ é atribuída à respiração dos anéis piridínicos cujos átomos de nitrogênio estão fortemente coordenados ao $\mathrm{Cu}^{2+}$ e a banda em $1011 \mathrm{~cm}^{-1}$ é atribuída à respiração de outro anel piridínico cuja interação com o $\mathrm{Cu}^{2+}$ é menos intensa. Este anel é, provavelmente, o central que deve estar mais distante do íon metálico devido à geometria da tpy complexada. 


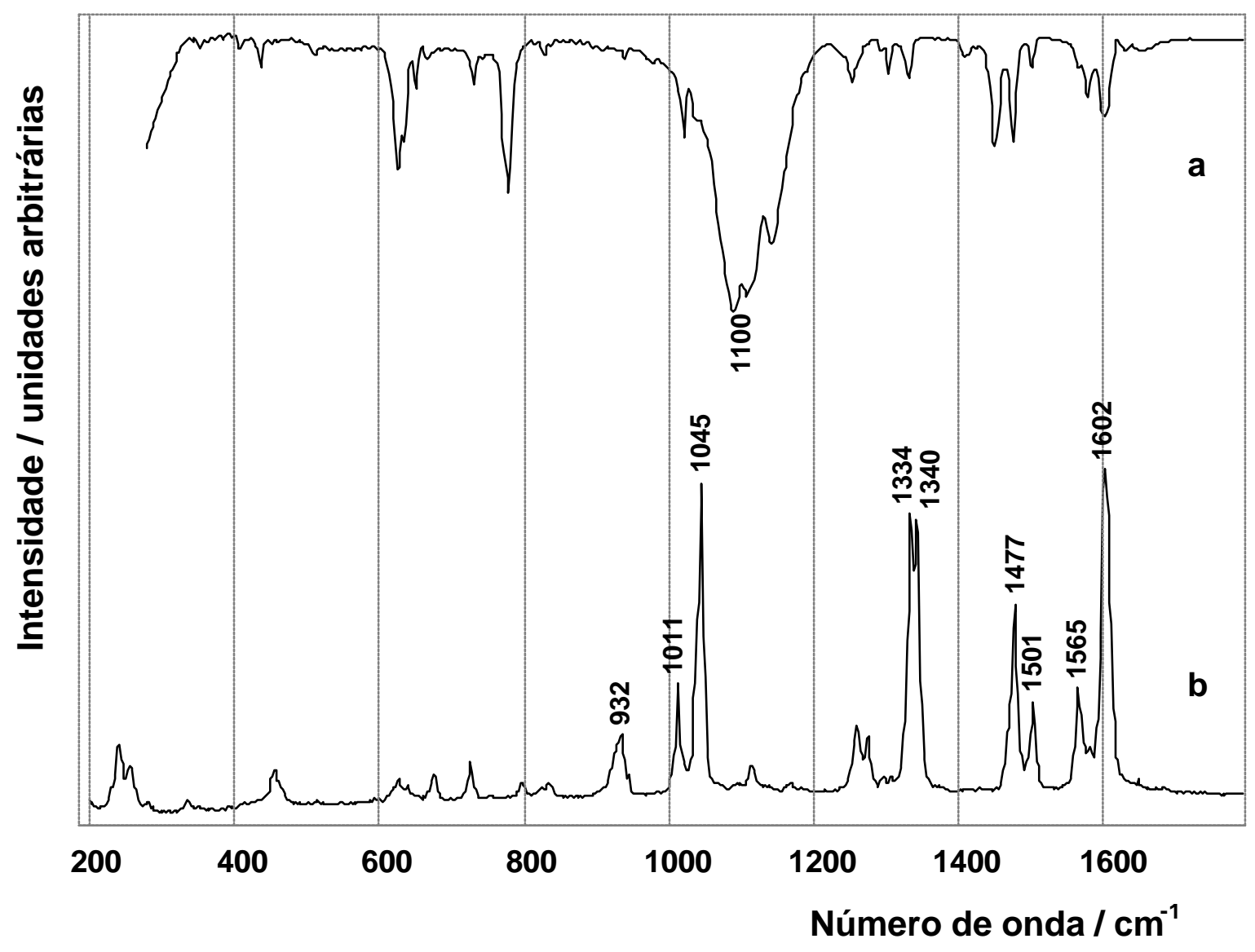

FIGURA 39: Espectros infravermelho (em pastilha de $\mathrm{KBr}$ ) (a) e Raman, $\lambda_{0}=632,8 \mathrm{~nm}$ (b) do complexo $\left[\mathrm{Cu}(\mathrm{II}) \mathrm{tpyH}_{2} \mathrm{OClO}_{4}\right] \mathrm{ClO}_{4}$ no estado sólido.

$\mathrm{Na}$ obtenção dos espectros Raman deste complexo foram observadas alterações no padrão espectral com a potência e o tempo de exposição à radiação excitante. Com o uso de baixa potência do laser (da ordem de $3 \mathrm{~mW}$ ), esta variação foi minimizada. A evolução do espectro Raman com a exposição ao laser é apresentada na figura 40 .

Algumas alterações espectrais são observadas, tais como, as bandas em 1334, 1340 e $1602 \mathrm{~cm}^{-1}$ que apresentam sensível deslocamento para 1325, 1330 (ombro) e $1592 \mathrm{~cm}^{-1}$, respectivamente. 


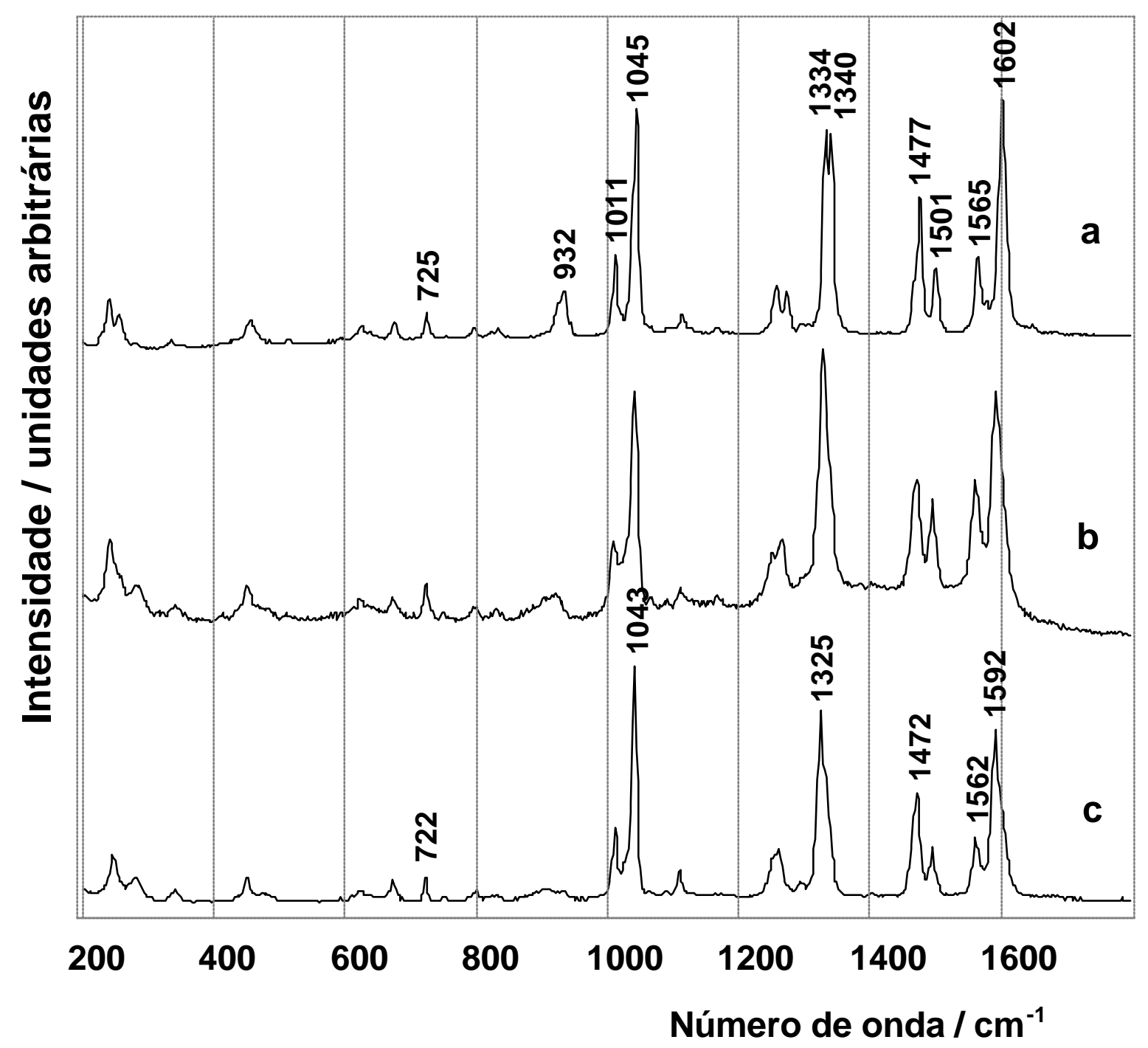

FIGURA 40: Evolução dos espectros Raman do complexo $\left[\mathrm{Cu}(\mathrm{II}) \mathrm{tpyH}_{2} \mathrm{OClO}_{4}\right] \mathrm{ClO}_{4}$ com a potência do laser: $3 \mathrm{~mW}$ (a), $8 \mathrm{~mW}$ (b) e $30 \mathrm{~mW}$ (c). $\lambda_{0}=632,8 \mathrm{~nm}$

Simultaneamente a essas variações nas bandas da porção tpy ocorrem mudanças no padrão espectral das bandas atribuídas ao ânion $\mathrm{ClO}_{4}^{-}$, na região do espectro entre 300 e $1000 \mathrm{~cm}^{-1}$ (figura 41). Utilizando-se os resultados do estudo anterior (figura 12 e tabela 6), no qual a perda da degenerescência dos modos vibracionais ocorre progressivamente com a mudança de simetria do ânion $\mathrm{ClO}_{4}{ }^{-}$, pode-se afirmar que as alterações observadas, tais como o deslocamento da banda 
em $932 \mathrm{~cm}^{-1}$ para $906 \mathrm{~cm}^{-1}$ e a perda de degenerescência da banda em $457 \mathrm{~cm}^{-1}$, onde aparecem três bandas em 419, 452 e $479 \mathrm{~cm}^{-1}$, caracterizam o surgimento do ânion $\mathrm{ClO}_{4}{ }^{-}$coordenado por dois átomos de oxigênio ao $\mathrm{Cu}^{2+}$. A banda em $930 \mathrm{~cm}^{-1}$ pode ser atribuída ao ânion $\mathrm{ClO}_{4}{ }^{-}$como contra-íon.

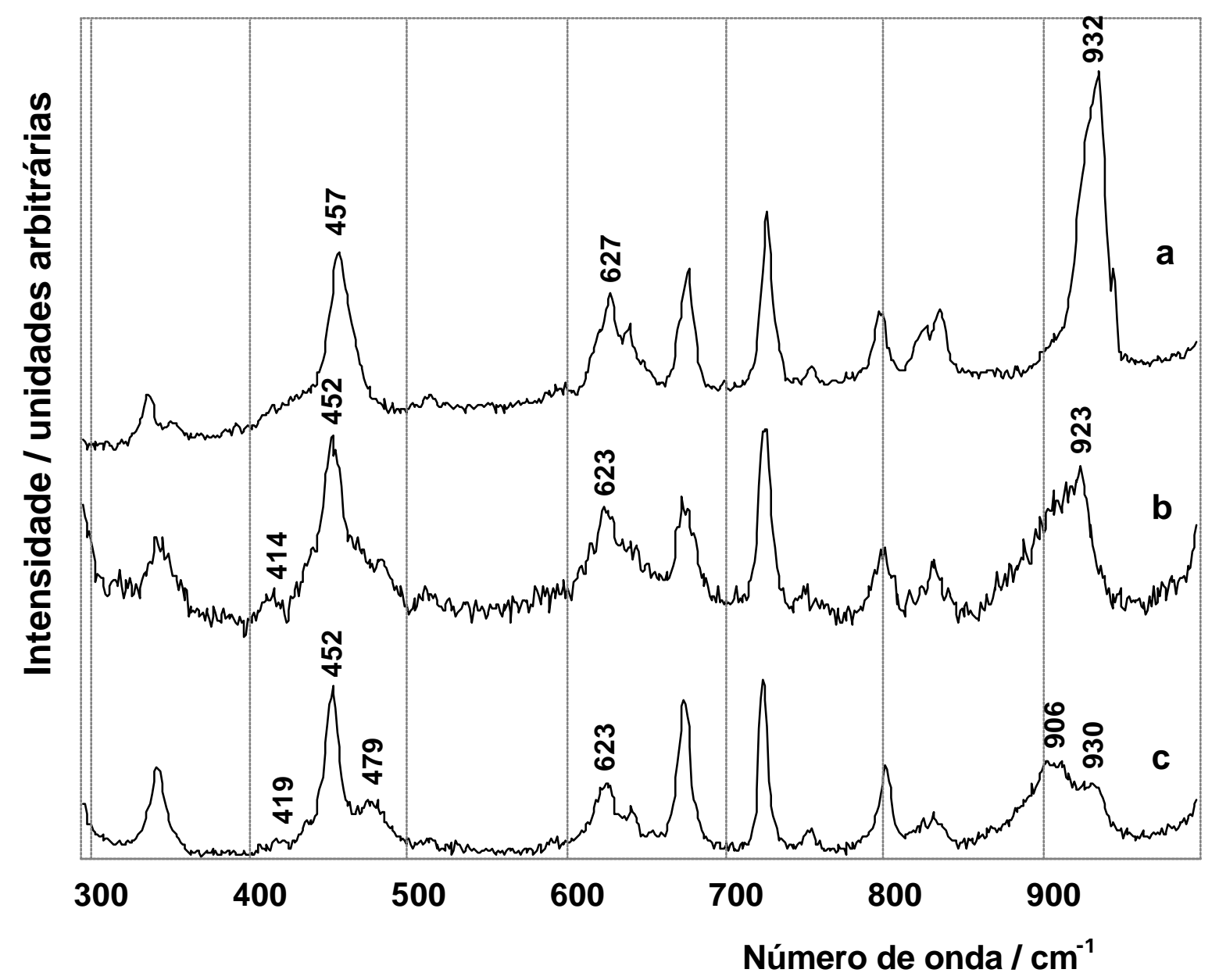

FIGURA 41: Evolução dos espectros Raman do complexo $\left[\mathrm{Cu}(\mathrm{II}) \mathrm{tpyH}_{2} \mathrm{OClO}_{4}\right] \mathrm{ClO}_{4}$ com a potência do laser: $3 \mathrm{~mW}$ (a), $8 \mathrm{~mW}$ (b) e $30 \mathrm{~mW}$ (c). $\lambda_{0}=632,8 \mathrm{~nm}$

Pelos resultados obtidos pode-se concluir que no início o complexo possui o íon $\mathrm{Cu}^{2+}$ com número de coordenação 5, sendo a segunda hipótese proposta para a estrutura do complexo a mais viável: a tpy coordenada tridentada, a água coordenada pelo oxigênio e um ânion $\mathrm{ClO}_{4}{ }^{-}$coordenado por apenas um átomo de oxigênio. Com a incidência do laser há geração de calor e a coordenação da água ao 
íon metálico é desfeita, passando o $\mathrm{ClO}_{4}{ }^{-}$a coordenar ao $\mathrm{Cu}^{2+}$ através de dois átomos de oxigênio,mantendo-se o número de coordenação do íon metálico.

\subsection{2 - PERFIL DE EXCITAÇÃO DO [Cu(II)tpyH $\left.\mathrm{OClO}_{4}\right] \mathrm{ClO}_{4}$}

Foi levantado o perfil de excitação deste complexo para constatar-se a magnitude do efeito Raman ressonante, pois considerou-se que a intensidade relativa da banda em $1045 \mathrm{~cm}^{-1}$, atribuída ao modo de respiração do anel da tpy, estava fora dos padrões dos outros complexos utilizados. O composto possui cor azul e seu espectro eletrônico é apresentado na figura 42.

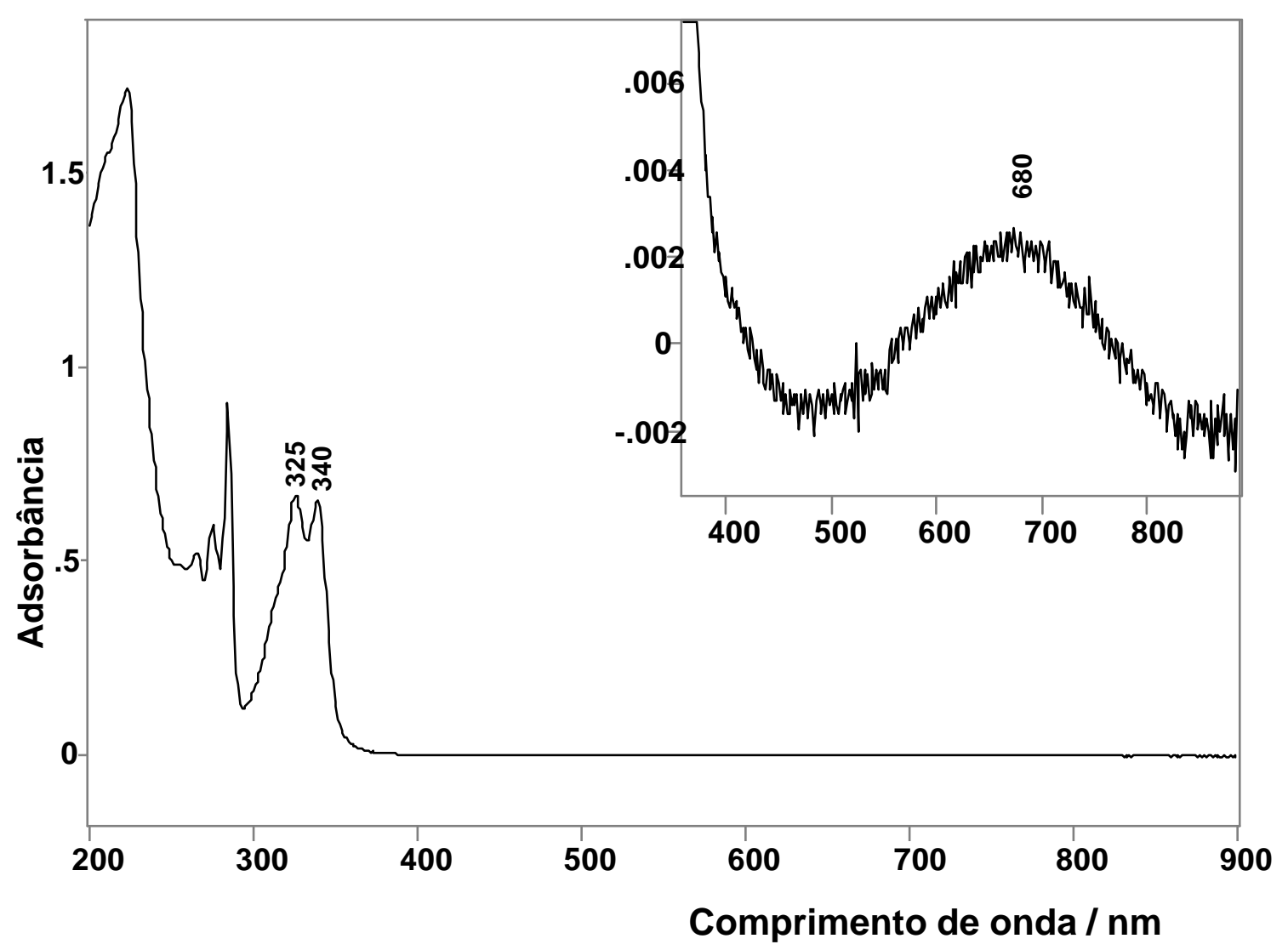

FIGURA 42: Espectro eletrônico do complexo $\left[\mathrm{Cu}(\mathrm{II}) \mathrm{tpyH}_{2} \mathrm{OClO}_{4}\right] \mathrm{ClO}_{4}$ em solução aquosa $1 \mathrm{mM}$ contendo $\mathrm{NaClO}_{4} 0,1 \mathrm{M}$. Cela de $10 \mathrm{~mm}$. No destaque, região do visível ampliada onde está presente uma banda de transição interna do $\mathrm{Cu}(\mathrm{d}-\mathrm{d})$ com máximo no vermelho. 
Os espectros Raman deste complexo, obtidos em diferentes radiações excitantes, são apresentados na figura 43.

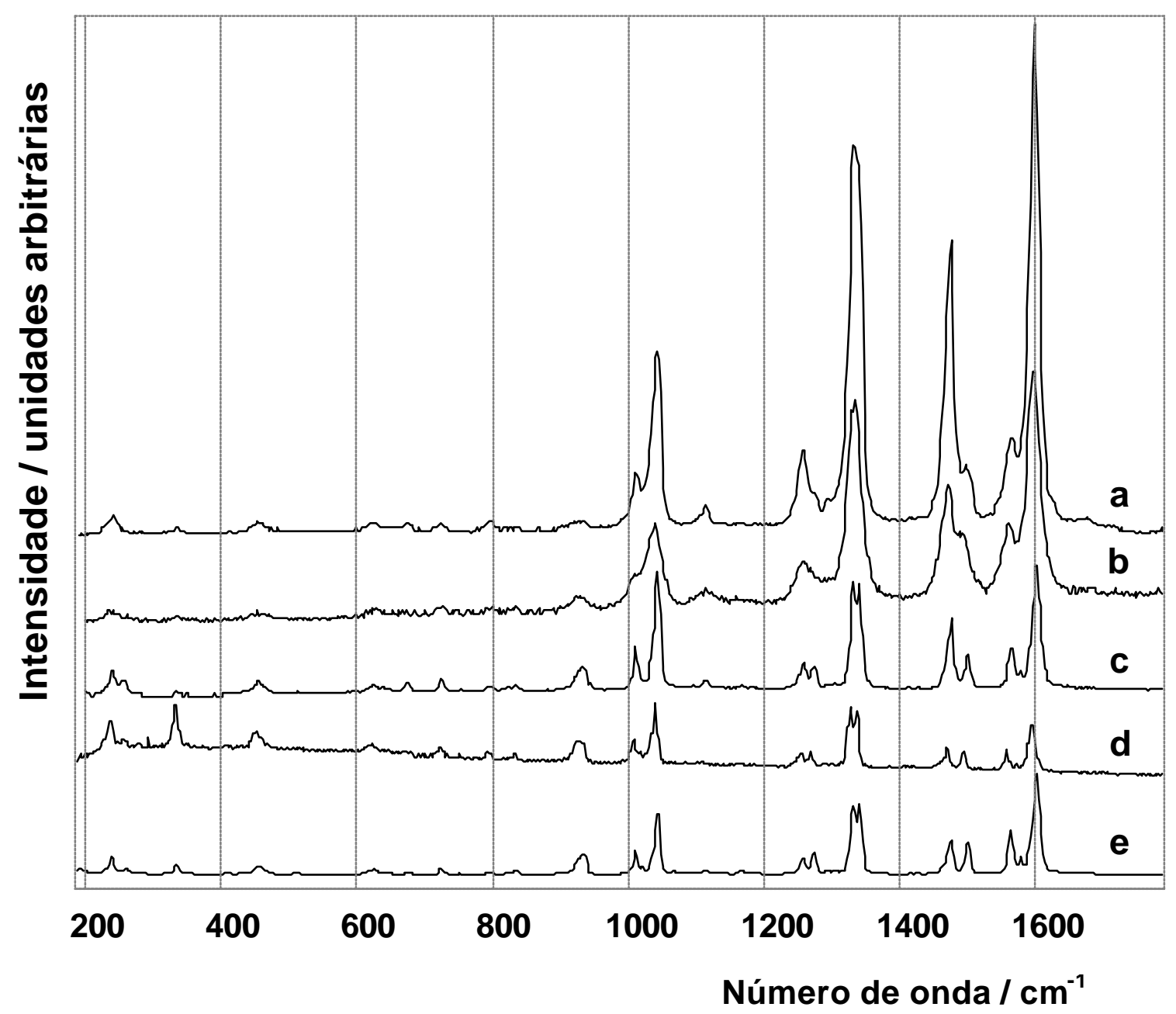

FIGURA 43: Espectros Raman do complexo $\left[\mathrm{Cu}(\mathrm{II}) \operatorname{tpyH}_{2} \mathrm{OClO}_{4}\right] \mathrm{ClO}_{4}$ no estado sólido com uso de cela rotatória e em diferentes radiações excitantes: $488 \mathrm{~nm}$ (a), 514,5 nm (b), 632,8 nm (c), $782 \mathrm{~nm}$ (d) e $1064 \mathrm{~nm}$ (e).

As alterações mais bruscas observadas na região de $1600 \mathrm{~cm}^{-1}$ no espectro Raman, para a radiação excitante 782 nm, são devidas à queda de eficiência no detector do espectrômetro nestas freqüências. O uso do naftaleno dissolvido em 
acetonitrila foi utilizado como padrão e permitiu que fossem efetuadas as correções nas intensidades relativas nesta região do espectro para esta radiação excitante.

Para efetuar-se uma melhor análise das alterações espectrais obtidas pela variação da radiação excitante foi montada a tabela abaixo com as intensidades relativas das principais bandas dos espectros, tomando-se a intensidade da banda em $932 \mathrm{~cm}^{-1}$, atribuída ao ânion $\mathrm{ClO}_{4}^{-}$, como padrão interno.

TABELA 7: Intensidades relativas das bandas dos espectros do complexo $\left[\mathrm{Cu}(\mathrm{II}) \mathrm{tpyH}_{2} \mathrm{OClO}_{4}\right] \mathrm{ClO}_{4}$ em diferentes radiações excitantes. banda em $932 \mathrm{~cm}^{-1}=1$.

\begin{tabular}{|c|c|c|c|c|c|}
\hline $\mathrm{n}^{\mathbf{0}}$ onda $/ \mathrm{cm}^{-1}$ & $\lambda_{0}=488 \mathrm{~nm}$ & $\lambda_{0}=514,5 \mathrm{~nm}$ & $\lambda_{0}=632,8 \mathrm{~nm}$ & $\lambda_{0}=782 \mathrm{~nm}$ & $\lambda_{0}=1064 \mathrm{~nm}$ \\
\hline 725 & 1 & 0,5 & 0,5 & 0,5 & 0,3 \\
\hline 1012 & 5 & 2 & 2 & 1 & 1 \\
\hline 1044 & 17 & 6 & 4 & 3 & 3 \\
\hline 1258 & 7 & 3 & 1 & 1 & 1 \\
\hline 1272 & 3 & 2 & 1 & 1 & 1 \\
\hline 1330 & 35 & 13 & 5 & 4 & 3 \\
\hline 1340 & 34 & 13 & 5 & 4 & 3 \\
\hline 1475 & 27 & 7 & 3 & 2 & 2 \\
\hline 1500 & 5 & 4 & 1 & 1 & 2 \\
\hline 1565 & 8 & 5 & 2 & 2 & 2 \\
\hline 1600 & 48 & 15 & 5 & 4 & 5 \\
\hline
\end{tabular}

Pode-se observar que todas as bandas do espectro aumentam de intensidade quando o comprimento de onda da radiação excitante utilizada é deslocado para o azul. Esta intensificação é causada pelo efeito Raman pré-ressonante com as bandas em 325 ou $340 \mathrm{~nm}$ (figura 42). A seletividade do efeito pode ser observada pelas diferentes intensificações observadas para cada modo vibracional. Como exemplo, as intensificações observadas ao utilizar-se radiações excitantes no vermelho e no 
azul para as bandas em 1330, 1340, 1475 e $1600 \mathrm{~cm}^{-1}$ foram de 10 a 13 vezes e estes fatores são muito maiores do que os observados para as demais bandas.

Este estudo mostra que a banda da transição eletrônica do complexo, com máximo em $680 \mathrm{~nm}$, não possui intensidade suficiente para que ocorra o efeito Raman ressonante, porém, em razão dela o composto possui coloração azulada.

\subsection{3 - SERS EX SITU E IN SITU DO [Cu(II)tpyH $\left.\mathrm{OClO}_{4}\right]_{\mathrm{ClO}_{4}}$}

Espectros SERS ex situ do complexo $\left.\mathrm{Cu}(\mathrm{II}) \mathrm{tpyH}_{2} \mathrm{OClO}_{4}\right] \mathrm{ClO}_{4}$ adsorvido sobre eletrodo de $\mathrm{Cu}$ foram obtidos utilizando-se $\mathrm{Cl}^{-}$como ânion-suporte e soluçõesmãe aquosas em $\mathrm{pH}=6,0$. Os espectros apresentados na figura 44 mostram que o espectro obtido do eletrodo girando é diferente do obtido com o eletrodo parado e, portanto, o adsorbato não é estável termicamente, quando exposto à radiação excitante.

Nestes espectros, a baixa relação sinal-ruído é devida à baixa adsorção do complexo sobre a superfície do eletrodo. Isto pode ser explicado pela presença de $\mathrm{Cu}_{2} \mathrm{O}$ sobre a superfície metálica ${ }^{18}$, caracterizada pelas bandas em 525 e $620 \mathrm{~cm}^{-1}$ (figura 28 ).

O espectro do complexo no estado sólido (figura 39) assemelha-se bastante ao espectro dele adsorvido (figura 44-b), caracterizando uma interação apenas eletrostática do composto com a superfície. Com o tempo de incidência do laser na amostra o calor gerado não é disperso, o que leva à variação no espectro (figura 44-a). O novo padrão espectral assemelha-se ao da tpy adsorvida sobre eletrodo de $\mathrm{Cu}$ (figura 28). Portanto, pode-se afirmar que a decomposição térmica do complexo adsorvido leva à adsorção da tpy sobre a superfície metálica do eletrodo, dando origem ao complexo de superfície do tipo II. 


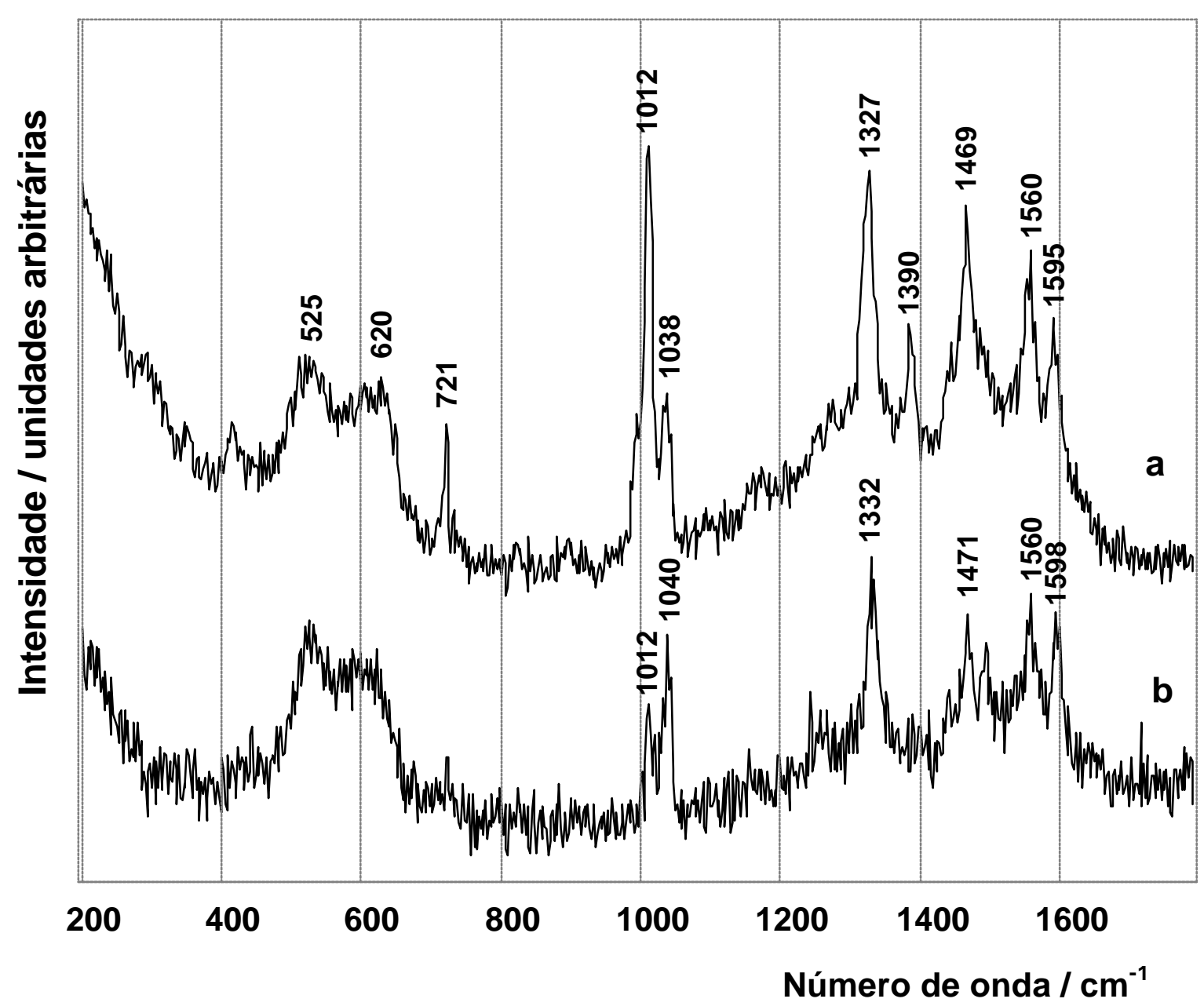

FIGURA 44: SERS ex situ do sistema $\mathrm{Cu} /\left[\mathrm{Cu}(\mathrm{II}) \mathrm{tpyH}_{2} \mathrm{OClO}_{4}\right] \mathrm{ClO}_{4} / \mathrm{Cl}^{-}$em solução-mãe aquosa, $\mathrm{pH}=6,0$, com eletrodo parado (a) e girando (b).

Os espectros SERS in situ do complexo $\left[\mathrm{Cu}(\mathrm{II}) \mathrm{tpyH}_{2} \mathrm{OClO}_{4}\right] \mathrm{ClO}_{4}$ adsorvido sobre eletrodo de $\mathrm{Cu}$, utilizando-se CI como ânion-suporte, em solução aquosa com $\mathrm{pH}=6,0$, são apresentados na figura 45 .

Novamente, a presença do $\mathrm{Cu}_{2} \mathrm{O}$ na superfície do eletrodo pode ser confirmada pelas bandas em 525 e $620 \mathrm{~cm}^{-1}$. A baixa adsorção do composto pode ser atribuída à presença deste óxido.

No potencial de repouso, em $-0,1 \mathrm{~V}$, já é possível observar-se a decomposição do complexo pois o padrão espectral observado é o da tpy adsorvida 
sobre a superfície, coordenando ao metal pelos seus átomos de nitrogênio. Com a aplicação de potencial no sentido catódico, para valores mais negativos que $-0,4 \mathrm{~V}$, ocorre a redução do óxido e a adsorção do composto torna-se mais efetiva. Até o potencial aplicado de $-0,7 \mathrm{~V}$ é a tpy que prevalece adsorvida sobre a superfície do eletrodo, como uma espécie semelhante ao complexo de superfície do tipo II, caracterizada pelas bandas em 1013, 1326, 1471, 1558 e $1592 \mathrm{~cm}^{-1}$. Portanto o complexo $\left[\mathrm{Cu}(\mathrm{II}) \operatorname{tpyH}_{2} \mathrm{OClO}_{4}\right] \mathrm{ClO}_{4}$ sofre decomposição em toda a faixa de potencial utilizada, sendo a tpy que ad sorve sobre a superfície metálica.

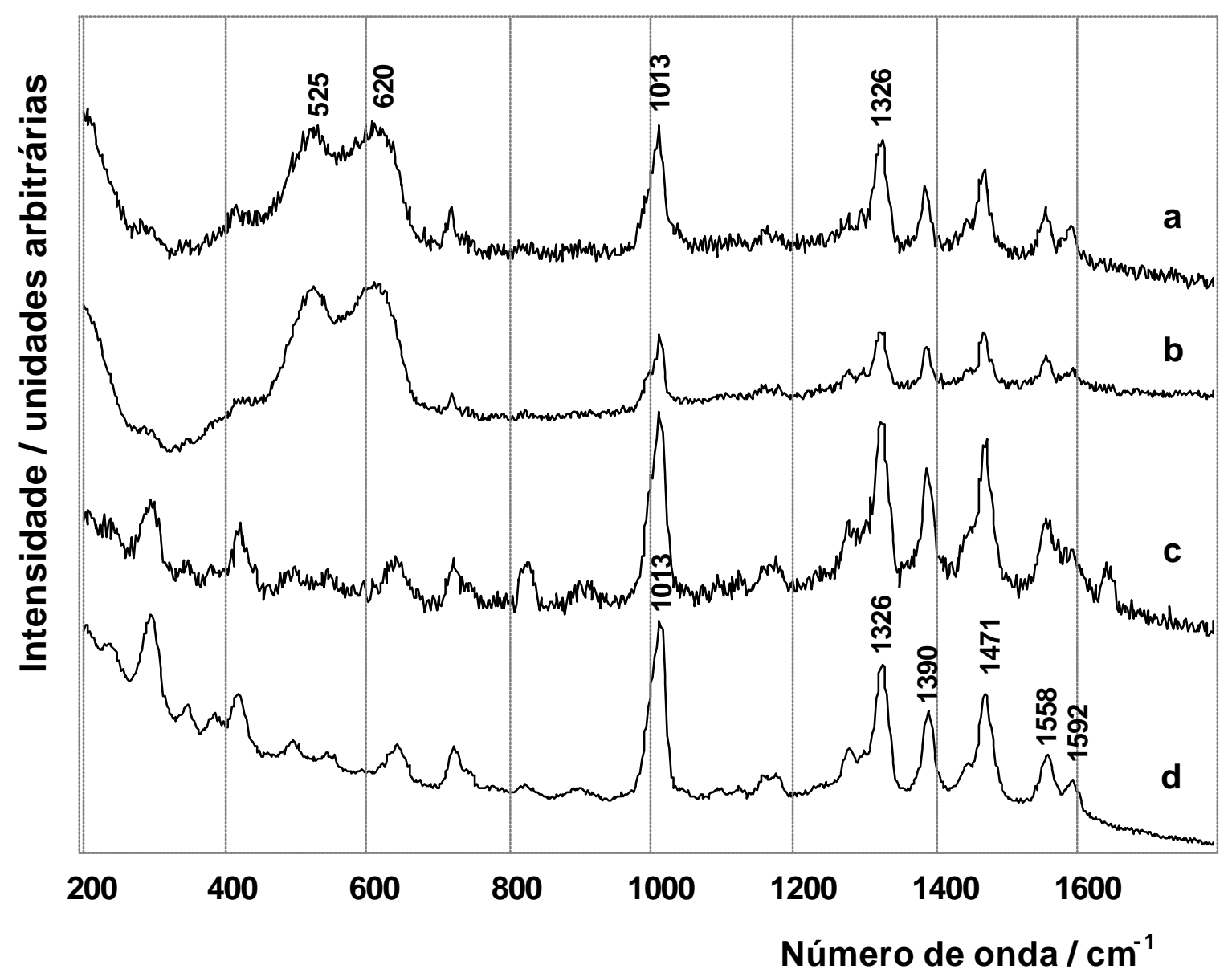

FIGURA 45: Espectros SERS in situ do sistema $\mathrm{Cu} /\left[\mathrm{Cu}(\mathrm{II}) \mathrm{tpyH} \mathrm{H}_{2} \mathrm{OClO}_{4}\right] \mathrm{ClO}_{4}(\mathrm{aq}) / \mathrm{Cl}$ em $\mathrm{pH}=6$, em vários potenciais: repouso $=-0,1 \mathrm{~V}(\mathrm{a}),-0,4 \mathrm{~V}(\mathrm{~b}),-0,6 \mathrm{~V}(\mathrm{c}),-0,7 \mathrm{~V}(\mathrm{~d})$. 
Para investigar-se a adsorção do complexo $\left[\mathrm{Cu}(\mathrm{II}) \operatorname{tpyH}_{2} \mathrm{OClO}_{4}\right] \mathrm{ClO}_{4}$ sobre uma superfície metálica em potenciais mais positivos foram obtidos os espectros SERS in situ em eletrodo de $\mathrm{Ag}$, com ânion-suporte $\mathrm{ClO}_{4}{ }^{-}$, em solução aquosa e $\mathrm{pH}=6,0$ (figura 46).

Aplicando-se um potencial de $+0,3 \mathrm{~V}$ ou de $+0,2 \mathrm{~V}$ observa-se que o complexo $\left[\mathrm{Cu}(\mathrm{II}) \mathrm{tpyH}_{2} \mathrm{OClO}_{4}\right] \mathrm{ClO}_{4}$ adsorvido é estável e seu espectro se assemelha ao do estado sólido (figura 39), a menos de pequenos deslocamentos de freqüência e de pequenas alterações nas intensidades relativas de algumas bandas.

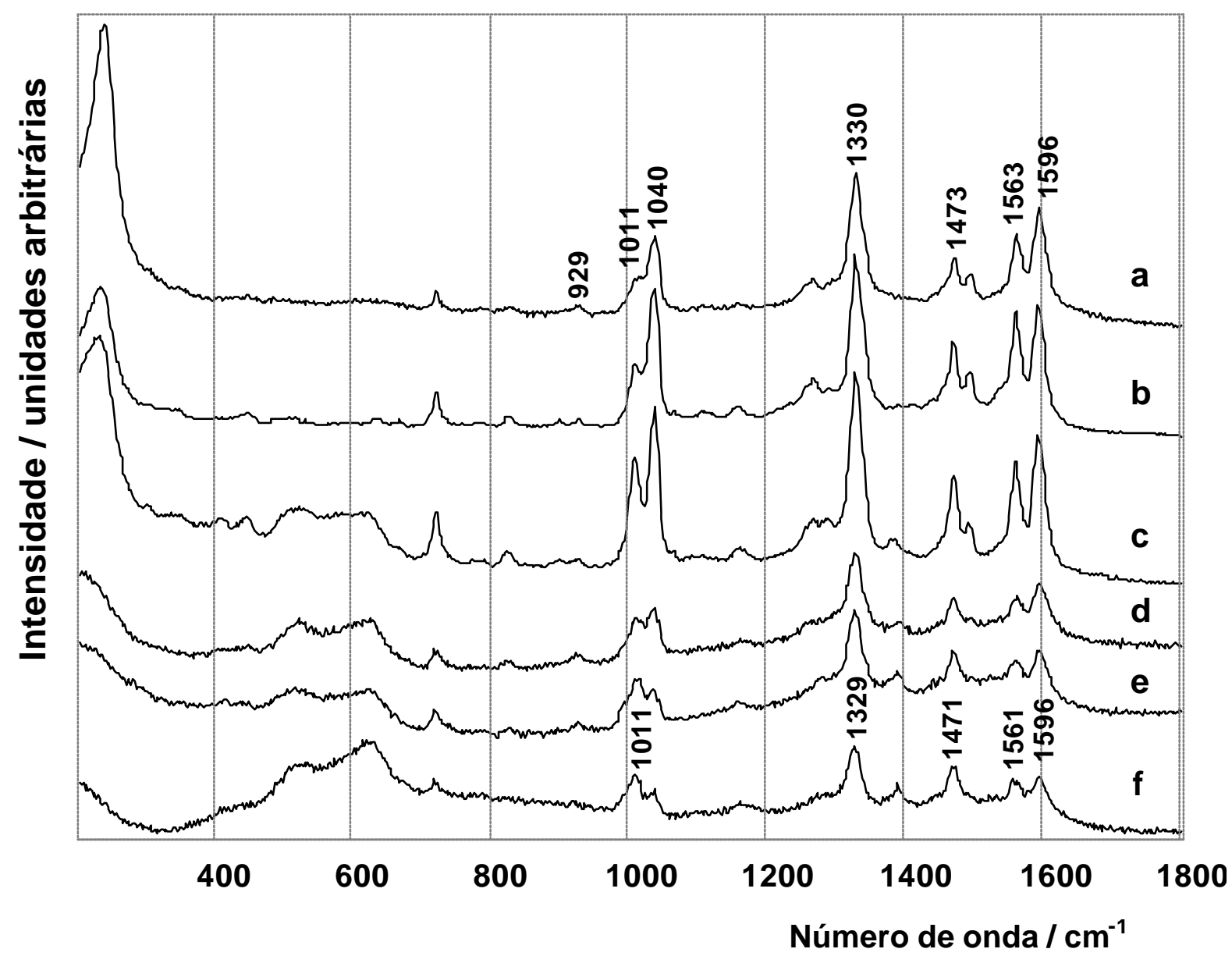

FIGURA 46: Espectros SERS in situ do sistema $\mathrm{Ag} /\left[\mathrm{Cu}(\mathrm{II}) \mathrm{tpyH}_{2} \mathrm{OClO}_{4}\right] \mathrm{ClO}_{4}(\mathrm{aq}) / \mathrm{ClO}_{4}$ em $\mathrm{pH}=6$, em vários potenciais: $+0,3 \mathrm{~V}(\mathrm{a}),+0,2 \mathrm{~V}(\mathrm{~b}),+0,1 \mathrm{~V}(\mathrm{c}), 0,0 \mathrm{~V}(\mathrm{~d}),-0,1 \mathrm{~V}(\mathrm{e})$, $-0,2 \mathrm{~V}(\mathrm{f})$. 
Quando é aplicado um potencial de $+0,1 \mathrm{~V}$ a decomposição do complexo pode ser observada pela diminuição da intensidade relativa da banda em $1040 \mathrm{~cm}^{-1}$, acomp anhada do surgimento das bandas em 525 e $620 \mathrm{~cm}^{-1}$ atribuídas ao $\mathrm{Cu}_{2} \mathrm{O}$. Aplicando-se o potencial entre $0,0 \mathrm{~V}$ e $-0,2 \mathrm{~V}$ a decomposição do complexo é intensificada.

Portanto, conclui-se que o complexo $\left[\mathrm{Cu}(\mathrm{II}) \mathrm{tpyH}_{2} \mathrm{OClO}_{4}\right] \mathrm{ClO}_{4}$ adsorve sobre superfícies metálicas de $\mathrm{Ag}$ e $\mathrm{Cu}$ de forma estável apenas em potenciais mais positivos que $+0,2 \mathrm{~V}(\mathrm{Ag} / \mathrm{AgCl})$. Quando são aplicados potenciais que permitem a redução do $\mathrm{Cu}^{2+}$ a $\mathrm{Cu}^{+}$, este último estabiliza como $\mathrm{Cu}_{2} \mathrm{O}$ sobre a superfície do eletrodo e ocorre a decomposição do complexo. Para potenciais aplicados onde ocorre a redução do $\mathrm{Cu}^{+}$a $\mathrm{Cu}^{0}$ há adsorção da porção tpy sobre a superfície metálica através dos seus átomos de nitrogênio, formando-se um complexo de superfície do tipo II.

\section{REFERÊNCIAS}

1. A. Sarkar e S. Chakravorti, Spectrosc. Lett., 27 (3), 305 (1994).

2. G. Varsányi, Vibrational Spectra of Benzene Derivates, Academic Press, 1969, New York and London.

3. J. A. Draeger, Spectroch. Acta, 39-A, 809 (1983).

4. D. Steele e E. R. Lippincott, J. Mol. Spectrosc., $\underline{6}, 238$ (1961).

5. L. Ould-Moussa, M. Castellà-Ventura, E. Kassab, O. Poizat, D. P. Strommen e J. R. Kincaid, J. Raman Spectrosc., 31, 377 (2000).

6. A. de Bonis, G. Compagnini, R. S. Cataliotti e G. Marletta, J. Raman Spectrosc., 30, 1067 (1999).

7. C. A. Bessel. R. F. See. D. L. Jameson, M. R. Churchill e K. J. Takeuchi, J. Chem. Soc., Dalton Trans., 3223 (1992).

8. F. R. Dollish, W. G. Fateley e F. F. Bentley, Characteristic Raman Frequencies of Organic Compounds, John Wiley \& Sons, 1974, New York.

9. A. Hergold-Brundic, Z. Popovix e D. Matkovic-Calogovic, Acta Cryst., C52, 3154 (1996).

10. S. Schneider, G. Brehm, C.-J. Prenzel, W. Jäger, M. I. Silva, H. D. Burrows e S. T. Formosinho, J. Raman Spectrosc., 27, 163 (1996).

11. P. Bonhôte, J.-E. Moser, R. Humphry-Baker. N. Vlacopoulos, S. M. Zakeeruddin, L. Walder e M. Grätzal. J. Am. Chem. Soc., 121, 1324 (1999). 
12. K. Nakamoto, Infrared and Raman Spectra of Inorganic and Coordination Compounds, John Wiley \& Sons, 1986, New York.

13. B. J. Hathaway e A. E. Underhill, J. Chem. Soc., 3091 (1961).

14. M. Kim e K. Itoh, J. Phys. Chem., 91, 126 (1987).

15. H. Saito, J. Raman Spectrosc., 24, 191 (1993).

16. M. Kim e K. Itoh, J. Eletroanal. Chem., 188, 137 (1985).

17. M Kim e K Itoh, Chem. Lett., 357 (1984).

18. Y. S. Pang, H. J. Hwang e M. S. Kim, J. Mol. Struct., 441, 63 (1998).

19. J. A. Creighton, Surface Science, 124, 209 (1983).

20. Texier F., Servant L., Bruneel J. L. e Argoul F., J. Electroanal. Chem., 446, 189 (1998).

21. Atkins P. W., Physical Chemistry, Oxford University Press, 1998, Oxford.

22. M. Maskus e H. D. Abrunã, Langmuir, 12, 4455 (1996).

23. M. A. Bryant e J. E. Pemberton, J. Am. Chem. Soc., 113(10), 3629 (1991).

24. M. A. Bryant e J. E. Pemberton, J. Am. Chem. Soc., 113(22), 8284 (1991).

25. C. J. Sandroff e D. R. Herschbach, J. Phys. Chem., 86, 3277 (1982).

26. L. S. Pinheiro e M. L. A. Temperini, Surface Science, 441, 45 (1999).

27. L. S. Pinheiro e M. L. A. Temperini, Surface Science, $\underline{464}, 176$ (2000). 


\section{4 - CONCLUSÕES}

O monitoramento da adsorção da tpy em superfície de Ag através da espectroscopia Raman intensificada pela superfície mostra diferentes interações entre o composto e a superfície metálica e os espectros obtidos representam uma média das espécies presentes no adsorbato.

Em experimentos ex situ, realizados com solução-mãe etanólica ou em soluções-mãe aquosas em diferentes pH(s) e com diferentes ânions-suporte, observase a formação de complexos de superfície onde a tpy coordena com os átomos dos aglomerados metálicos através dos pares de elétrons dos nitrogênios dos anéis piridínicos. Nestes complexos de superfície a conformação da tpy é cis-cis. Quando o pH utilizado é ácido a tpy protonada em solução adsorve perdendo o próton para coordenar ao metal.

Não foi observada a redução eletroquímica da tpy, tanto em solução aquosa, quanto em solventes não orgânicos. Em experimentos in situ a espécie predominante na superfície do eletrodo no potencial de repouso, para qualquer ânion-suporte utilizado, é a mesma observada nos experimentos ex situ. Esta espécie, denominada complexo de superfície do tipo I assemelha-se ao complexo $\left[\mathrm{Ag}\right.$ (I)tpyNO $\left.\mathrm{N}_{3}\right]$ e pode ser descrita como um complexo entre os átomos dos aglomerados de $\mathrm{Ag}$, que possuem certa carga positiva, os ânions adsorvidos e a tpy, coordenada ao metal pelos pares de elétrons dos nitrogênios dos anéis piridínicos. Com a aplicação de potenciais negativos ocorre a redução dos átomos de $\mathrm{Ag}$ dos aglomerados superficiais resultando na formação de outro complexo superficial, denominado do tipo II, onde a interação da tpy com os átomos dos aglomerados metálicos de Ag é mais forte.

Estes complexos superficiais são estabilizados pela presença dos ânions coadsorvidos na superfície metálica. A interação que ocorre entre os átomos de nitrogênio da tpy e os átomos de Ag da superfície do eletrodo favorece a adsorção da molécula em uma posição próxima à vertical. 
Quando soluções eletrolíticas com $\mathrm{pH}=0,0$ são utilizadas a tpy protonada adsorve, em pequena quantidade, sobre a superfície metálica através da formação de par-iônico com o ânion adsorvido sobre o eletrodo. Sua adsorção também é observada, em pequenas quantidades, quando I' é utilizado devido maior recobrimento da superfície por este ânion.

Apesar do deslocamento da banda de respiração do anel ser bastante sensível ao tipo de complexo superficial presente no adsorbato, indicando que as constantes de força associadas a esta vibração são bastante alteradas, não se observa mudança significativa na freqüência da banda do estiramento Ag-N.

Quando potenciais mais negativos são aplicados ocorre a dessorção dos ânions e a adsorção da tpy em uma posição próxima à horizontal através dos elétrons $\pi$ dos anéis piridínicos.

Utilizando-se eletrodo de $\mathrm{Cu}$ a tpy adsorve de maneira semelhante à observada em $\mathrm{Ag}$, formando complexos de superfície e adsorvendo próxima à horizontal em potenciais mais negativos.

A presença do ânion $\mathrm{ClO}_{4}{ }^{-}$adsorvido na superfície do eletrodo através de um ou dois átomos de oxigênio foi observada neste trabalho. Em experimentos ex situ este ânion adsorve à prata por dois átomos de oxigênio e com o calor gerado pela incidência do laser passa a adsorver apenas por um átomo de oxigênio. Em experimentos in situ o $\mathrm{ClO}_{4}{ }^{-}$adsorve por apenas um átomo de oxigênio no potencial de repouso, passando a adsorver por dois átomos de oxigênio quando potencial mais negativo é aplicado.

Os espectros SERS da tpy-SH adsorvida em Ag mostram intensificação das bandas relacionadas à parte alifática-tiol da molécula, comprovando a ligação à superfície pelo átomo de enxofre. As bandas da parte tpy possuem padrão espectral semelhante ao observado no espectro Raman da tpy sólida, indicando que não há interação dos anéis piridínicos com a superfície.

Os espectros SERS da tpy adsorvida em Ag são diferentes dos espectros SERS da tpy-SH adsorvida em Ag, mostrando que esta técnica permite investigar 
diferentes centros de adsorção. A ligação pelo enxofre à superfície metálica é forte o suficiente para permitir o crescimento de estruturas moleculares sobre o adsorbato através da coordenação de compostos organo-metálicos com os átomos de nitrogênio da tpy.

Utilizando-se a variação das intensidades relativas das bandas foi possível verificar-se, com a técnica SERS, a adsorção diferente da tpy em superfície de Ag na presença da mpy. A tpy adsorve em uma posição horizontal, sem que haja a coordenação dos átomos de nitrogênio do adsorbato com os átomos de Ag. Em solução-mãe aquosa com $\mathrm{pH}=1,8$ a tpy protonada também adsorve horizontalmente sobre a superfície do eletrodo. Portanto a tpy, na presença da mpy, adsorve sem a formação dos complexos superficiais.

A caracterização do complexo $\left[\mathrm{Cu}(\mathrm{II}) \mathrm{tpyH}_{2} \mathrm{OClO}_{4}\right] \mathrm{ClO}_{4}$ mostra que o ligante $\mathrm{H} \mathrm{O}$ está fracamente ligado ao íon $\mathrm{Cu}^{2+}$ pois com o tempo de exposição à radiação excitante o ligante $\mathrm{ClO}_{4}{ }^{-}$passa de mono a bidentado. $\mathrm{O}$ estudo Raman ressonante deste complexo mostra que as bandas na região de 300 a $350 \mathrm{~nm}$ são responsáveis pela variação das intensidades relativas das bandas Raman com a radiação laser utilizada. Por outro lado, os espectros SERS mostram que este complexo é instável na superfície metálica, decompondo com o potencial em óxido de cobre (I) e dando origem à adsorção da tpy como um complexo de superfície do tipo II. 